NBSIR 84-2920

\title{
Thermal Performance Testing of Passive Solar Components in the NBS Calorimeter
}

\begin{abstract}
M. E. McCabe
C. E. Hancock

M. Van Migom
\end{abstract}

U.S. DEPARTMENT OF COMMERCE

National Bureau of Standards

National Engineering Laboratory

Center for Building Technology

Gaithersburg, MD 20899

August 1984

Prepared for

U.S. Department of Energy
רffice of Solar Heat Technologies assive and Hybrid Solar Energy Division Vashington, DC 20585



M. E. McCabe

C. E. Hancock

M. Van Migom

U.S. DEPARTMENT OF COMMERCE

National Bureau of Standards

National Engineering Laboratory

Center for Building Technology

Gaithersburg, MD 20899

August 1984

Prepared for

U.S. Department of Energy

Office of Solar Heat Technologies

Passive and Hybrid Solar Energy Division

Washington, DC 20585

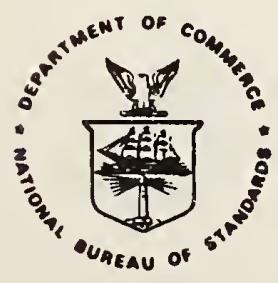

U.S. DEPARTMENT OF COMMERCE, Malcolm Baldrige, Secretary NATIONAL BUREAU OF STANDARDS. Ernest Ambler, Director 



\begin{abstract}
Studies of the thermal performance of passive solar buildings have indicated a need for precise measurement of solar heat gain and thermal heat loss or gain for modular passive/hybrid solar components. A description of the design, calibration, and initial operational results for a new calorimetric test facility designed to perform these measurements is presented in this report. It is anticipated that this test facility will provide a substantial improvement in the measuring techniques for passive and hybrid solar components over the field test cells currently in use.

Thermal performance data were taken for four passive solar test articles during the winter of 1982-1983, including two windows and two collector-storage walls. The U-Values and Shading Coefficients for the two windows were measured and correlated with outdoor environmental variables. Operational problems with the test facility are described and future improvements are suggested. The application of the test results for evaluating standard laboratory test procedures for windows is discussed. A draft procedure for measuring and reporting U-Values for windows based on laboratory testing is presented.
\end{abstract}


ABSTRACT $\ldots \ldots \ldots \ldots \ldots \ldots \ldots \ldots \ldots \ldots \ldots \ldots \ldots \ldots \ldots \ldots \ldots \ldots \ldots \ldots \ldots \ldots \ldots \ldots \ldots \ldots \ldots \ldots \ldots \ldots$

LIST OF TABLES $\ldots \ldots \ldots \ldots \ldots \ldots \ldots \ldots \ldots \ldots \ldots \ldots \ldots \ldots \ldots \ldots \ldots \ldots \ldots \ldots \ldots \ldots \ldots \ldots \ldots$

LIST OF FIGURES $\ldots \ldots \ldots \ldots \ldots \ldots \ldots \ldots \ldots \ldots \ldots \ldots \ldots \ldots \ldots \ldots \ldots \ldots \ldots \ldots \ldots \ldots \ldots \ldots$

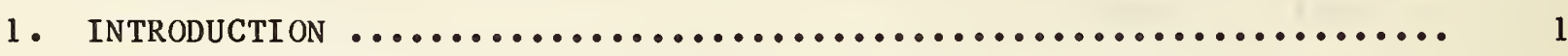

1.1 BACKGROUND ...................................... 1

1.2 PASSIVE SOLAR COMPONENTS: CLASSIFICATION AND EXISTING TEST

METHODS ........................................ 1

1.3 TEST METHODS FOR DIRECT GAIN FENESTRATION $\ldots \ldots \ldots \ldots \ldots \ldots \ldots \ldots \ldots . . \ldots$

1.4 TEST METHODS FOR PASSIVE SOLAR SYSTEMS $\ldots \ldots \ldots \ldots \ldots \ldots \ldots \ldots \ldots \ldots \ldots . \ldots$

1.5 NEED FOR CALORIMETRIC TEST FACILITY $\ldots \ldots \ldots \ldots \ldots \ldots \ldots \ldots \ldots \ldots \ldots . \ldots$

2. DESCRIPTION OF NBS PASSIVE SOLAR CALORIMETER ................. 6

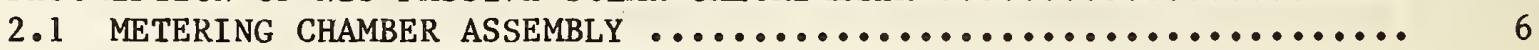

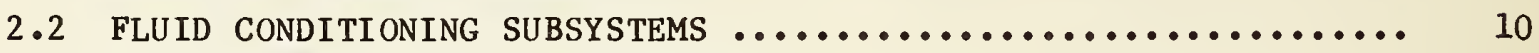

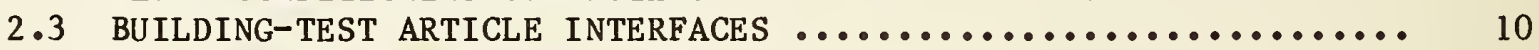

2.4 DATA ACQUISITION SYSTEM $\ldots \ldots \ldots \ldots \ldots \ldots \ldots \ldots \ldots \ldots \ldots \ldots \ldots \ldots \ldots \ldots \ldots \ldots$

3. PERFCRMANCE EVALUATION PROCEDURES .......................... 23

4. TEST FACILITY CHECKOUT AND CALIBRATION ....................... 26

4.1 ANALYSIS OF ERROR ............................... 26

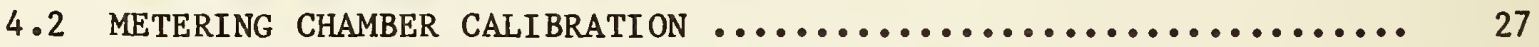

4.3 AIR VELOCITY AND TEMPERATURE DISTRIBUTION ............... 29

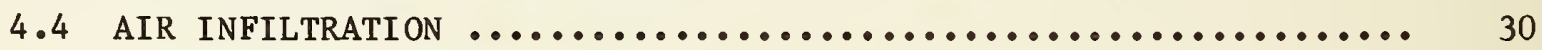

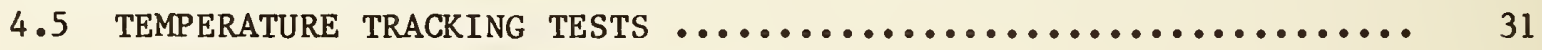

5. DESCRIPTION OF TEST ARTICLES ............................ 32

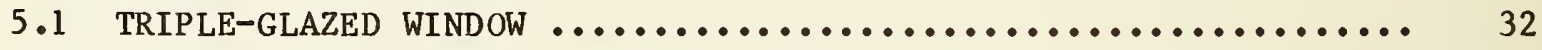

5.2 SINGLE-GLAZED WINDOW WITH INSULATING SHUTTERS $\ldots \ldots \ldots \ldots \ldots \ldots \ldots \ldots . \ldots \ldots$

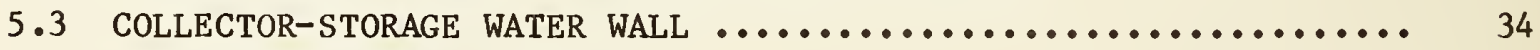

5.4 COLLECTOR-STORAGE PCM WALL ....................... 37

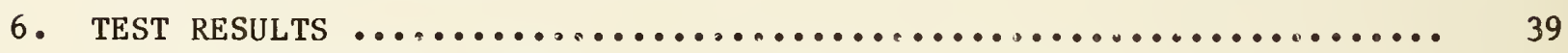

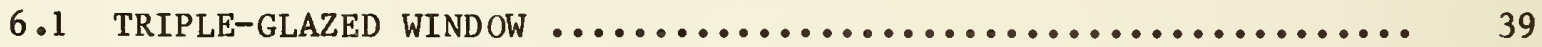

6.2 SINGLE-GLAZED WINDOW WITH INSULATING SHUTTERS $\ldots \ldots \ldots \ldots \ldots \ldots \ldots . . \ldots 4$

6.3 COLLECTOR-STORAGE WATER WALL ...................... 45

6.4 COLLECTOR-STORAGE PCM WALL ......................... 45

6.5 CORRELATION NEEDS FOR COLLECTOR-STORAGE WALLS ............ 48

7. EVALUATION OF INITIAL OPERATION OF NBS PASSIVE SOLAR CALORIMETER ... 50

8. USE OF THE TEST RESULTS FOR EVALUATING EXISTING TEST PROCEDURES

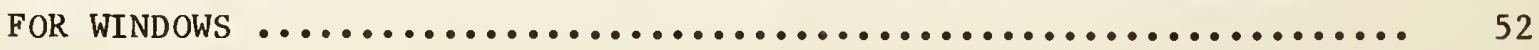

9. NOMENCLATURE ............................................ 54

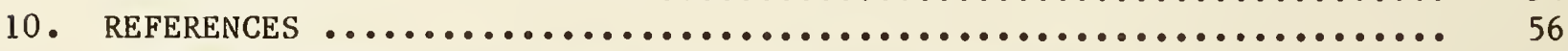

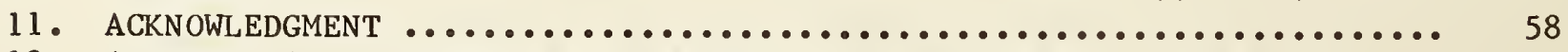

12. APPENDIX A - PROCEDURE FOR MEASURING AND REPORTING U-VALUE FOR

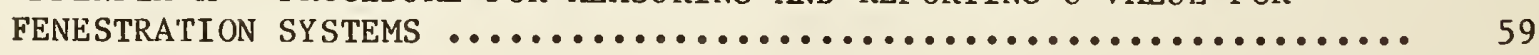




\section{LIST OF TABLES}

Page

Table 1. Test Results for Triple-glazed Window ...................

Table 2. Test Results for Single-glazed Window with Insulating

Shutters

Table A-1. Proposed Test Conditions for Sealed Glazing Unit and

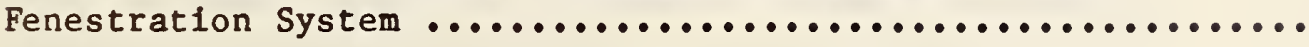




\section{LIST OF FIGURES}

Page

Figure 1. Photograph of NBS/DoE passive solar test building ........ 8

Figure 2. Floor plan of passive solar test building .............. 8

Figure $3 . \quad$ schematic drawing of metering chamber $\ldots \ldots \ldots \ldots \ldots \ldots \ldots \ldots \ldots$

Figure 4. Photograph of metering chamber with solar absorber panel partially removed ............................... 12

Figure 5. Photograph of metering chamber in horizontal position ....... 12

Figure 6. Schematic drawing of solar absorber panel .............. 13

Figure 7. Photograph of solar absorber panel .................. 13

Figure 8. Solar absorber panel cooling water circuit ............. 15

Figure 9. Photograph of photovoltaic array used for the emergency freeze protection system .......................... 15

Figure 10. Air-conditioning unit cooling water circuit ............ 16

Figure 11. Photograph of fluid conditioning systems .............. 16

Figure 12. Vertical aperture - test article interface ............ 17

Figure 13. Photograph of vertical aperture interface with standard double-glazed window .............................

Figure 14. Skylight test article - horizontal aperture interface .....................................

Figure 15. Photograph of test fixture installed in horizontal aperture .

Figure 16. Photograph of skylight test article installed in horizontal aperture .....................................

Figure 17. Schematic drawing of data acquisition system .............

Figure 18. Photograph of normal incidence pyrheliometer installed in tracking mount $\ldots \ldots \ldots \ldots \ldots \ldots \ldots \ldots \ldots \ldots \ldots \ldots \ldots \ldots \ldots$

Figure 19. Photograph of vertical aperture with pyranometer installed to

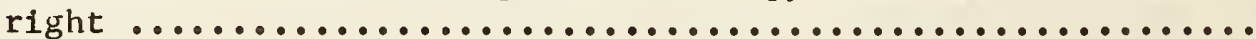


F1gure 21. Photograph of instrumentation, control and data acquisition rack .................................. 22

Figure 22. Schematic drawing of performance evaluation procedures ...... 24

F'igure 23. Metering chamber energy balance ....................... 24

F1gure 24. Schematic drawing of guard heater panels ................ 28

Figure 25. Air velocity distribution in metering chamber ........... 28

F1gure 26. Schematic drawing of triple-glazed window and test frame .... 33

Figure 27. Photograph of triple-glazed window test article .......... 33

Figure 28. Schematic drawing of single-glazed window with insulating shutters ......................................... 35

Figure 29. Photograph of single-glazed window with insulating shutters • 35

Figure 30. Photograph of collector-storage water wall installed in

test frame $\ldots \ldots \ldots \ldots \ldots \ldots \ldots \ldots \ldots \ldots \ldots \ldots \ldots \ldots \ldots \ldots \ldots \ldots$

Figure 31. Drawing of collector-storage water wall installed in test bullding ........................................ 36

Figure 32. Photograph of collector-storage PCM wall ................ 38

Figure 33. Environmental conditions for triple-glazed window ......... 40

Figure 34. Net heat transfer rate for triple-glazed window .......... 40

Figure 35. Correlations for triple-glazed window .................. 43

F1gure 36. Environmental conditions - collector-storage water wall ..... 47

Figure 37. Net heat transfer rate and temperature - collector-storage

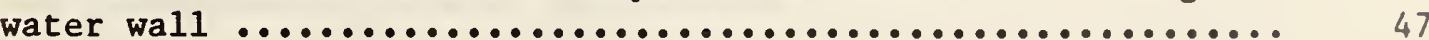

Figure 38. Environmental conditions - collector-storage PCM wall ...... 49

Figure 39. Net heat transfer rate and $\Delta T$ - collector-storage PCM wall . . 49

Figure A-1. Hypothetical performance for sealed glazing unit ......... 



\section{INTRODUCTION}

\subsection{BACKGROUND}

Passlve solar buildings are structures designed to use radiant solar energy for space heating and may take advantage of avallable environmental heat sinks such as the outside air, the ground and the sky, for space cooling. Frequently, elements of a passive solar building's thermal envelope such as walls, windows, roofs, and floor slabs are used to transfer heat between the inside occupied spaces and the outside environment. Since the intensity of solar radiation and the external thermal environments vary with time, designers of passive solar buildings require information on the dynamic thermal behavior of the various building envelope components in order to integrate them into successful building designs.

The thermal behavior of bullding elements under both steady-state and transient conditions can be predicted using numerical heat-transfer simulation models, provided the thermophysical properties of the materials are known and the thermal boundary conditions at each interface can be determined. In practice however, nonhomogeneities in the materials used in building construction and complexities in calculating thermal boundary conditions often result in significant uncertainties in performance predictions based on thermal modeling.

These considerations have led to recent efforts to experimentally determine the thermal characteristics of materials, components, systems, and entire buildings with considerable emphasis placed on measurement of entire buildings. This report describes a new experimental facility designed to measure thermal characteristics at the component level. The testing of full-scale passive solar components in this facility is anticipated to lead to a better understanding of the basic heat transfer mechanisms involved in a passive solar building and thereby contribute to an improved technology base.

\subsection{PASSIVE SOLAR COMPONENTS: CLASSIFICATION AND EXISTING TEST METHODS}

In previous work [1]*, a survey of passive solar products resulted in an interim classification consisting of ten different generic passive solar components for purposes of thermal testing. That report defined a passive solar component as being: (1) capable of mass production economies; (2) fabricated in modular incremental sizes to permit ready integration into buildings; and (3) designed to utilize solar energy in conjunction with natural thermal processes such as conduction, free convection, radiation and evaporation to reduce fossil energy consumed in buildings for purposes of space heating, space cooling, and/or domestic water heating.

Direct Gain Fenestration (DGF), such as windows, glazed doors, and skylights, and Collector-Storage Wall (CSW) modules were identified as being most advanced in terms of commercial availability and acceptance by the design community for use

* Numbers in brackets identify the references listed in Section 10 
in passive solar buildings, therefore higher priority was assigned to experimental evaluation of those components.

In the previous report, a survey of available thermal test procedures was performed to assess the applicability of existing test methods for passive solar components. Test procedures that are useful for the DGF classification were identified, and recommendations were made for evaluation of these laboratory-based procedures by comparison with field-based testing under controlled interior conditions. Recommendations were also made for the development of new test procedures for component classifications for which test methods were not available. A program to develop test procedures for CSW modules was also presented.

\subsection{TEST METHODS FOR DIRECT GAIN FENESTRATION}

The American Society of Heating, Refrigerating, and Air-Conditioning Engineers (ASHRAE) has used a simple design procedure for predicting the instantaneous rate of solar and thermal energy transfer through building fenestration systems [2-5]. That procedure, while orginally intended for determining summer design-day heat gains through fenestration systems to permit sizing of cooling systems, is also being used to characterize DGF systems used in passive solar heating applications. However the thermal performance of fenestration systems is known to exhibit substantial variation in response to climatic conditions such as ambient temperature, air velocity, and solar irradiance. Therefore it is possible that thermal analysis of buildings containing substantial glazed area, when based on the single-point, design-day thermal characteristics of the installed fenestration, might result in substantial error in the calculated energy consumption or an incorrect choice between alternative fenestration systems.

\subsubsection{Heat Transfer Considerations}

The transfer of heat through a solar irradiated window into a building space can be considered to consist of the following three processes:

1. Direct transmission of radiant solar energy,

2. Convective and radiative transfer of radiant solar energy absorbed by the glazing,

3. Convective and radiative transfer of heat due to outdoor-to-indoor temperature difference.

In the ASHRAE procedure, the two solar-driven processes are combined into a single term, and the net rate of heat transfer into the conditioned space per unit area of glazing is given by:

$$
q_{N E T}=F I_{T}+U\left(T_{O}-T_{i}\right)
$$


$F$ is the solar heat gain coeffiçient,

$\mathrm{I}_{\mathrm{T}}$ is the solar irradiance, $\mathrm{w} / \mathrm{m}^{2}$ (Btu/hr $\mathrm{ft}^{2}$ ),

$U$ is the overall coefficient of heat transfer, $\mathrm{w} / \mathrm{m}^{2}{ }^{\circ} \mathrm{C}\left(\mathrm{Btu} / \mathrm{hr} \mathrm{ft}{ }^{\circ} \mathrm{F}\right)$,

$\mathrm{T}_{\mathrm{O}}-\mathrm{T}_{1}$ is the outside-to-inside temperature difference, ${ }^{\circ} \mathrm{C}\left({ }^{\circ} \mathrm{F}\right)$.

It is common practice to reference the solar heat gain coefficient $F$, for a particular glazing or shading product to a reference glazing $F_{R E F}$, consisting of a single sheet of double-strength clear glass. The ratio F/F RE is called Shading Coefficient. Manufacturers of glazing products characterize their products by providing Shading Coefficient data at a selected value of solar irradiance, ambient temperature, and external heat transfer coefficient corresponding to the ASHRAE summer design condition. Fenestration U-Value data are presented in the ASHRAE handbook [5], for both winter and summer design conditions.

\subsubsection{Fenestration Test Methodology}

The simplified design procedure of ASHRAE has led to a thermal test methodology for fenestration systems in which Shading Coefficient is determined independently of U-Value. Shading Coefficient is often measured in outdoor calorimeters under conditions of natural convection and with zero outside-to-inside temperature difference. U-Value is measured in laboratory hot boxes under forced convection conditions and with no solar irradiation. The test methodology assumes that the net heat-transfer rate per unit area of fenestration can be determined by adding the contribution due to solar irradiance (Shading Coefficient $x$ Solar Heat Gain Factor ${ }^{* *}$ and the contribution due to temperature difference $(U \times \Delta T)$.

This ASHRAE design procedure appears to provide reasonably accurate results for simple fenestration systems, which have low solar energy absorbing components such as single or double-glazed, clear windows. However, its application for characterizing the more complex fenestrations proposed for use in passive solar applications is unknown [6]. Multiple-glazed fenestrations having spectrally-selective, low-emittance coatings, which reduce radiative heat loss without substantially reducing solar gain, are now commercially available. New optical switching materials, which modulate solar gain in response to temperature or solar intensity, are also being developed [7]. The development of these new high-performance fenestration systems suggests that the existing test methodology and building fenestration characterization should be carefully reviewed to determine their adequacy for passive solar applications.

** Tabulated values of Solar Heat Gain Factor for reference glazing are provided in Ref. 5. 
Test methods for passive solar systems and components have evolved differently from the test methods for building fenestration systems. Most often, testing was performed on passive solar systems installed in small outdoor test rooms or cells, with naturally occurring climatic conditions and with widely varying test room air and surface temperatures [8].

Although the results of those passive solar testing programs have yielded significant information on the operating principles and the relative thermal efficiencies of various passive solar systems and components, the use of such test rooms with uncontrolled air and surface temperatures may not be useful for standard testing of modular passive solar components. In the test rooms, the air and surface temperatures are often uncontrolled, and therefore are sensitive to the thermal characteristics of the particular room, such as its insulation thickness, surface area, thermal mass, and air leakage rate. Uncontrolled air and surface temperatures in test rooms tend to modify temperaturedependent heat-transfer mechanisms, such as free convection and infrared radiative transfer. This results in measured thermal performance that is strongly facility-dependent, a highly undesirable characteristic for a standard test procedure.

\subsection{NEED FOR CALORIMETRIC TEST FACILITY}

In consideration of the shortcomings of the existing test methods for both fenestration and passive solar systems, the need for a new calorimetric test facility was established. The test facility would provide controlled interior surface and air temperatures, thereby simulating an ideal room, and would accurately measure the rate of heat transfer between the the passive solar component and the indoor environment.

The potential use of the test facility is twofold: (1) to provide a comparison between outdoor test data from the calorimeter and data from indoor test facilities which may use combinations of simulated solar radiation, ambient temperature, and wind velocity; (2) to measure the thermal performance of passlve solar components under realistic field conditions and attempt to quantify the contributions from various heat transfer mechanisms. The former use would support the development or validation of new and existing standard test methods and the latter use would support research activities for the passive solar program sponsored by the U.S. Department of Energy. For example, natural convection in enclosures is being investigated using both modeling and experimental techniques based on idealized boundary conditions in which vertical surfaces are isothermal. One of the design features of the test facility is to measure surface heat transfer rate and resolve it into convective and radiative components. Data of this type are useful to obtain a better understanding of the thermal behavior of passive solar components and the interaction with the buiding space in which they are installed. More specific details on the conceptual design and performance specifications for the test facility are given in references 9 and 10 . 
The remainder of this report describes the design, construction, calibration, instrumentation, and performance evaluation procedures for the NBS passive solar calorimeter. The initial winter season of operation is described and results are presented for four passive solar test articles. Operating problems encountered during the initial test period and recommended improvements in the facility are described. The use of the field test results for evaluating existing laboratory procedures for measuring U-Value of windows is discussed. An outline of a draft procedure for measuring and reporting U-Value of fenestration systems such as windows, patio doors, and skylights is presented in the appendix. 


\section{DESCRIPTION OF NBS PASSIVE SOLAR CALORIMETER}

The passive solar calorimeter is installed in one of the test rooms in the NBS/DOE Passive Solar Test Building, which is located at the NBS Annex immediately south of the main NBS campus in Gaithersburg, MD. The test building was constructed in 1981 to obtain thermal performance data for full-scale passive solar systems in buildings. A photograph of the exterior of the test building is shown in figure 1. A floor plan of the building showing the interior layout of the building experiments and the calorimeter is provided in figure 2. Detailed information on the passive solar features and instrumentation installed in the Passive Solar Test Building are given in reference 11.

An advantage to locating the solar calorimeter in the Passive Solar Test Building is the opportunity for the simultaneous thermal testing of two identical passive solar components: one in the idealized room environment provided by the calorimeter and the other in the more realistic, full-scale room environment provided by one of the test cells. This will allow qualitative assessment of the affect of the calorimeter environment on component thermal performance.

The passive solar calorimeter test facility consists of the following major assemblies and subsystems, each of which is described in the following sections :

1. metering chamber assembly,

2. fluid conditioning subsystems,

3. building-test article interface, and

4. data acquisition system.

\subsection{METERING CHAMBER ASSEMBLY}

The function of the metering chamber assembly is to completely enclose the interior of a test article with controlled air and surface temperatures and thereby simulate an interior space in a building. An energy balance establishes the net rate of heat transfer between the test article and the metering chamber.

The metering chamber assembly, shown schematically in figure 3, includes a five-sided metering chamber constructed of rigid polyurethane foam insulation $150 \mathrm{~mm}$ ( 6 inches) thick everywhere except $100 \mathrm{~mm}$ ( 4 inches) on the bottom. The metering chamber can be mounted efther vertically against the south wall or horizontally against the ceiling of the calorimeter room. It is externally supported by a structural frame of welded aluminum angles which has no penetrations through the insulation. The metering chamber assembly is mounted on a welded steel dolly with casters to permit movement of the assembly in the calorimeter room. A pair of telescoping-tube trunnion supports are attached to the dolly to permit rotation and the raising and lowering of the metering chamber to the ceiling test position using a hand-operated winch. 
Figure 4 is a photograph showing the air handling equipment installed in the metering chamber with the solar absorber panel removed for clarity. Figure 5 is a photograph of the metering chamber assembly installed in the horizontal test position for a component installed in the building roof. In the vertical position, the metering chamber is bolted against the building interface and sealed with closed-cell foam gaskets to minimize infiltration air exchange with the test room. In the horizontal position, the metering chamber is clamped and sealed against the ceiling of the test room using telescoping steel pipe columns located at each corner.

The metering chamber surface temperature and air temperature are individually controlled by the solar absorber panel conditioning unit and the air-conditioning unit, respectively. To assist in developing the conceptual thermal design of the metering chamber and to aid in sizing the absorber panel and air-conditioning units, a 65-node thermal network of the metering chamber assembly was prepared. The thermal model consisted of an finite-difference representation of the metering chamber, the absorber panel and coolant tubes, and a single-glazed window representing a "worst-case" test article. The general purpose thermal analyzer program SINDA [12], was used to solve the heat transfer equations. The results of the design study are presented in reference 9.

The average surface temperature is maintained in the calorimeter by forced circulation of water through the solar absorber panel. The panel, shown schematically in figure 6 , is a soldered assembly of copper sheets and tubes painted with a black paint having measured solar absorptance of 0.95 and normal infrared emittance of 0.88 . Figure 7 is a photograph of the absorber panel assembly prior to painting. The solar absorber panel fits within the metering chamber and is positioned sufficiently close to the test article to absorb almost all the solar energy transmitted by DGF type test articles and to provide a temperature controlled, nearly isothermal, radiative heat sink (or heat source) for the test article. Temperature control is achieved by sensing the average surface temperature of the panel with a grid of six thermocouples wired so that these junctions are in a parallel circuit. The averaging thermocouple grid provides a control signal to a solid-state temperature controller which regulates the duty cycle of a water heater located in the absorber panel inlet pipe.

A unfform air temperature is maintained in the calorimeter by circulation of air at low velocity between the test article interior surface and the absorber panel. Temperature control is achieved in the air-conditioning unit by first removing heat and then adding heat to the circulating air using the water-cooled heat exchanger and an electric heater, respectively. The cooling water flow rate and inlet temperature to the heat exchanger are manually set to provide a constant rate of energy removal from the airstream based on anticipated ambient conditions. A pair of duct heaters located downstream of the cooling heat exchanger are used to increase the air temperature to maintain the setpoint value. The average air temperature in the metering chamber is sensed by a grid of six type $T$ (copper-constantan) thermocouples wired in parallel. The averaging thermocouple grid provides a control signal to a solid-state temperature controller which controls the duty cycle of the air heater. Control of air velocity and direction in the metering chamber is provided by a solid-state motor controller, 


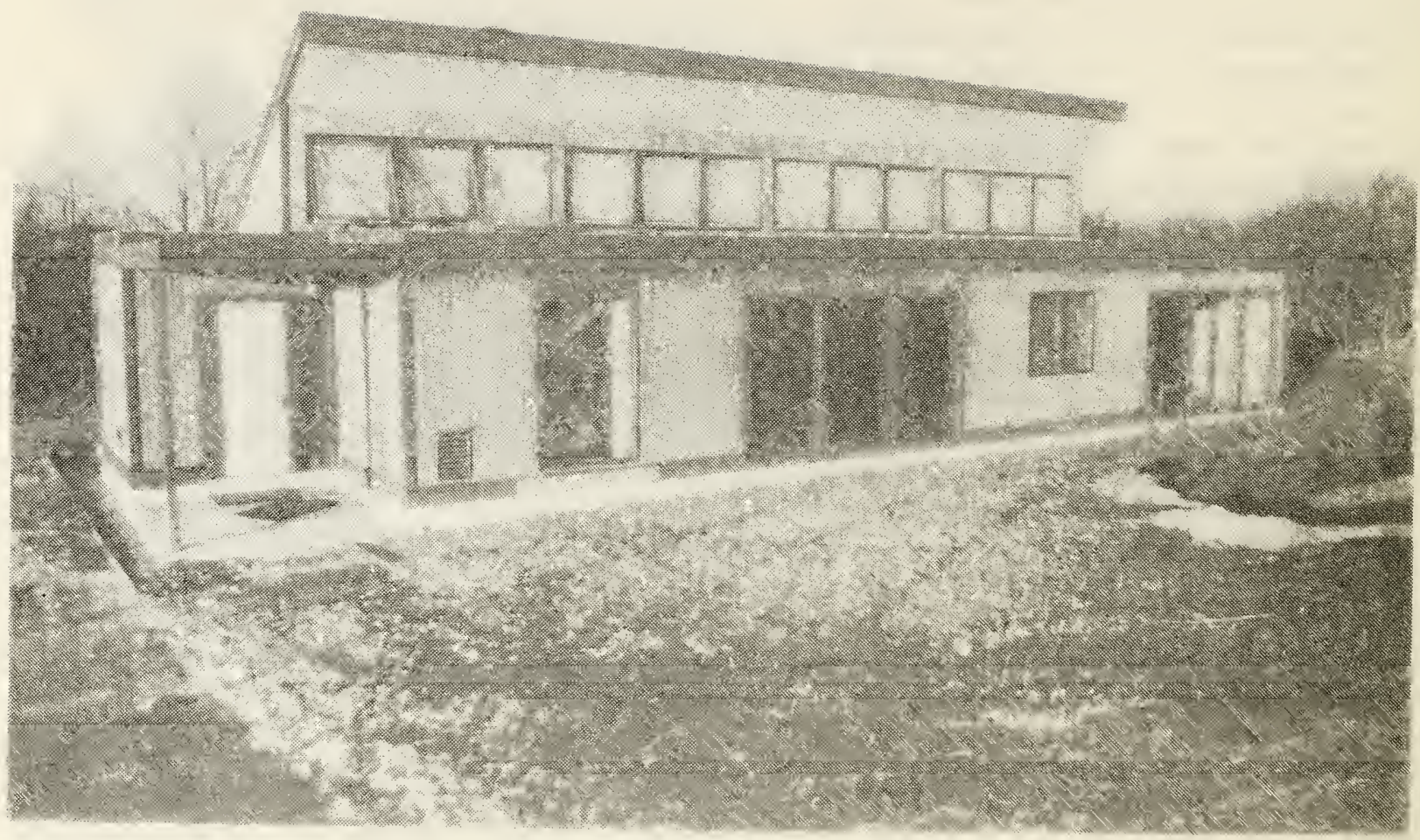

Figure 1. Photograph of NBS/DoE passive solar test building

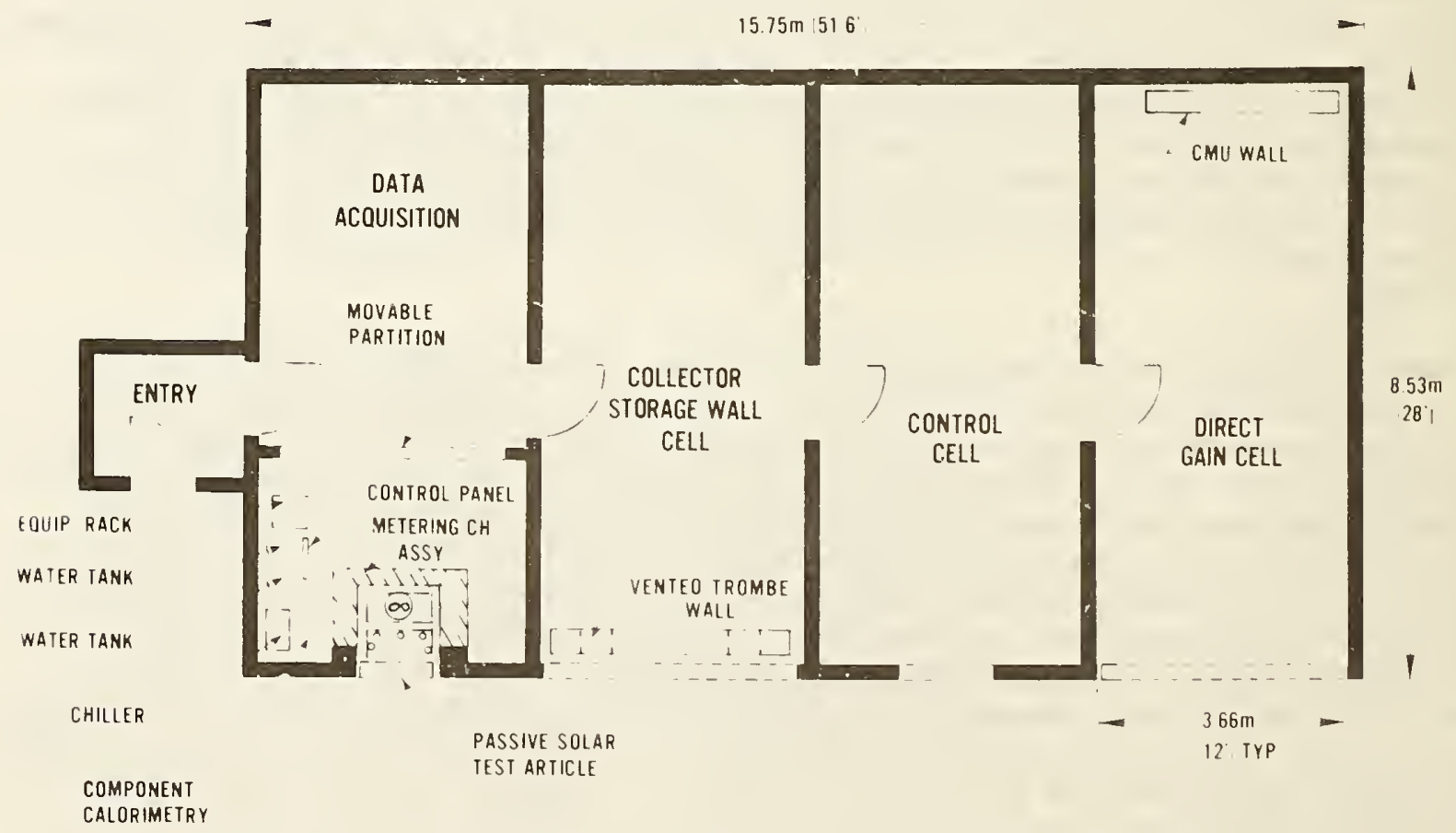

Figure 2. Floor plan of passive solar test building 


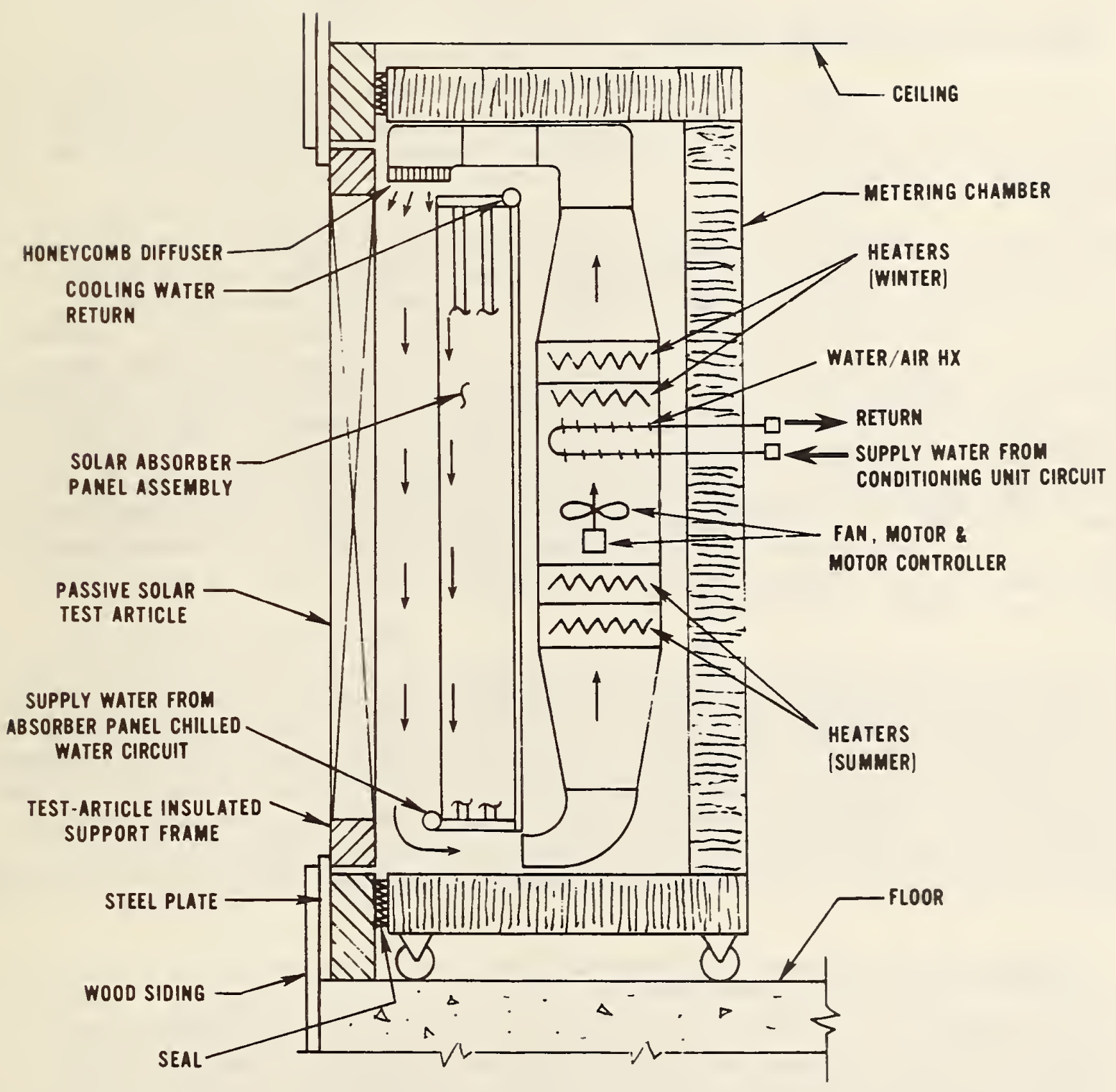

Figure 3. Schematic drawing of netering chamber 
which regulates the speed and direction of a belt-driven, axial-flow fan. The fan circulates air over the test article in the downward direction in the winter and upward direction in the summer in accordance with the motion that would result from free convection

flow.

\subsection{FLUID CONDITIONING SUBSYSTEMS}

The function of the fluid conditioning subsystems is to provide temperature control for the absorber panel and for the air cooling coil in the metering chamber. Distilled water is used as the heat transfer medium in both fluid conditioning subsystems.

Figure 8 shows a schematic drawing of the solar absorber panel water circuit, which contains the primary circulating pump, emergency pump, heat rejection pump, 195l (52 gal.) storage tank, 2500W ( $8532 \mathrm{Btu} / \mathrm{h}$ ) immersion heater, solid-state temperature controller, and an air-cooled water chiller. Thermal energy from the absorber panel is transferred to the storage tank from which it is rejected to ambient air by the $2600 \mathrm{~W}(9000 \mathrm{Btu} / \mathrm{h})$ water chiller. Provision for emergency circulation of storage tank water by a battery-operated, low capacity pump during power outage was made to prevent freezing of the absorber panel during conditions of subfreezing ambient temperature. Sufficient thermal energy is contained in the storage tank to maintain the temperature of the absorber panel above freezing for at least 24 hours. The emergency coolant pump storage battery is kept on a trickle charge using a small photovoltaic array shown in figure 9 .

A schematic drawing of the air-conditioning unit is shown in figure 10 . This unit consists of a circulating pump, a $114 \mathrm{l}$ ( $30 \mathrm{gal}$.) storage tank, a 500W $(1700 \mathrm{Btu} / \mathrm{h})$ immersion heater, and a $700 \mathrm{~W}(2500 \mathrm{Btu} / \mathrm{h})$ water chiller. The thermal energy absorbed in the water/air heat exchanger in the metering chamber is rejected to the calorimeter room through the water chiller. Control of the calorimeter room temperature is provided by the building heating and cooling system to a nominal $\pm 1^{\circ} \mathrm{C}\left( \pm 2^{\circ} \mathrm{F}\right)$ of the room set point. Figure 11 is a photograph showing both the fluid conditioning subsystems installed in the test facility.

\subsection{BUILDING-TEST ARTICLE INTERFACES}

The purpose of the building interface is to provide structural support for the test article and thermal isolation from the building. Flanking loss, the undesired heat flow between the metering chamber and outdoors, is minimized by carefully sealing joints to prevent air leakage and by reducing heat conduction by providing the building interface with a substantial thickness of rigid insulation between outdoor and indoor surfaces.

Each passive solar component to be tested is assembled in a suitable test frame and installed in either the vertical south-facing aperture, or the horizontal aperture of the NBS Passive Solar Test Building. Details of the passive solar components and test frames are provided in section 5 . Figures 
$12 a, b$, and $c$, shows the vertical building interface construction details at the head, sill and vertical sections, respectively.

Figure 13 is a photograph of the vertical aperture of the building interface with a double-glazed window provided for nonglazed components. Modular passive solar components provided with a self-contained glazing system are accommodated by removing the double-glazed window and sealing the test article's glazing system against the steel plates of the building interface.

Test articles substantially smaller in size than the nominal 1.26 by $2.09 \mathrm{~m}$ ( $49-1 / 2$ by $82-1 / 2$ inches) test article can be accommodated in the test facility by installing blanking heater panels in the unoccupied portions of the aperture. The electric strip heaters in the blanking panels are temperature controlled to offset heat loss and thereby maintain nearly adiabatic boundary conditions at their interior surfaces. Details of the blanking panels are provided in section 4 .

Figure 14 shows the installation of a test article in the horizontal aperture of the buflding interface. In this case, the nominal 1.22 by $1.54 \mathrm{~m}$ ( 48 by 72 inches) horizontal aperture is fitted with a special, insulated test fixture to accommodate a 0.79 by $0.79 \mathrm{~m}(30-1 / 4$ by $30-1 / 4$ inches $)$ test skylight. Figure 15 is a photograph of the test fixture and figure 16 shows the skylight installed in the horizontal aperture.

\subsection{DATA ACOUISITION SYSTEM}

The data acquisition system consists of the measurement sensors, signal conditioning circuits, display meters, and data scanning and storage devices shown schematically in figure 17. Measured variables include temperature (absolute and differential), solar irradiance (total and direct normal), flow rate, velocity, and electric power. The primary measurement sensors used in the test facility are thermocouples, differential thermopiles, pyranometers, a pyrheliometer, turbine flow meters, two types of air velocity sensors, and watt transducers.

Temperature is measured with 24 gauge, type-T (copper-constantan) thermocouples. Sixteen surface-mounted thermocouples are attached to the absorber panel and eight thermocouples are installed in the air space between the absorber panel and the test article to monitor the operation of the metering chamber and the temperature control systems. Thermocouples also measure the temperature at various locations on the metering chamber walls and the test article, in the two fluid conditioning subsystems, and of the outdoor and room environments.

The temperature change of the water in each fluid conditioning subsystem within the metering chamber thermal envelope is measured with a differential thermopile. Each thermopile consists of 30 pairs of type-T thermocouple junctions located at the inlet and outlet pipes at the exterior of the metering chamber. Turbulence inducing pipe fittings are located immediately upstream of each thermopile to insure well-mixed flow. 


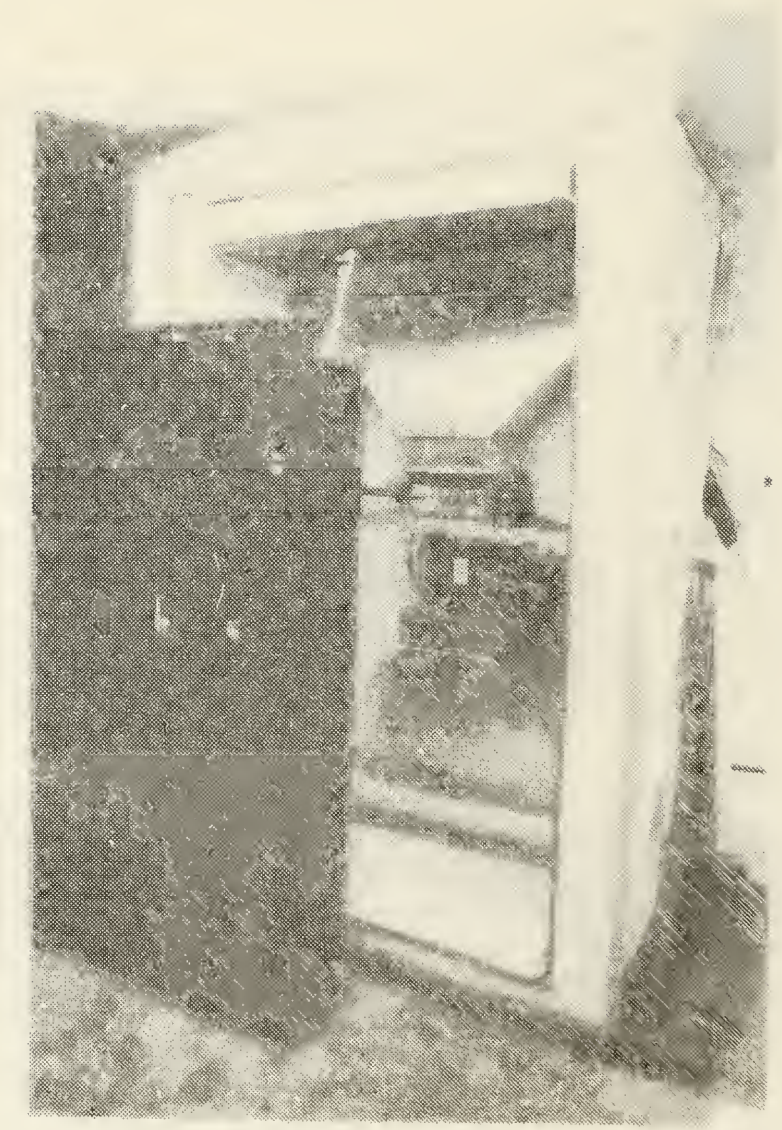

Figure 4. Photograph of metering chamber with solar absorber panel partially removed

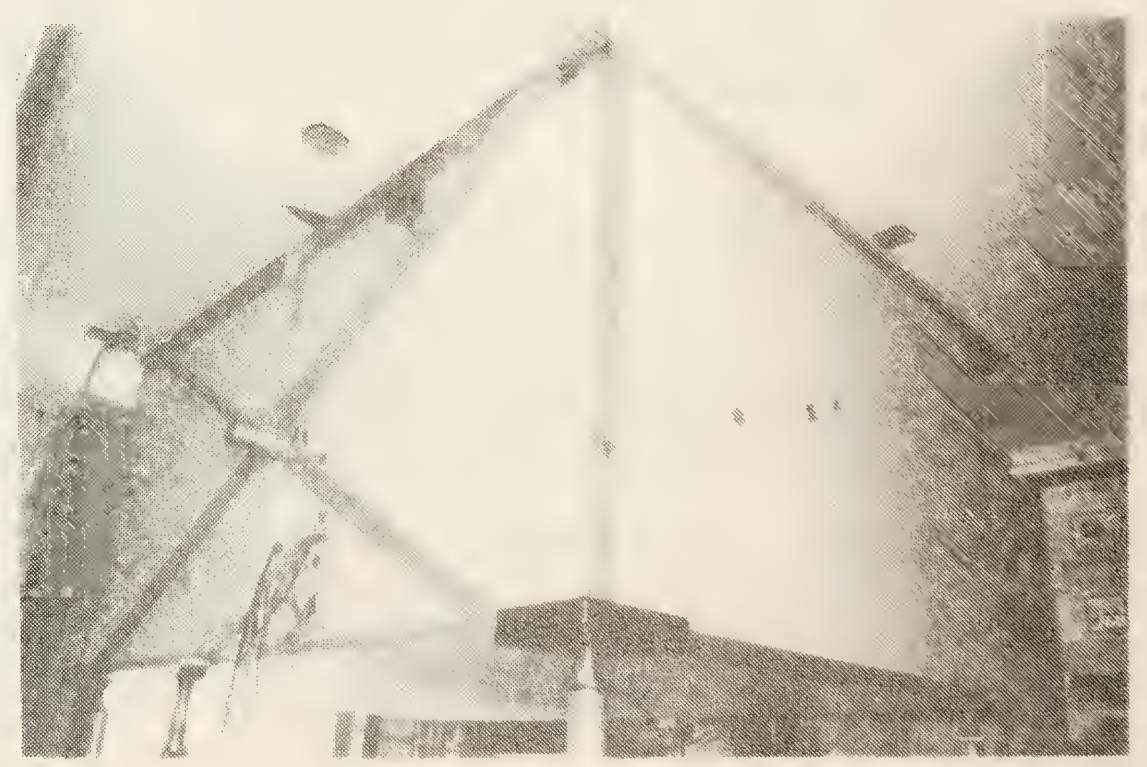

Figure 5. Photograph of netering chamber in horizontal position 


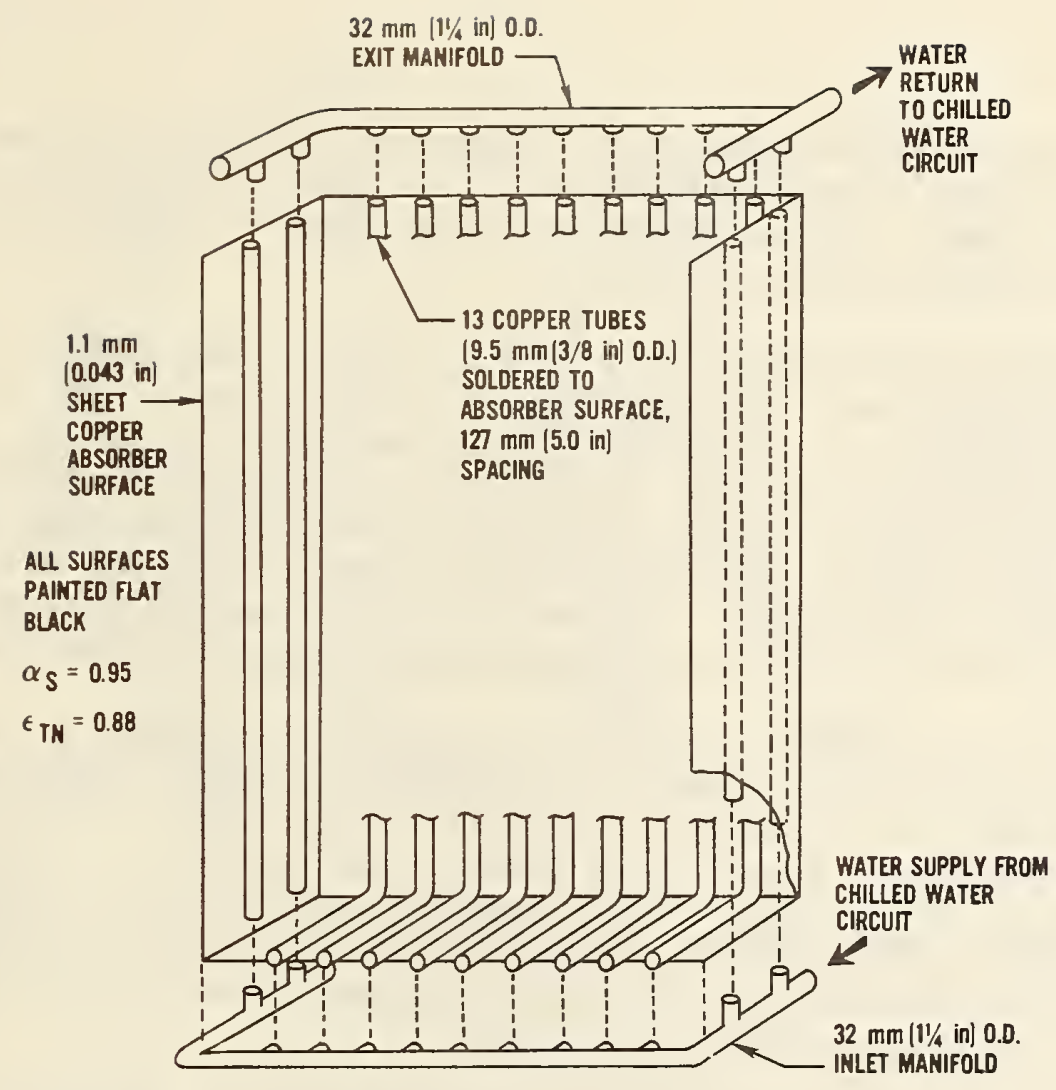

Figure 6. Schematic drawing of solar absorber panel

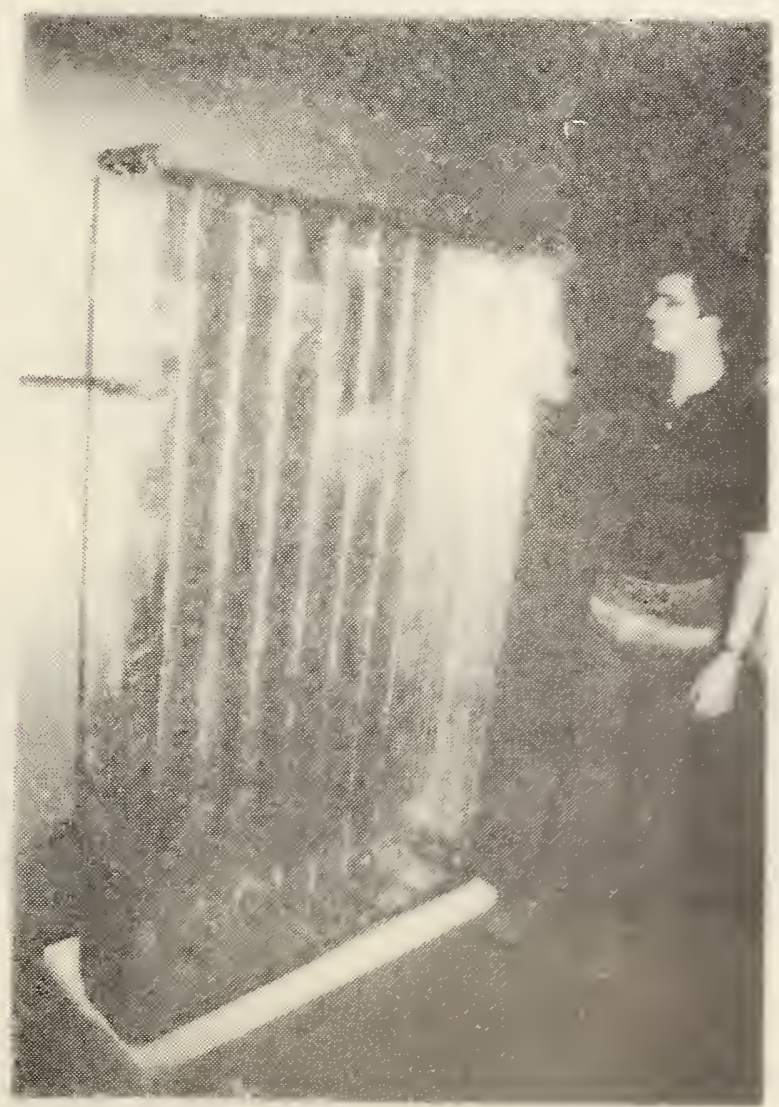

Figure 7. Photograph of solar absorber panel 
Turbine flowmeters are used in each of the water conditioning subsystems to measure flow rate. These sensors develop a signal that is proportional to the volume of fluid flow. A frequency-to-voltage converter makes this signal compatible with the data logger.

A pyrheliometer and two pyranometers are used to measure the direct normal and the total solar irradiance, respectively. A photograph of the pyrheliometer installed in a sun tracking mount is shown in figure 18. One of the pyranometers is installed horizontally at the roof aperture and the other is installed vertically at the wall aperture. The pyranometers measure the total amount of solar irradiation including both beam and diffusely reflected radiation from the sky, ground, and building. Figure 19 is a photograph of the vertical pyranometer installed next to the aperture at approximately mid-height.

The electrical power and energy supplied to the metering chamber are measured with watt transducers and an electronic integrating module, respectively. The watt transducers consist of Hall Effect devices that provide an output analog signal of instantaneous real power. The analog power signal is integrated to provide an analog signal proportional to the number of watt-hours of energy. Transducers measure all the electrical power and energy input to the metering chamber, including the air heaters, the fan motor and speed control, and the test article (if it requires operating energy).

The outside wind speed and direction are sensed with three, mutuallyperpendicular wind driven propellers located approximately $3 \mathrm{~m}$ (10 ft.) in front of the vertical aperture. Each propeller drives a generator which produces a voltage signal proportional to the component of wind velocity in the direction in which the propeller is facirig. Figure 20 is a photograph of the wind sensor installation.

The data acquisition system initially installed in the test facility used an analog data logger to scan and print the temperature and millivolt sensor readings and a nine track tape recorder to store data on magnetic tape. The data logger has the capability of reading 40 type-T thermocouple channels for temperature measurement and 20 channels for other analog voltage measurements, including solar radiation, outdoor wind velocity, metering chamber air velocity, water flow rate, and electric power and energy.

Visual display of up to 30 channels of temperature data is available with a digital panel meter having a resolution of $0.1{ }^{\circ} \mathrm{C}\left(0.2^{\circ} \mathrm{F}\right)$. Other analog sensor displays such as pressure, temperature, and flowrate, are available using pressure gauges, liquid-in-glass thermometers, and rotameters, respectively. These sensors are primarily used to monitor operation of the test facility. Figure 21 is a photograph of the instrumentation cabinet for the data acquisition system, visual displays and control equipment in the passive solar calorimeter. 


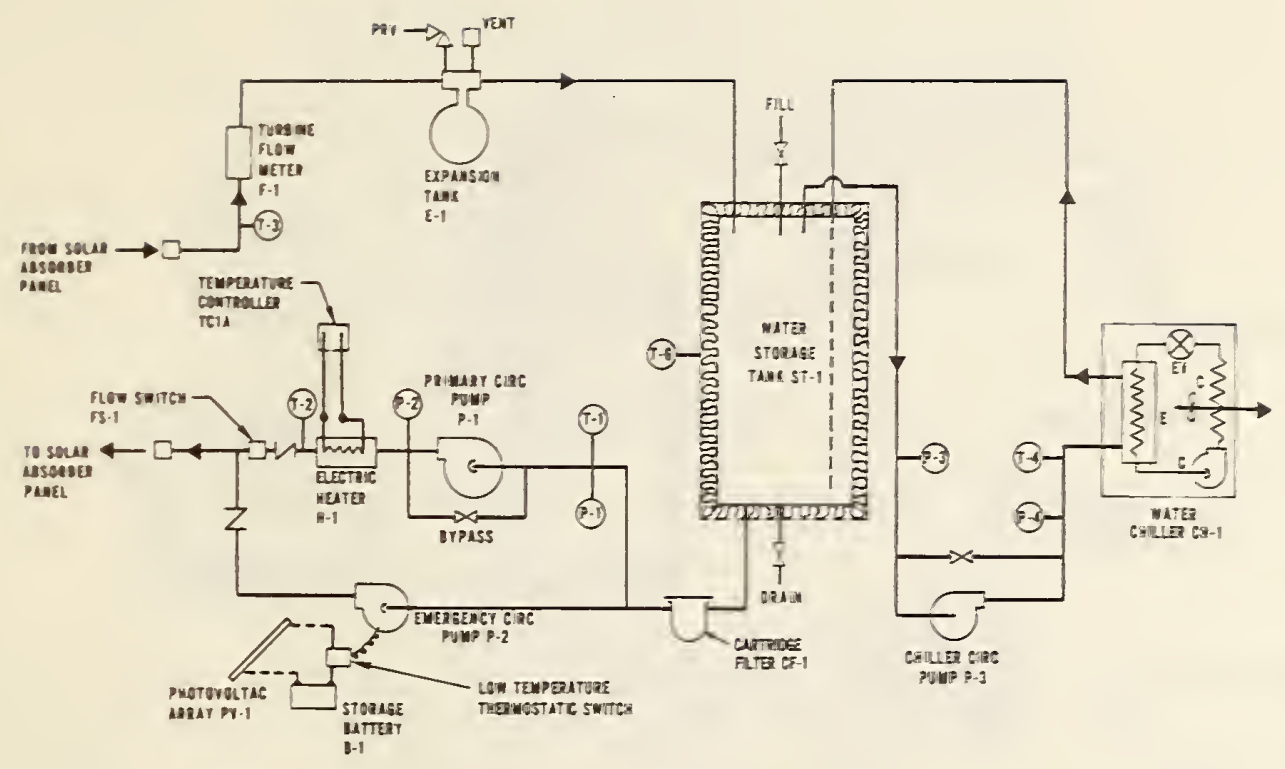

Figure 8. Solar absorber panel cooling water circuit

Figure 9. Photograph of photovoltaic array used for the emergency freeze protection system

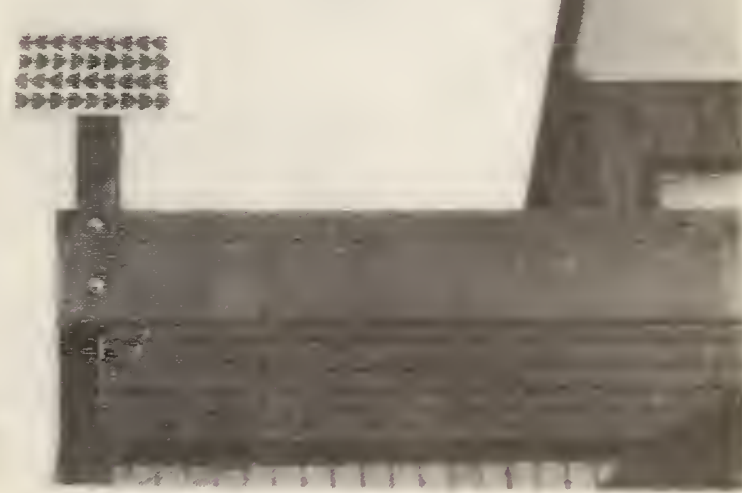




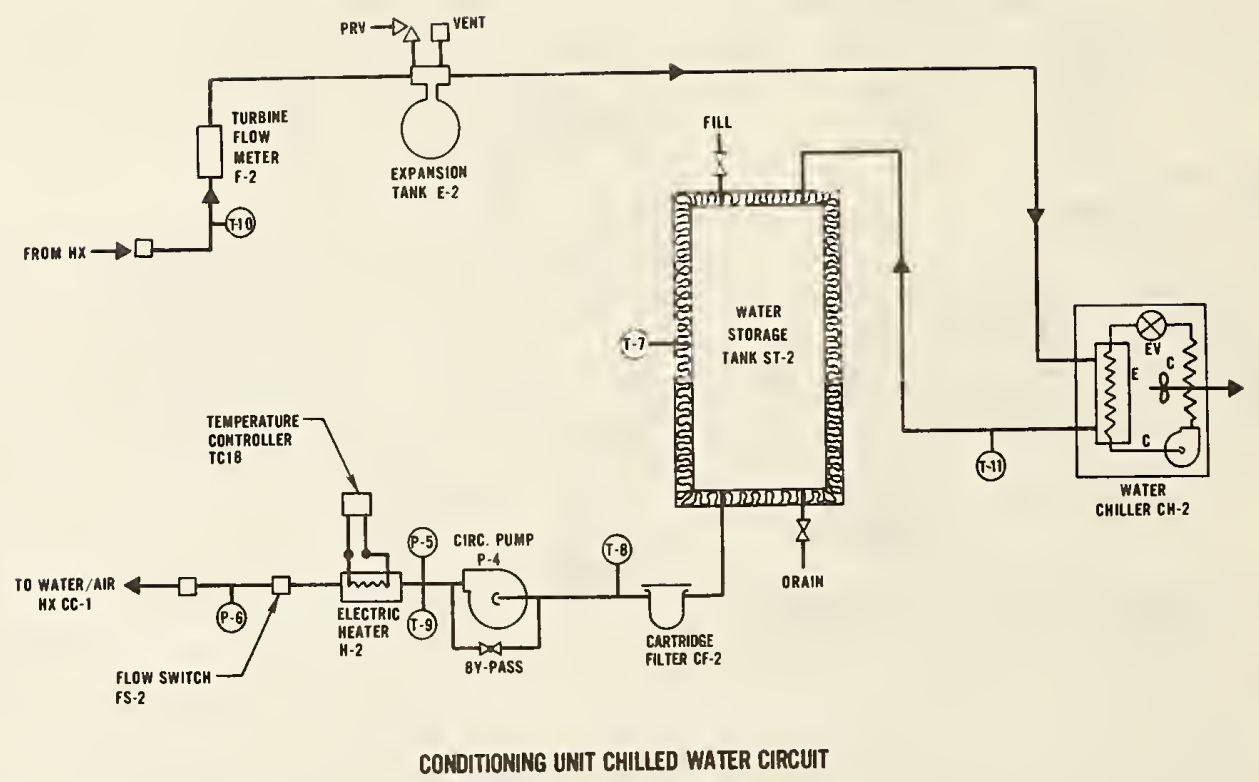

Figure 10. Air-conditioning unit cooling water circuit

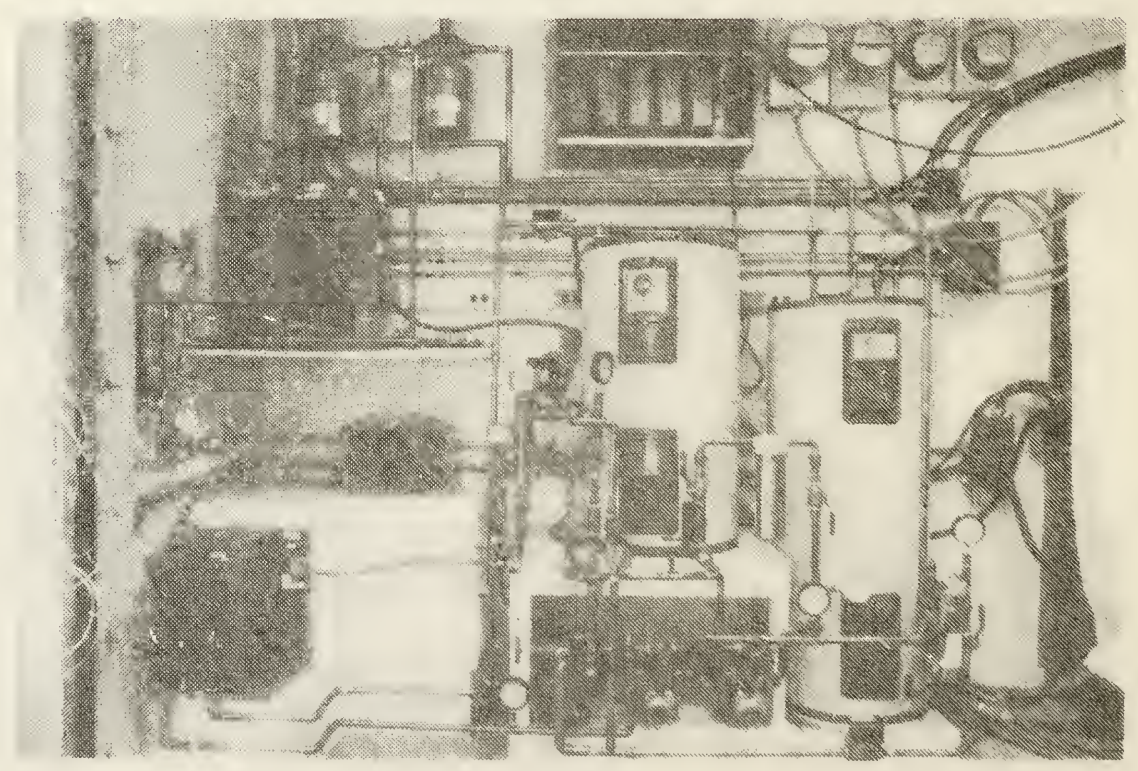

Figure 11. Photograph of fluid conditioning systems 

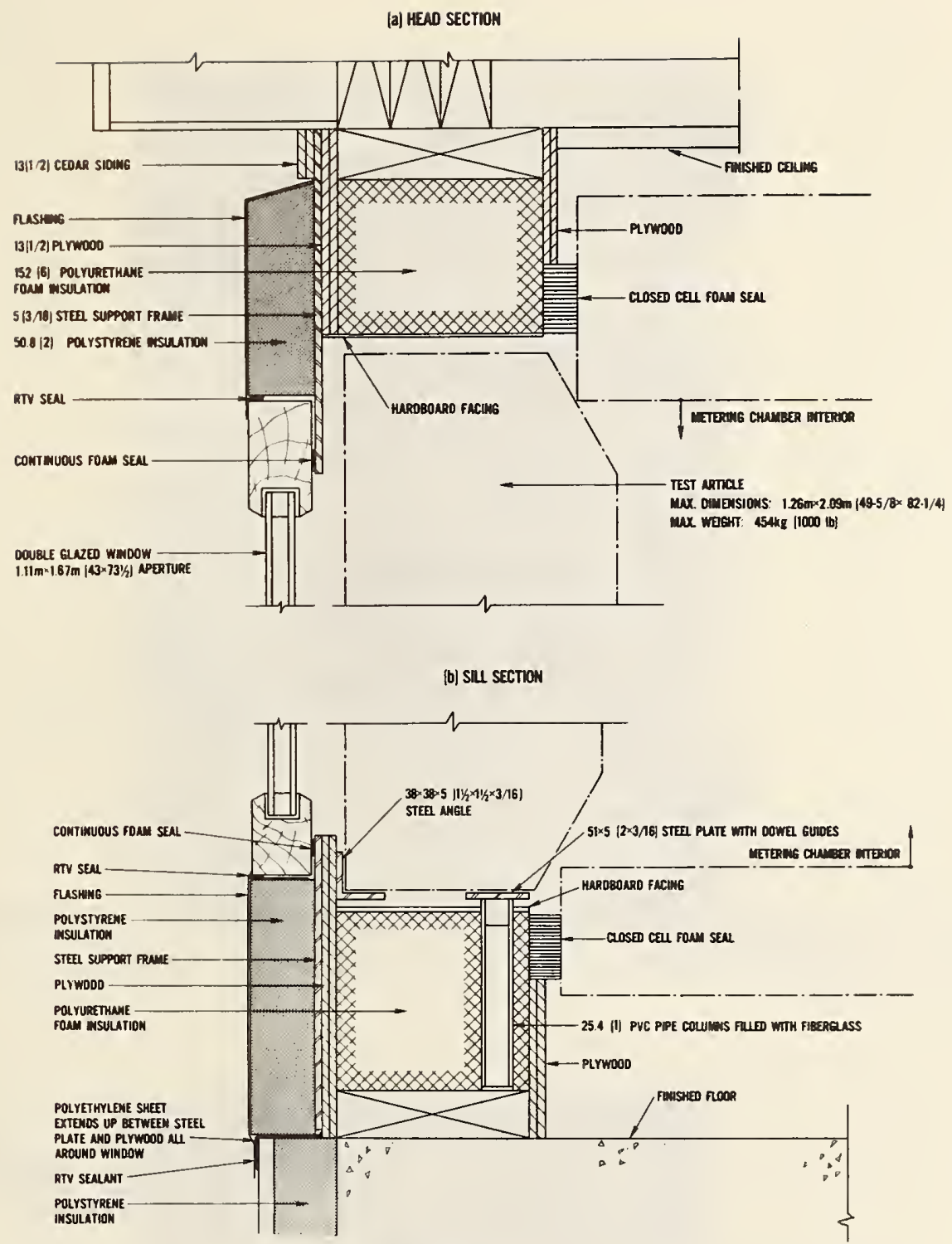

(c) VERTCLE SECTION

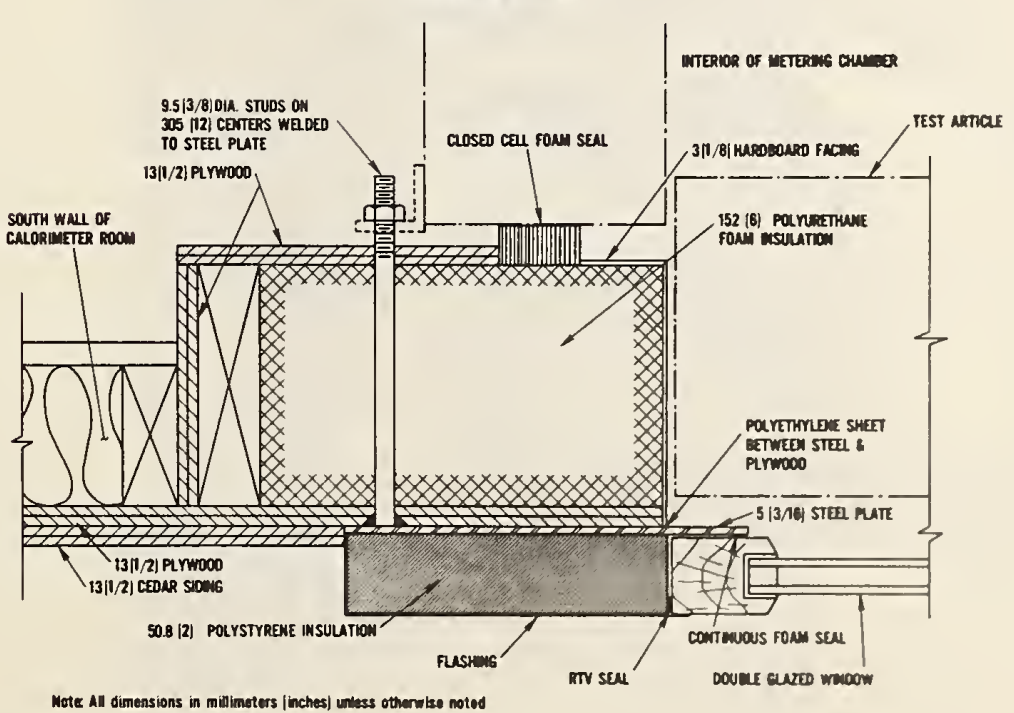

Figure 12. Vertical aperture - test article interface 


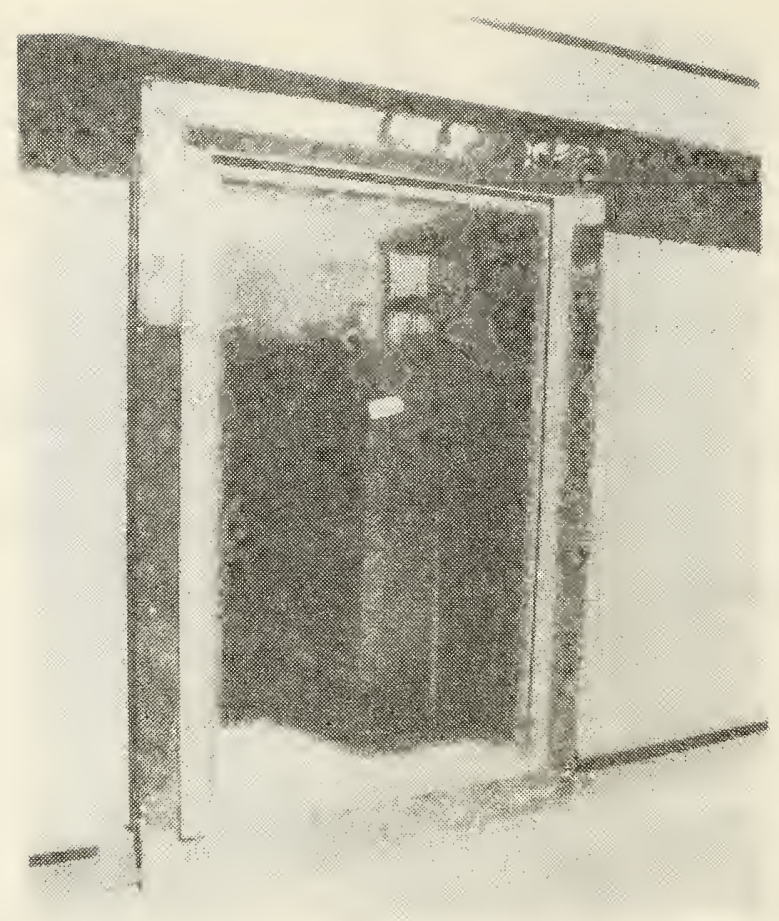

Figure 13. Photograph of vertical aperture interface with standard double glazed window

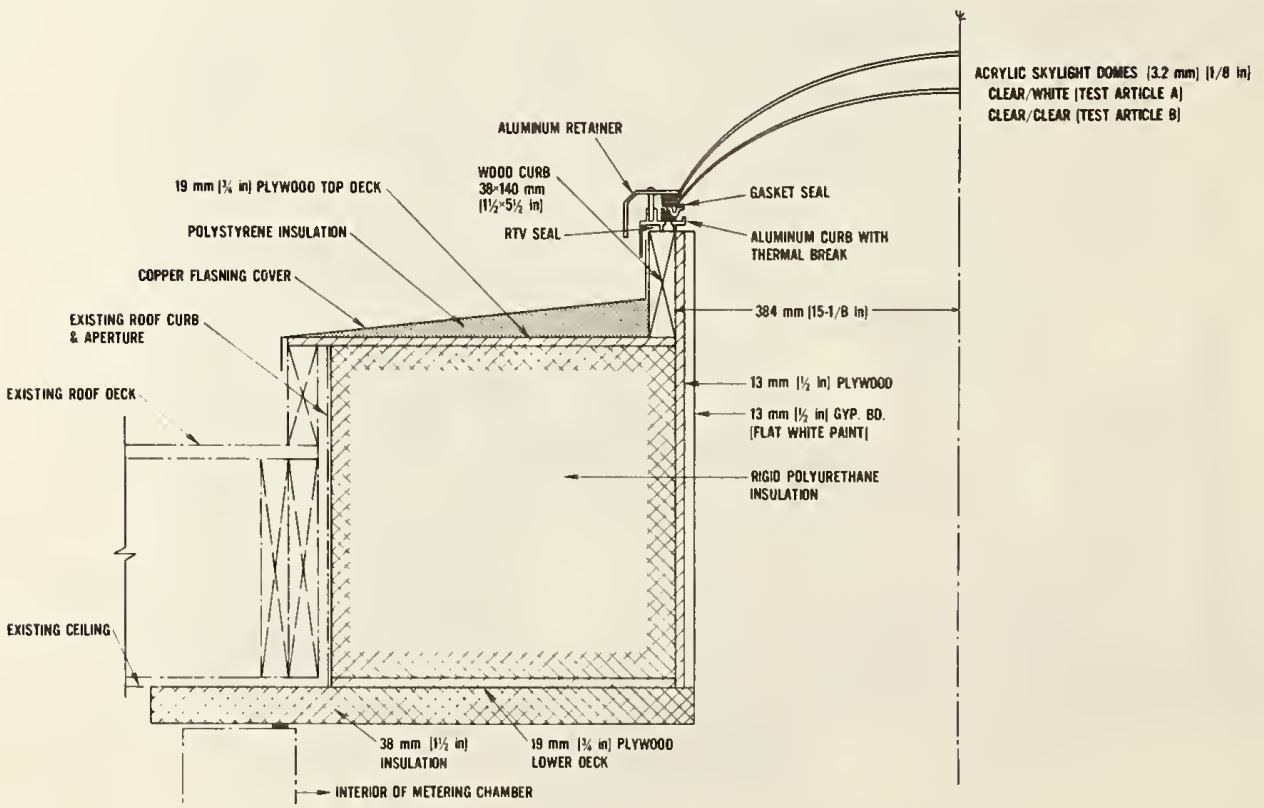

Figure 14. Skylight test article - horizontal aperture interface 


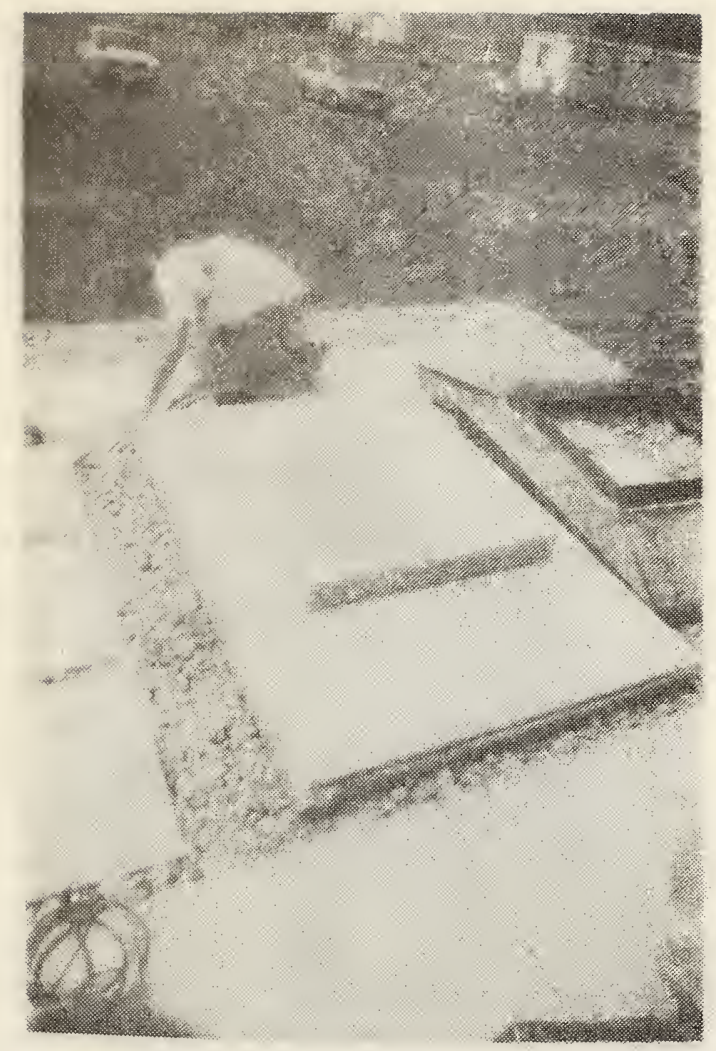

Figure 15. Photograph of test fixture installed in horizontal aperture

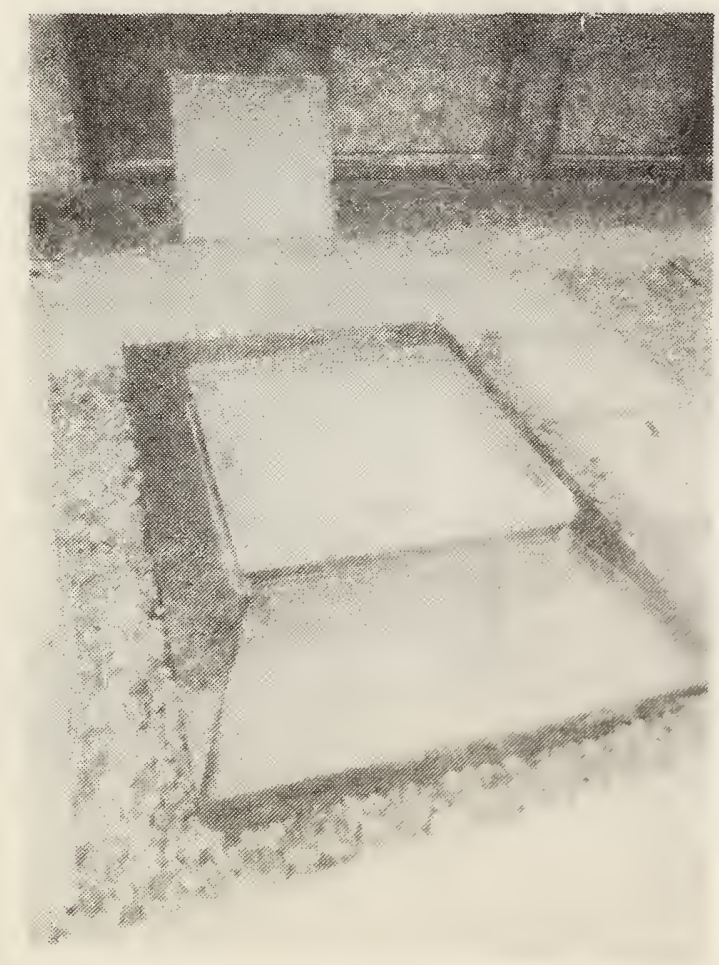

Figure 16. Photograph of skylight test article installed in horizontal aperture 


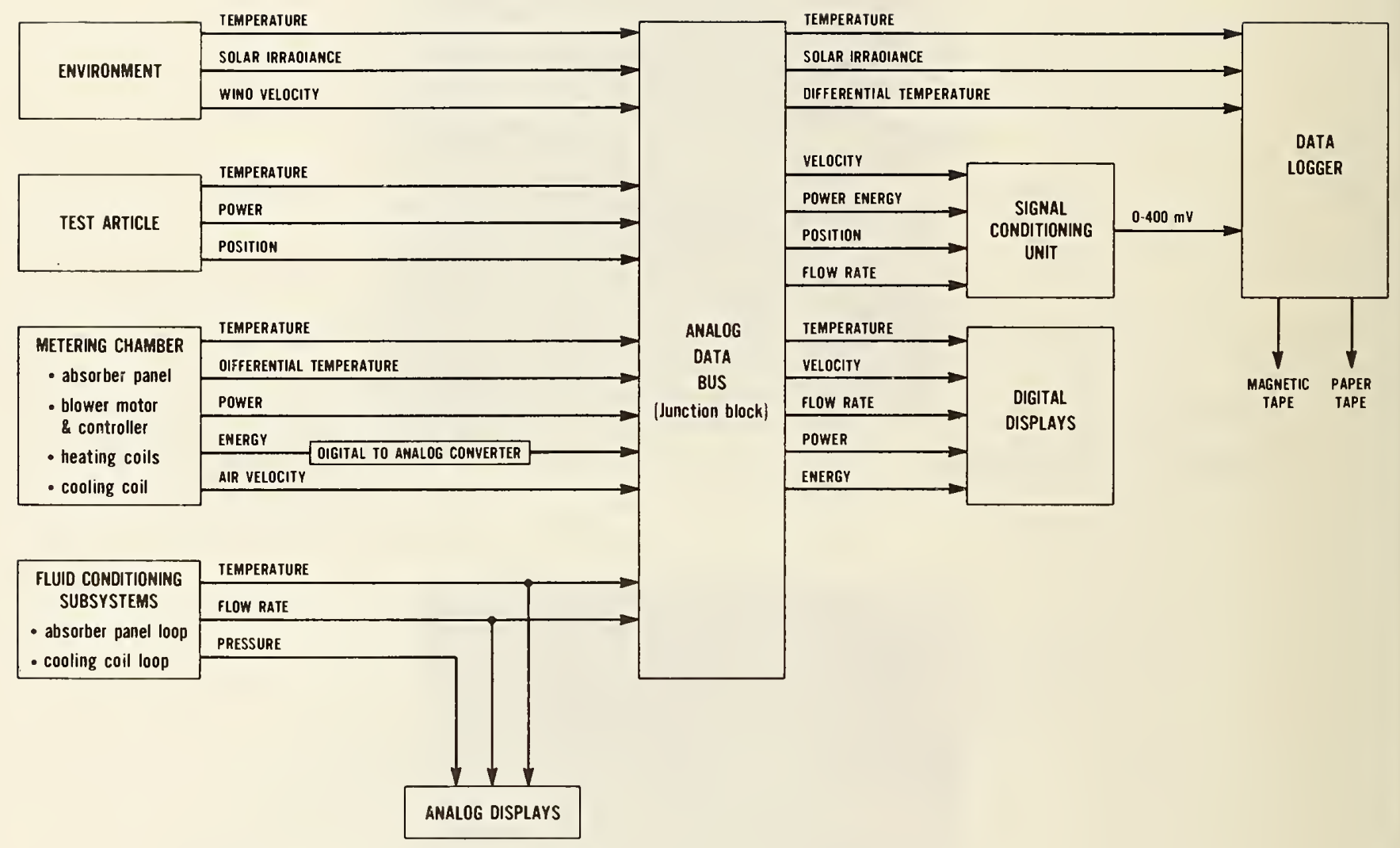

Figure 17. Schematic drawing of data acquisition system 


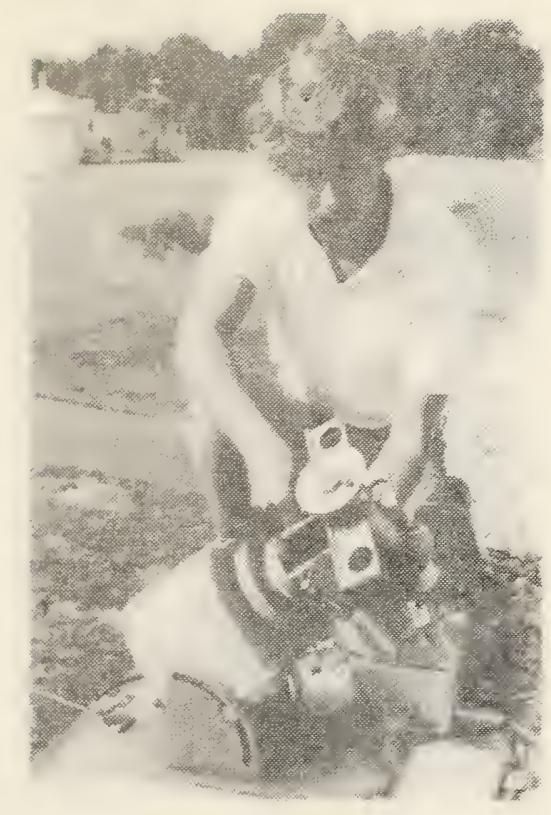

Figure 18. Photograph of normal incidence pyrheliometer installed in tracking mount

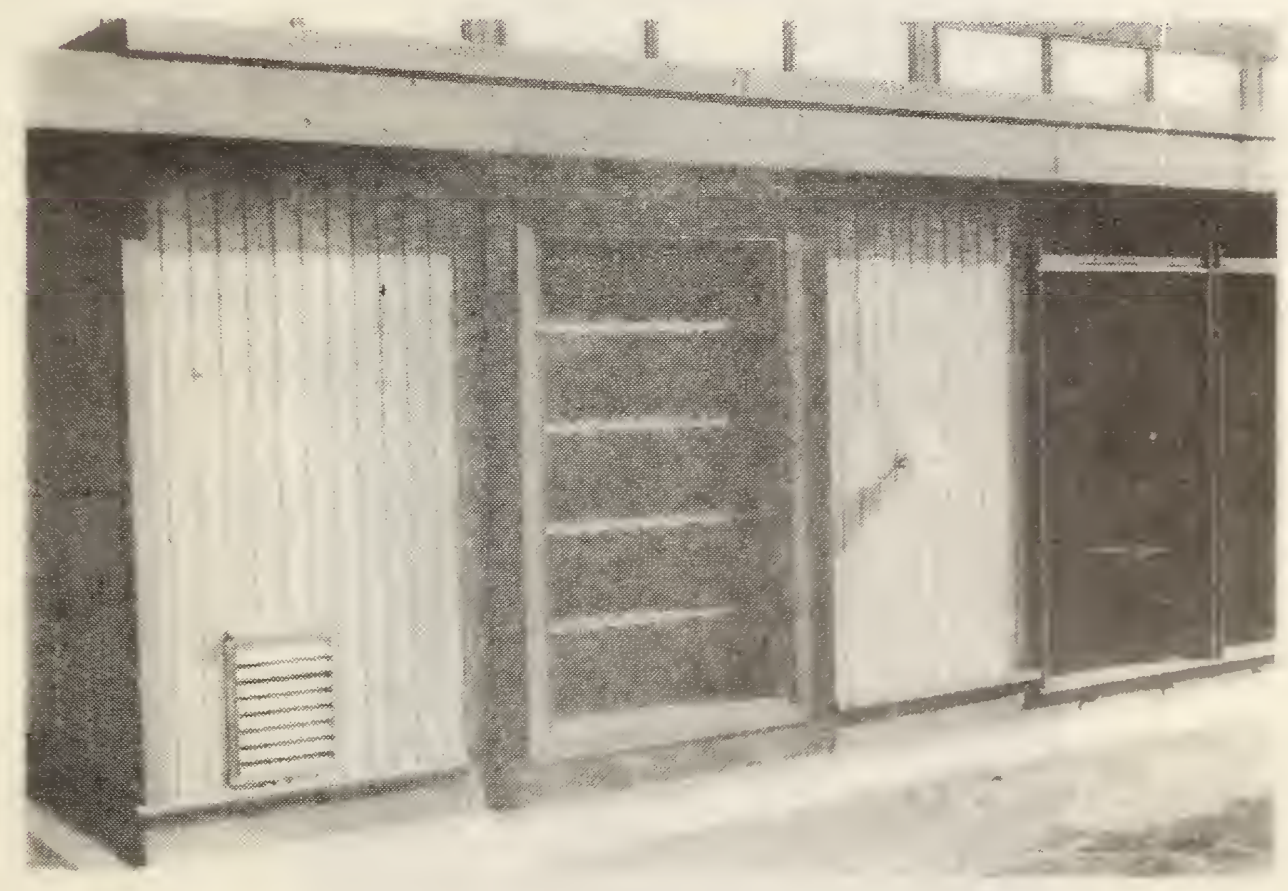

Figure 19. Photograph of vertical aperture with pyranometer Installed to right 


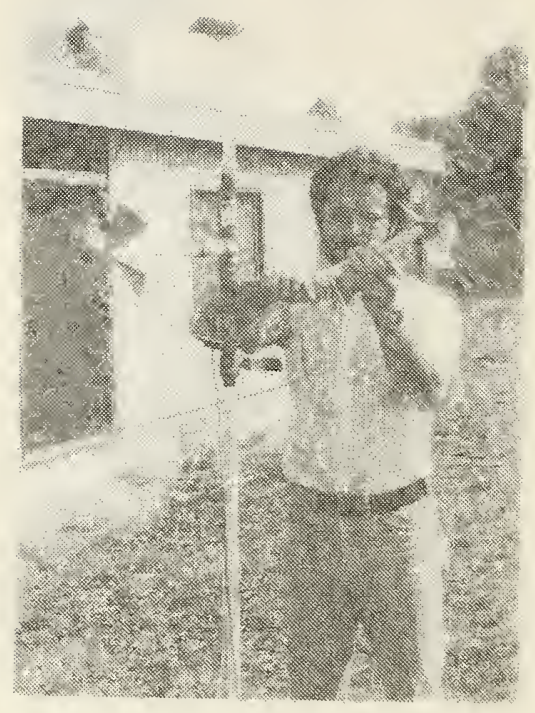

Figure 20. Photograph of thre-axis wind sensor installation

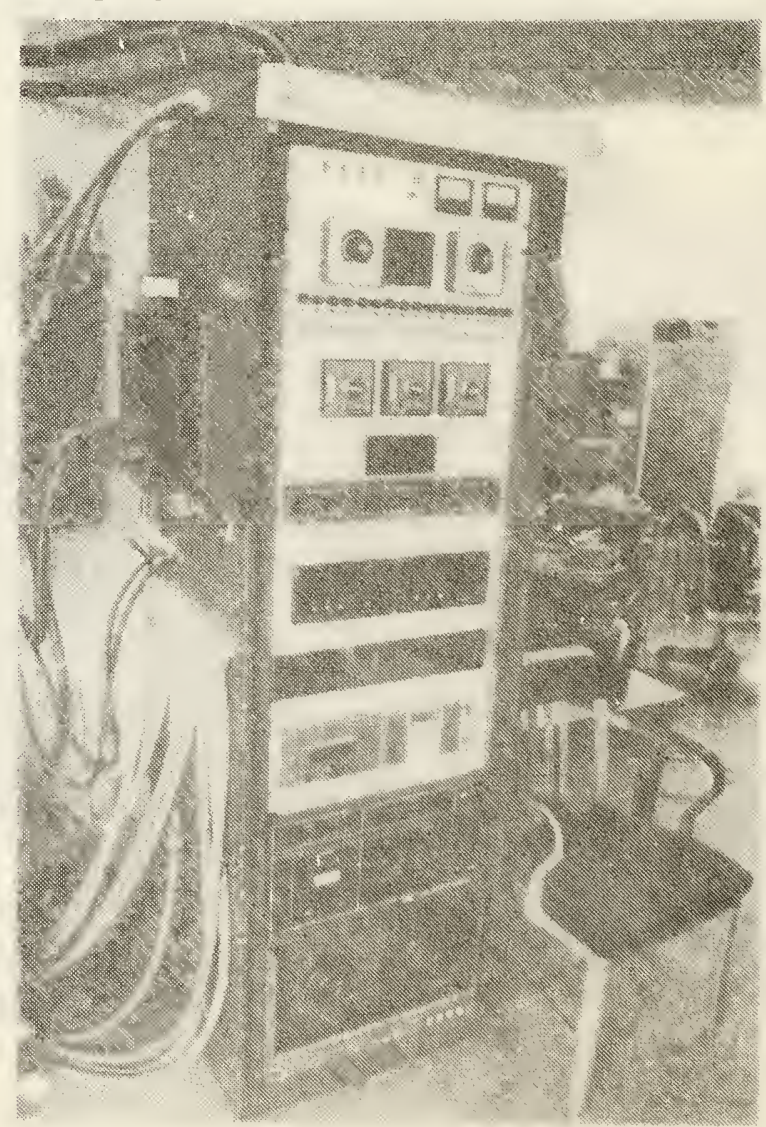

Figure 21. Photograph of instrumentation, control and data acquisition rack 


\section{PERFORMANCE EVALUATION PROCEDURES}

Therinal performance evaluation for each test article was performed using the ininicomputer located in the Center for Building Technology in NBS. The performance evaluation procedures are shown schematically in figure 22 . Sensor data, scanned by the data logger, are recorded on magnetic tape and printed on paper tape. Approximately one minute is required to scan the 60 data channels. The scan rate is four scans per hour. Electronic modules were used to continuously scan and integrate the voltage signals from the differential thermopiles, turbine flow meters, watt transducers, pyranometers and wind sensors, thereby improving the accuracy of these measurements over that possible with the relatively slow scan rates available with the data logger.

A data file containing the raw scan data is created in the CBT minicomputer from the data stored on the paper or magnetic tape. The scan data are converted to engineering units using measured calibration constants, which are stored In a separate data file. The scan data in engineering units are then used to perform a heat-balance calculation, and a listing is made of all computed and measured energy flows. The scan data heat-balance information is then integrated to provide hourly average values, which are archived. Further evaluation of the hourly test results is performed using a statistical analysis program and a graphics plotting routine.

Figure 23 is a schematic drawing showing the energy transfer across the boundaries of a control volume located within the metering chamber. It is assumed that: (1) there is negligible air infiltration exchange between either the outside or the room air and the metering chamber air; (2) there are no latent heat transfer processes due to evaporation or condensation of moisture at cold surfaces; and ( 3 ) there is no energy storage within the metering chamber other than possibly within the test article. The latter assumption is justified by controlling the mean absorber panel temperature, $\mathrm{T}_{\mathrm{ABS}}$, and the mean chamber air temperature, $\mathrm{T}_{\mathrm{AIR}}$ to constant values. Based on these assumptions, the net instantaneous rate of thermal energy transfer between the test article and metering chamber, QNET, is given by:

$$
Q_{\mathrm{NET}}=Q_{\mathrm{ABS}}+Q_{\mathrm{CC}}+Q_{\mathrm{LS}}-Q_{\mathrm{HC}}-Q_{\mathrm{FAN}}
$$

where: *

$$
Q_{A B S}=\frac{1}{\Delta E} \int \dot{M}_{A B S} C_{P}\left(T_{\text {OUT, }} A-T_{I N, A}\right) d t,
$$

* Nomenclature defined in section 9 


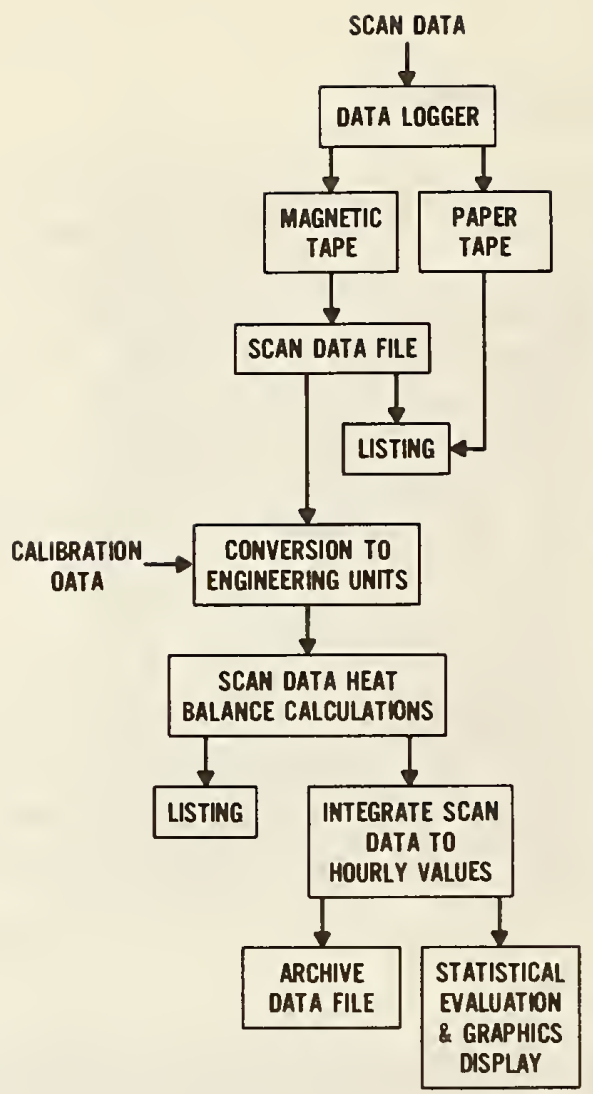

Figure 22. Schematic drawing of performance evaluation procedures

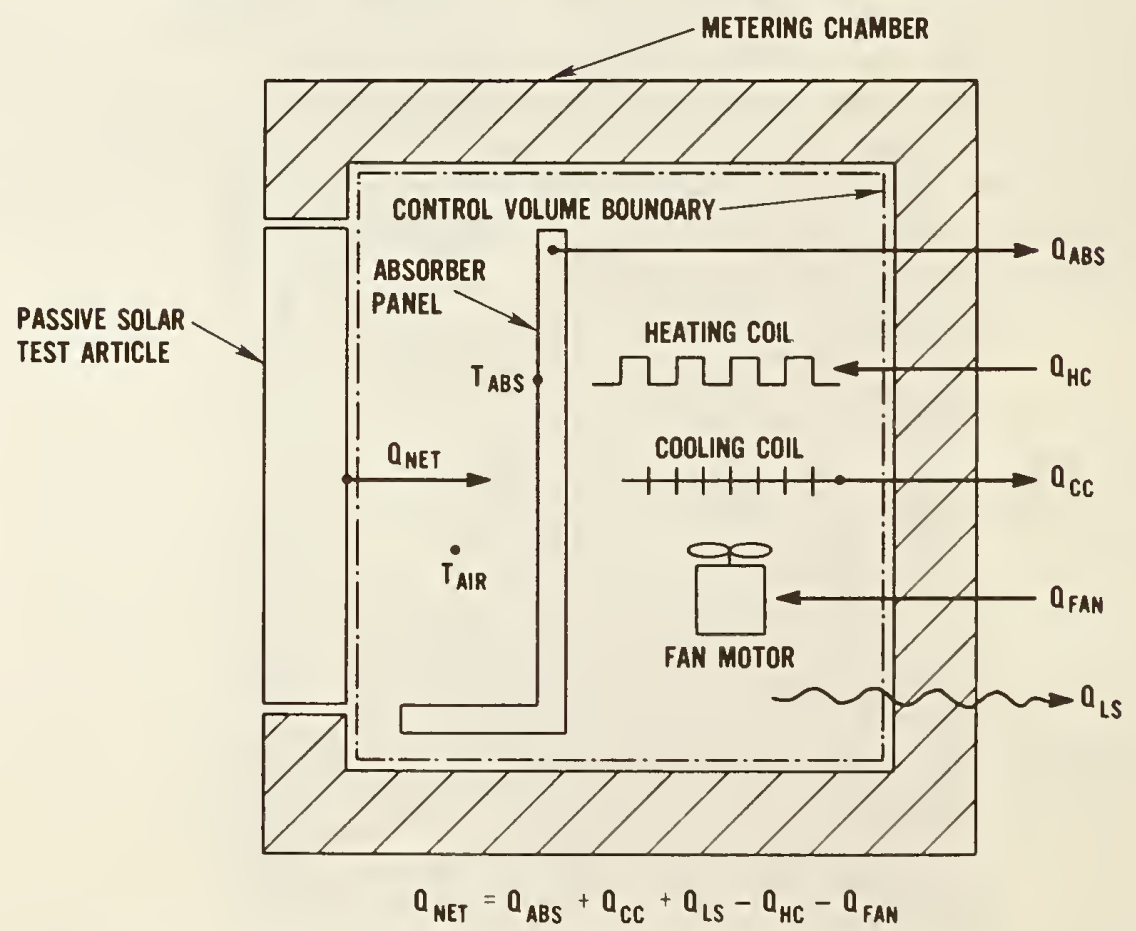

Figure 23. Metering chamber energy balance 


$$
\begin{aligned}
& Q_{C C}=\frac{1}{\Delta t} \int \dot{M}_{C C} C_{P}\left(T_{\text {OUT }, C}-T_{\text {IN }, C}\right) d t \text {, and } \\
& Q_{H C}=\frac{1}{\Delta t} \int\left(\frac{e^{2}}{R}\right)_{H C} d t .
\end{aligned}
$$

QFAN is the electrical energy input to the fan motor and it is assumed that all electrical energy supplied to the heating coils and for operating the fan and test articles (if provided) is converted into thermal energy. $Q_{\text {LS }}$ is the heat transfer rate between the metering chamber and the surrounding room due to conduction through the chamber walls and piping and convection through the instrumentation wiring openings. QLS is measured in the calibration tests, during which the test article is replaced by an adiabatic guard heater panel.

QNET consists of both convective and radiative components. The convective component is imposed on the metering chamber air stream adjacent to the test article and the radiative component is imposed on the absorber panel. For test articles with windows, the convective and radiative components may have opposite senses, i.e., solar radiative heat gain during the daytime being positive, while convective heat gain is negative (heat loss). The individual heat-balance relations for the absorber panel and metering chamber air suggest that if the mean temperatures of both the absorber panel and the adjacent air stream are equal, so that there is no net convective heat exchange between each other, then the absorber panel heat gain is due entirely to radiative heat transfer from the test article. This allows the test article's net heat-transfer rate, $Q_{N E T}$, to be resolved into its convective and radiative components.

One of the design objective for the calorimeter was to resolve the net heat transfer rate into convective and radiative components. This proved to be difficult to achieve and will be further discussed in the next section. 


\section{TEST FACILITY CHECKOUT AND CALIBRATION}

Upon completion of construction of the test facility in November 1982, a series of tests was performed to verify to operation according to specifications. These experiments were designed to test the ability of the mechanical and control systems and the data acquisition system to operate properly as planned. Individual instruments were calibrated, accuracies were determined, and an estimate of overall uncertainty in the measured results was made. Calibration of the metering chamber itself was necessary so that the small amount of heat loss through the chamber walls could be determined and accounted for in the overall energy balance. This was accomplished by placing guard heater panels in the vertical aperture to create an adiabatic wall and then operating the fluid conditioning equipment. The tests designed to check the normal operating conditions helped to establish adequate control procedures but also revealed some shortcomings of the calorimeter's capabilities. Improvements in the data acquisition and control systems were implemented as a result of the tests and the performance was found to be adequate. Testing for collecting useful data started in January 1983.

\subsection{ANALYSIS OF ERRORS}

The magnitude of the errors that might be expected in the test results are discussed in this section. The analysis of error is important since a high level of overall accuracy is desired and several special measurement problems exist. The measurement of small temperature differences that are a consequence of the attempt to separately measure the radiative and the convective components of heat flux were found to present the most difficult measurement problem. The significance of the errors in the test results was established and the principal sources of these errors identified. Specific improvements to the operation and measurement systems also discussed.

The individual measurements which must be made to determine the test article net heat transfer rate are defined by equation 2. In that equation, $\mathrm{Q}_{\mathrm{HC}}$ and QFAN are measurements of electrical energy which can readily be made with accuracies of better than 0.5 percent. QS is not measured directly but is determined from the metering chamber heat balance measured during calibration. The uncertainty in that heat balance component is the most significant error in the overall energy balance, however, the magnitude of QLS is usually small compared to other terms in the equation and thus is not generally a large contributor to the total error. The determination of QLS and 1 ts impact on the overall energy balance is discussed further in section 4.2 .

The greatest potential error occurs from the heat balance components, QABS and $Q_{C C}$, which are the changes in enthalpy of the fluid conditioning systems. Each component requires the measurement of a mass flow rate and a temperature difference $(\Delta T)$. Of the two, uncertainty in the measurement of the absorber panel fluid $\Delta \mathrm{T}$, generally constitutes the largest portion of error in the energy balance. This is due primarily to the conflicting goals of maintaining 
an isothermal absorber panel (both spatially and temporally) and of maintaining a measurable $\Delta \mathrm{T}$. To meet the isothermal requirement requires a large flow rate and hence, the fluid $\Delta \mathrm{T}$ should be near zero. However, to achieve better accuracy in the measurement of temperature difference, a large $\Delta \mathrm{T}$ should be maintained. For the results presented in this report, the mass flow rate of the absorber circulating fluid was held constant and the absorber $\Delta \mathrm{T}$ allowed to change in response to changing environmental conditions. Since the magnitude of QABS varies over a range of about 20 to 1 , the measurement of absorber $\Delta T$ at night has a relatively low accuracy and isothermal conditions are not closely maintained during periods of peak daytime solar radiation.

For the existing measurement system, the 95 percent uncertainty interval for temperature difference of measurements is estimated to be $0.02^{\circ} \mathrm{C}\left(0.04^{\circ} \mathrm{F}\right)$. This error in the $\Delta \mathrm{T}$ measurements results in a 15 watt uncertainty interval for $Q_{A B S}$ and a 5 wat uncertainty interval for $Q_{C C}$. These errors are much larger than all other measurement system errors combined and so must receive the greatest attention for future improvements. A control system that provides for variable flow rates depending upon the magnitude of $Q_{A B S}$ is a relatively simple modification that should produce significantly improved measurement capability.

\subsection{METERING CHAMBER CALIBRATION}

One term in the energy balance equation QLS, which accounts for heat lost through the insulated walls of the metering chamber is given by:

$$
Q_{L S}=(U A)_{M C}\left(T_{A I R}-T_{R M}\right)
$$

The overall heat-transfer coefficient, (UA) $M C$, of the metering chamber was determined experimentally by placing guard heater panels in the test article aperture to prevent heat loss and by maintaining the guard heater surface temperature equal to the metering chamber air and absorber panel temperature. When the conditioning and measurement systems were operated and a value of $\mathrm{Q}_{\mathrm{NET}}=0$ established by virtue of the guard heaters, $\mathrm{Q}_{\mathrm{LS}}$ was obtained by the energy balance, and (UA) MC could be calculated.

The guard heater panels are shown schematically in figure 24. They cons1st of three sections which completely fill the vertical aperture for the metering chamber calibration. The guard heater panels can also be used separately as individual adiabatic blanking panels to accommodate different size test articles in the vertical aperture. Each guard heater panel consists of an aluminum plate sandwiched between two pieces of rigid polyurethane foam insulation, with $102 \mathrm{~mm}$ ( 4 in.) insulation on the interfor side of the plate and 51 mm (2 in.) on the exterior. Resistance-foil strip heaters mounted on the plates are controlled by solid-state temperature controllers to maintain a constant average surface temperature equal to the setpoint temperature of the metering chamber. This design constrains the heat transfer rate through the blanking panels to less than $0.45(1.54 \mathrm{Btu} / \mathrm{h})$ watts when the guard heater plate temperature is within $1.0^{\circ} \mathrm{C}\left(1.8^{\circ} \mathrm{F}\right)$ of the metering chamber air temperature. 


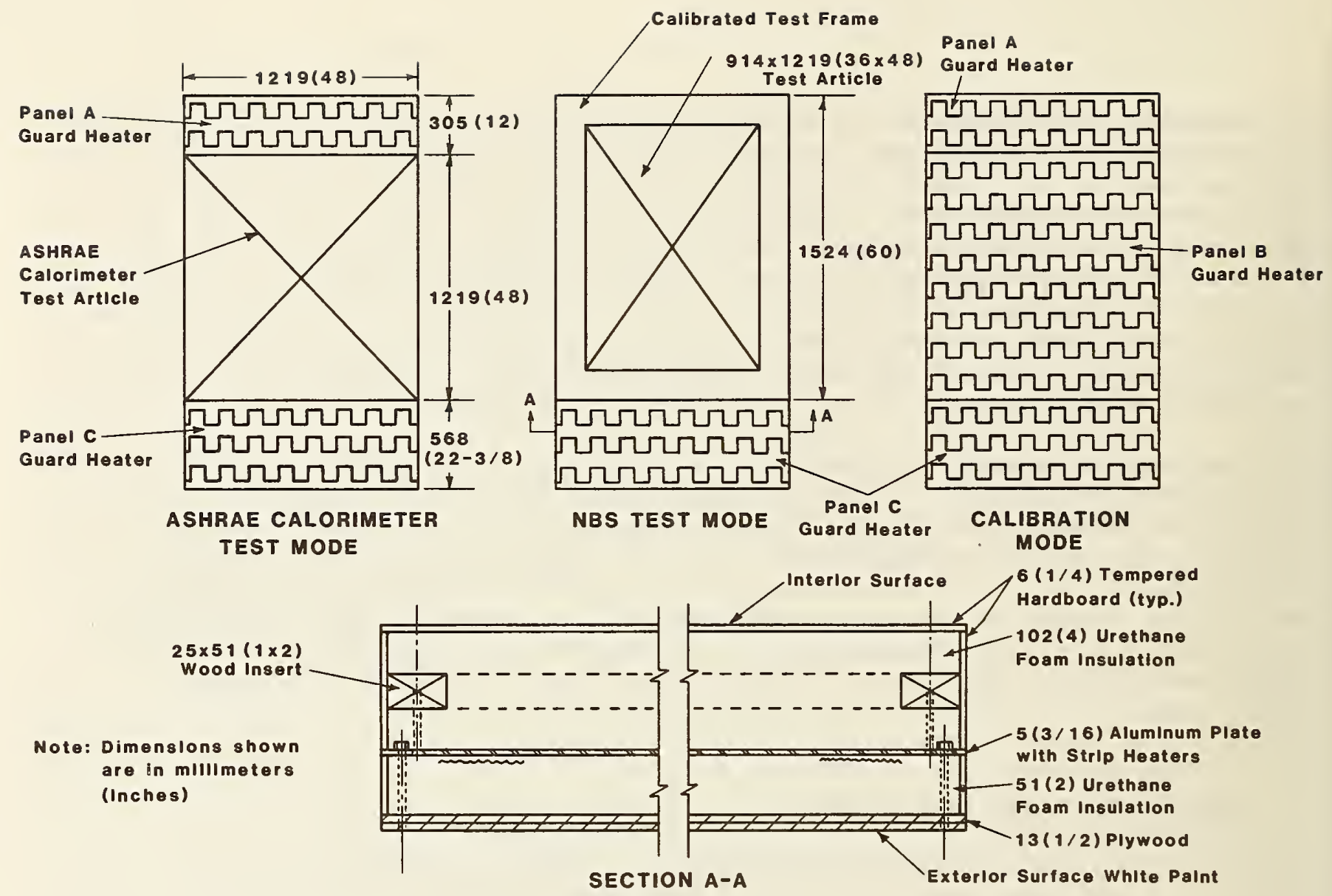

Figure 24. Schematic drawing of guard heater panels

(a) UPPER SECTION

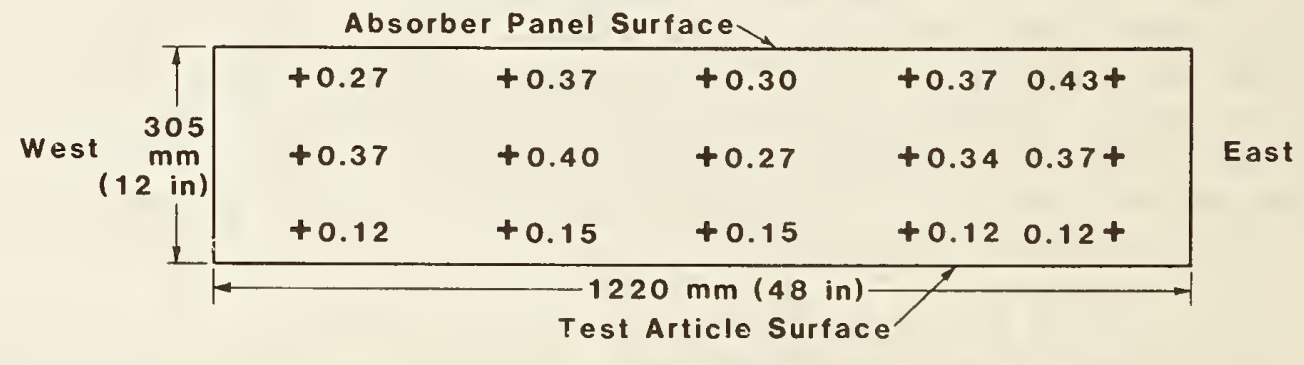

(b) MID SECTION

\begin{tabular}{lllll|}
\hline+0.37 & +0.40 & +0.37 & $+0.120 .06+$ \\
+0.18 & +0.18 & +0.30 & $+0.210 .12+$ \\
+0.06 & +0.09 & +0.12 & +0.06 & $0.03+$ \\
\hline
\end{tabular}

Note: Velocity measured at locations denoted by + , given in meter/sec. To convert to $\mathrm{ft} / \mathrm{sec}$, multiply by 197.

Figure 25. Distribution of air velocity $(\mathrm{m} / \mathrm{s})$ in the metering chamber 
The callbration tests were performed by operating all fluid conditioning equipment and instrumentation as they would be operated under normal testing conditions. The systems were allowed to run for several hours to reach equilibrium conditions after which the data was recorded for a perlod of about 8 hours. This test was repeated several times and from these data an average (UA)MC was calculated. Tests were also conducted without operation of the absorber panel in an attempt to reduce overall uncertainty.

The best estimate of the average (UA)MC obtained through the tests was $2.4 \mathrm{~W} /{ }^{\circ} \mathrm{C}$ $\left(4.5 \mathrm{Btu} / \mathrm{h}^{\circ} \mathrm{F}\right)$. This agrees reasonably well with the UA calculated from material properties of about $2.0 \mathrm{~W} /{ }^{\circ} \mathrm{C}\left(3.8 \mathrm{Btu} / \mathrm{h}^{\circ} \mathrm{F}\right)$. It should be noted that there are other possible heat-loss mechanisms that do not depend only on the difference in temperature between the room and the metering chamber interior and are therefore not included in this term. These include air infiltration and conduction to the outside environment either through the test article and 1 ts support frame or through or around the metering chamber itself. Another potential source of measurement error is due to exterior surfaces of the chamber being exposed to different ambient temperatures. Measurements indicated the bottom of the chamber to be about $6^{\circ} \mathrm{C}\left(3^{\circ} \mathrm{F}\right)$ colder and its top to be about $4^{\circ} \mathrm{C}\left(2^{\circ} \mathrm{F}\right)$ warmer than the average (mid-helght) room temperature.

\subsection{AIR VELOCITY AND TEMPERATURE DISTRIBUTION}

The velocity and temperature distributions of circulating air in the metering chamber were measured to determine their compliance with design criteria. These criteria specified uniform velocity and temperature across the aperture and a maximum velocity of less than $.45 \mathrm{~m} / \mathrm{sec}$. ( $1.5 \mathrm{fps}$ ) to minimize disturbance of natural convection at the surface of the test article. Development of these criteria is discussed in reference 9. Honeycomb flow straighteners were placed in the inlet section of the air duct to obtain a uniform air velocity distribution and a speed controller on the fan motor was adjusted to provide the desired velocity. The measurement was accomplished by closing the aperture of the calorimeter with a plywood panel and inserting a hot wire anenometer probe through small holes drilled in the panel. Readings were taken at nine points across the width, four points along the vertical dimension, and at three different depths for a total of 108 velocity measurements.

Figure 25 presents the most important results which show a small variation from side-to-side in a given horizontal plane but considerable variation from front to rear, with the higher velocities being near the absorber panel and monotonically decreasing toward the aperture. The velocity distribution in a vertical plane implies that there is some mixing from front to back in the lower portions. The average air velocity appears to satisfy the design criterion, especially the velocities nearest the test article which are sufficlently low so there is little chance for forced convection heat transfer. It is also clear however, that at some locations, velocities greater than the design value may induce some localized turbulence. Performing the same traverse pattern with a thermocouple revealed that there were no temperature differences greater than $0.1^{\circ} \mathrm{C}\left(0.2^{\circ} \mathrm{F}\right)$ anywhere within the air flow stream. 
Some potential operational and measurement problems with the fan were discovered during checkout. The system is designed so that the electric motor which operates the belt-driven fan is not located within the air flow stream. Hence when trying to discriminate between radiation and convection in the measurements, it is not clear whether the fan energy should be associated with the air or absorber (i.e., convection or radiation) portion of the energy halance. The recommended solution to this problem is discussed in section 7 .

\subsection{AIR INFILTRATION}

Although air infiltration is not explicitly measured in the calorimeter, the assumption was made that due to careful construction, it would be an insignificant component of the energy balance. To test the assumption, a pressurization test was performed on the metering chamber and the air leakage rate was determined as a function of pressure difference. This was accomplished by sealing the calorimeter aperture and installing a small blower to pressurize the chamber. The flow rate through the blower and the induced pressure difference across the walls of the chamber were measured at several blower speeds, providing a set of points to be fit to the equation:

$$
\mathrm{V}=\mathrm{C}(\Delta \mathrm{P})^{\mathrm{N}}
$$

where:

$$
\begin{aligned}
\mathrm{V} & =\text { volume flow rate of air, } \mathrm{l} / \mathrm{s} \text { (CFM) } \\
\Delta \mathrm{P} & =\text { pressure difference, } \mathrm{Pa} \text { (in } \mathrm{H}_{2} \mathrm{O} \text { ) } \\
\mathrm{C}, \mathrm{N} & \text { are parameters to be determined. }
\end{aligned}
$$

Parameters estimated from the data yield values of $\mathrm{C}=0.131$ and $\mathrm{N}=0.93$ in SI units and $\mathrm{C}=5.1$ and $\mathrm{N}=0.93$ in English Units.

This equation provides a quantitative measure of the air leakage characteristics of the metering chamber not associated with a test article. At a rating point of 4.0 Pascals $\left(0.016 \mathrm{in} . \mathrm{H}_{2} \mathrm{O}\right)$, the computed leakage would be about 0.7 air changes per hour. However, in practice the driving forces for infiltration through the metering chamber (wind and temperature difference) are very small because of its location within a controlled environment.

The more important consideration is to determine the air leakage characteristics of the test articles. If there is air leakage through the test article from the outside, this heat flow will show up in the energy balance and obscure the identification of other heat transfer mechanisms. Each test article is likely to have different air leakage characteristics and the interface with the calorimeter aperture may also leak. It is possible to perform a pressurization test for each test article as installed in the aperture or to use continuous tracer gas monitoring, but these tests would still not provide a quantitative measure of heat flow due to infiltration because it would not be known whether air coming into the calorimeter is from the surrounding room or from the outside. It is therefore desirable to minimize air leakage of all test articles to eliminate this consideration from the energy balance. 


\subsection{TEMPERATURE TRACKING TESTS}

Several separate control devices must be independently adjusted to provide the desired temperature control. The solid-state temperature controllers which control the heaters in both the air and absorber loops each have three parameters that determine their behavior; setpoint, bandwidth, and cycle-time. The two chillers are turned on and off by thermostats with adjustable setpoints and bandwidths. The response characteristics of the system are also sensitive to the liquid and air flow rates in the conditioning loops. A series of tests was performed to select values of control variables that would provide adequate control and to qualitatively determine the sensitivity of the system to each variable.

These tests primarily consisted of operating the entire calorimeter system in its normal mode and observing the temperature history of the air and absorber on a strip-chart recorder. As individual adjustments were made on the controllers, their effect could be observed, the objective being to eliminate any steady-state oscillation of the temperatures and to achieve equality of $\mathrm{T}_{\mathrm{AIR}}$ and $\mathrm{T}_{\mathrm{ABS}}$ to within the accuracy of the thermocouples. Another part of this test consisted of subjecting the system to step changes in radiation energy input by alternately opening and closing the aperture. These tests were intended to measure the response time of the system.

The tests demonstrated that it is difficult without a supervisory computer controller to coordinate the operation of several independent controllers to provide effective control over a wide range of inputs. The controllers are single-input and single-output devices, however, the variables to be controlled are functions of multiple-independent inputs. Control settings that provide correct operating of the calorimeter under a particular set of environmental conditions (e.g., day) may leave the system without adequate control under other conditions (e.g., night). It was found that control settings must be carefully chosen and periodically revised to minimize deviation from the control objectives. 
Four test articles were tested in the calorimeter between January and March 1983, including two direct gain fenestrations and two collector-storage wall modules. The facility is designed so that test articles can easily be changed within a single day. A typical test lasts from one to three weeks. As previously discussed, guarded heater panels of various sizes allow the dimensions of the test aperture to be changed to accommodate components that are not sized to fill the entire height of the aperture. A previously calibrated test frame is used with components of nominal $0.91 \mathrm{~m}$ by $1.22 \mathrm{~m}$ ( 36 by $48 \mathrm{in.}$ ) dimensions. The frame consists of a $0.15 \mathrm{~m}$ ( 6 in.) thick extruded polystyrene insulation layer sandwiched between $6 \mathrm{~mm}(1 / 4 \mathrm{in}$ ) plywood interior and exterior surfaces. Any heat flux through the frame is subtracted from the measured value of QNET by use of the heat-transfer coefficient determined by calibration.

\subsection{TRIPLE-GLAZED WINDOW}

A triple-glazed window was the first component to be tested. This window was mounted in the test frame described above and consisted of top and bottom double-glazed exterior sections, with interior single-glazed sections. The white-enamel aluminum frame was designed with a thermal break to limit conduction losses and provision was made for sealing against air leaks at all movable interfaces. The window is of the single hung type with the top sash fixed and the bottom moveable. An insect screen provided for the bottom half of the window was not in place during the test. A schematic drawing showing a vertical section through the window and test frame is shown in figure 26 . A photograph of this test article appears in figure 27.

Because this test article is smaller than the aperture, a guard heater panel was installed blanking out the lower section of the aperture. The test frame was attached to the steel plate at the outside surface of the aperture with wood screws. A tight fit was achieved between the aperture and the test article by placing precut rigid foam insulation in the larger gaps and insulating foam strips in the smaller gaps to minimize both air leakage and extraneous conduction losses.

Thermocouples made from type-T, 30 gauge wire were mounted at the center of each of the six glass sections of the window to measure surface temperatures for future comparison with computer model predictions. To maximize surface contact with the glass and to minimize the area exposed to solar radiation, the thermocouple lead wires were separated and formed into a $2.4 \mathrm{~cm}$ ( $1 \mathrm{in.)}$ diameter loop. The junction and loop was bonded to the glass with a thin layer of clear epoxy adhesive. However, despite these precautions the thermocouples are considered to provide reliable surface temperature measurements only at night, with daytime readings being less accurate due to the heating effect caused by solar radiation absorption at the junction and lead wires. A photovoltaic-cell type pyranometer was also mounted immediately behind and parallel to the interior glass to directly measure transmitted solar radiation.

Testing of the triple-glazed window began on January 15 and continued through January 25, 1983. Test results from six of the days are presented in section 6.1 . 


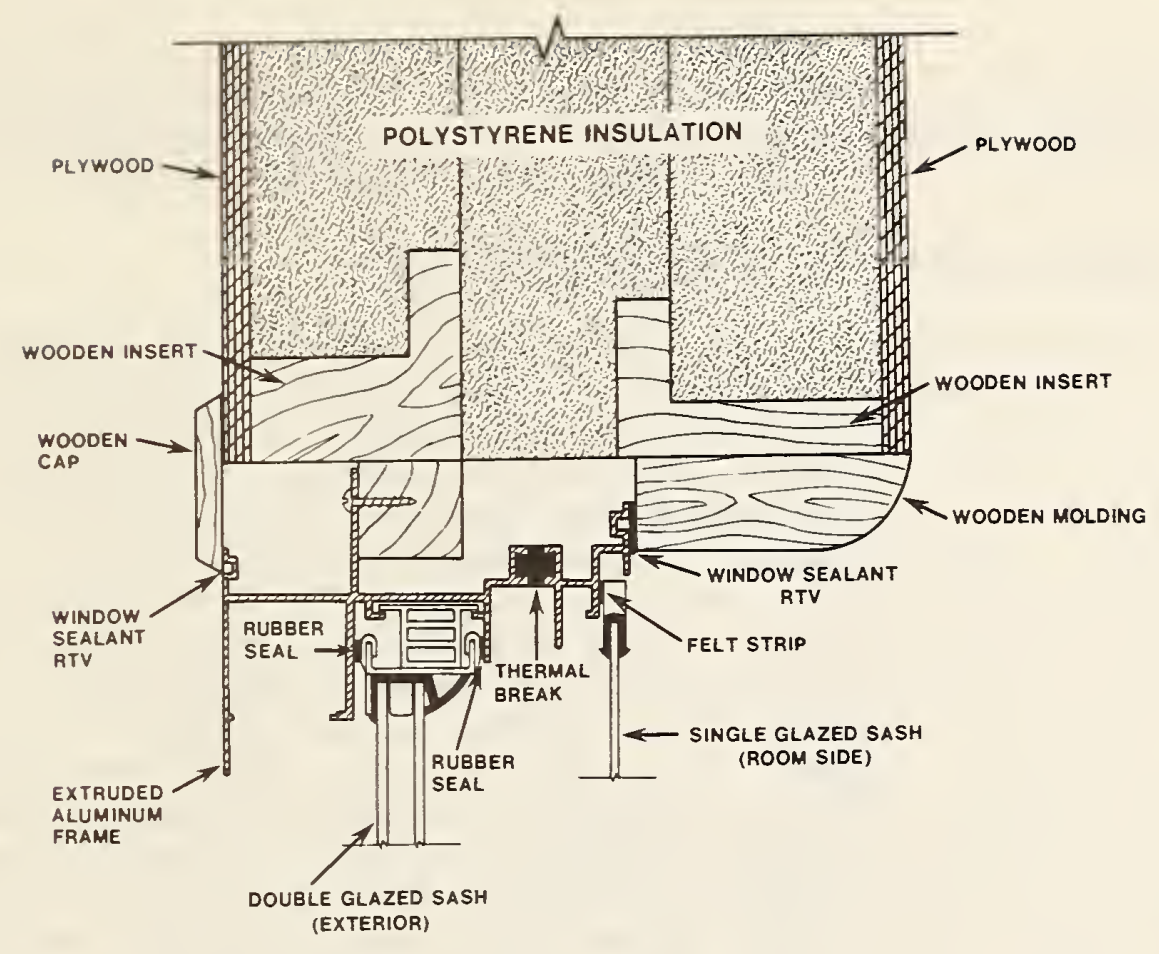

Figure 26. Schematic drawing of triple-glazed window and test frame

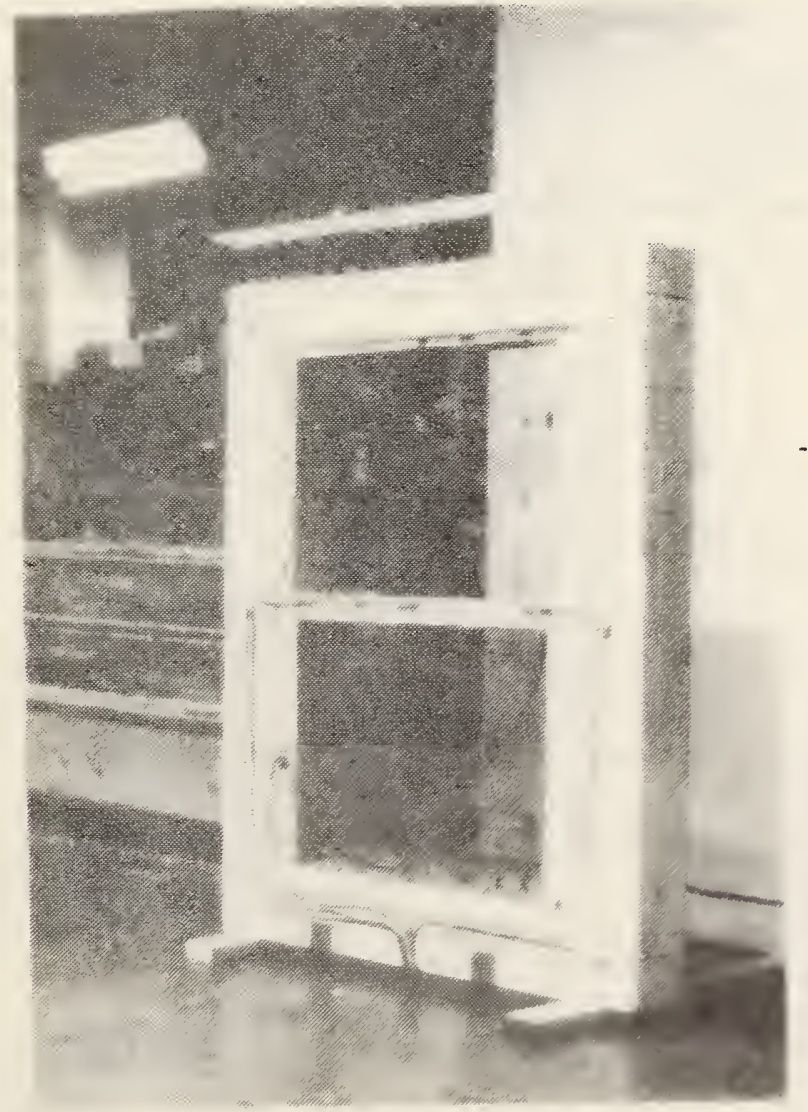

Figure 27. Photograph of triple-glazed window test article 
Some difficulties were encountered in operating the absorber panel chiller when ambient temperatures dropped below $0^{\circ} \mathrm{C}$, thus only a limited set of data are available when all system components were operating properly.

\subsection{SINGLE-GLAZED WINDOW WITH INSULATING SHUTTERS}

The second item tested was a fixed single-glazed window with interior bifold insulating wood shutters. Construction of the shutters is shown schematically in figure 28. A photograph of the component mounted in the standard test frame is shown in figure 29. The shutters are normally closed at night and during periods of low solar radiation and opened during the daytime to admit solar energy into a building. Air leakage through the shutters is minimized by foam weatherstripping between moveable pieces. The fixed single-glazing was caulked and sealed to the test frame and therefore considered to have essentially no air leakage. Daytime and nighttime tests for this test article with shutters open are of value for comparison between measured data and published ASHRAE data for single-glazing. Tests with shutters closed were interesting only at night or during very cloudy daytime periods as normal operation would dictate that they would be open during the day. The test article was installed in the aperture in a manner similar to that of the triple-glazed window, using the same guard heater panel and method of edge sealing. One thermocouple was installed at the center of the glass surface on the test article. The solar cell pyranometer was used to measure transmitted solar radiation when the shutters were open.

The tests began on January 26 and ended on February 6 producing seven days of useful data, although only three days were with closed shutters. Test results are presented in section 6.2. Problems with operation of the chiller persisted and thus limited the data considered to be useful for determining shading coefficient. These data were considered adequate for characterization of the insulating shutters and data collected for the single-glazing without shutters was considered useful for evaluating the capabilities of the system and instrumentation .

\subsection{COLLECTOR-STORAGE WATER WALL}

A test article utilizing water as a thermal storage medium was the first of two collector-storage walls to be tested. Figure 30 shows a photograph of the test article. This component, referred to as a water wall, consisted of opaque black plastic tanks, 1.14 (45 in.) high, 1.18 (46 1/2 in) wide and 0.18 (7in.) deep. Each tank will hold approximately $200 \ell(53 \mathrm{gal}$ ) of water and is mounted behind the standard double glazed window. An assembly with two of these tanks installed in the calorimeter aperture is illustrated in figure 31 . In order to accommodate both tank modules, the upper tank was modified by cutting off the top $0.30 \mathrm{M}$ ( $12 \mathrm{in.)}$ to allow it to fit within the vertical aperture and the opening was sealed with a layer of polystyrene insulation to prevent heat loss and water evaporation.

Thermocouples were installed on the front and rear surfaces of the water tanks and at three levels in the water inside each tank. Since the water wall is opaque, no measurements with the solar cell pyranometer were made. Also, the 
VERTICAL SECTION - INSULATING BIFOLD SHUTTER

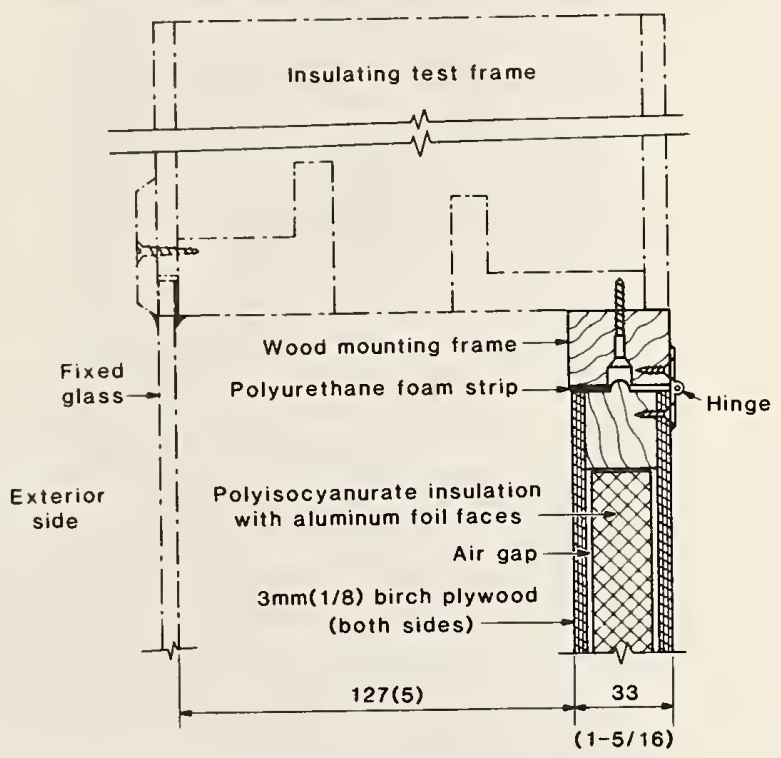

Figure 28. Schematic drawing of single-glazed window with insulating shutters

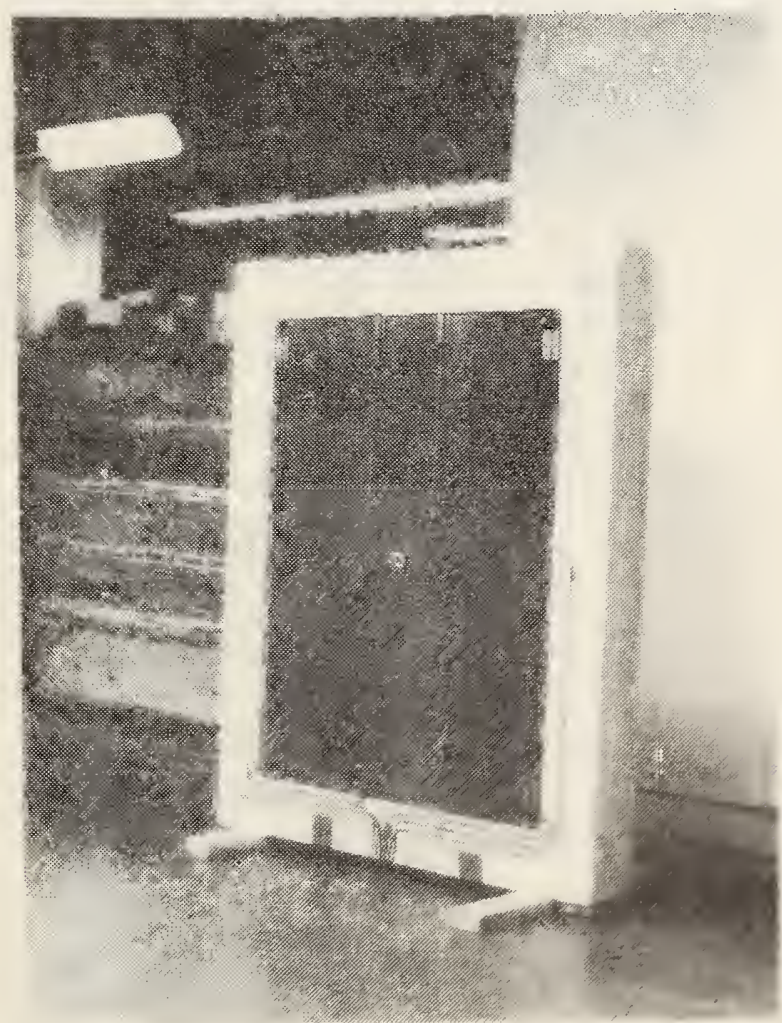

Figure 29. Photograph of single-glazed window with insulating shutters 


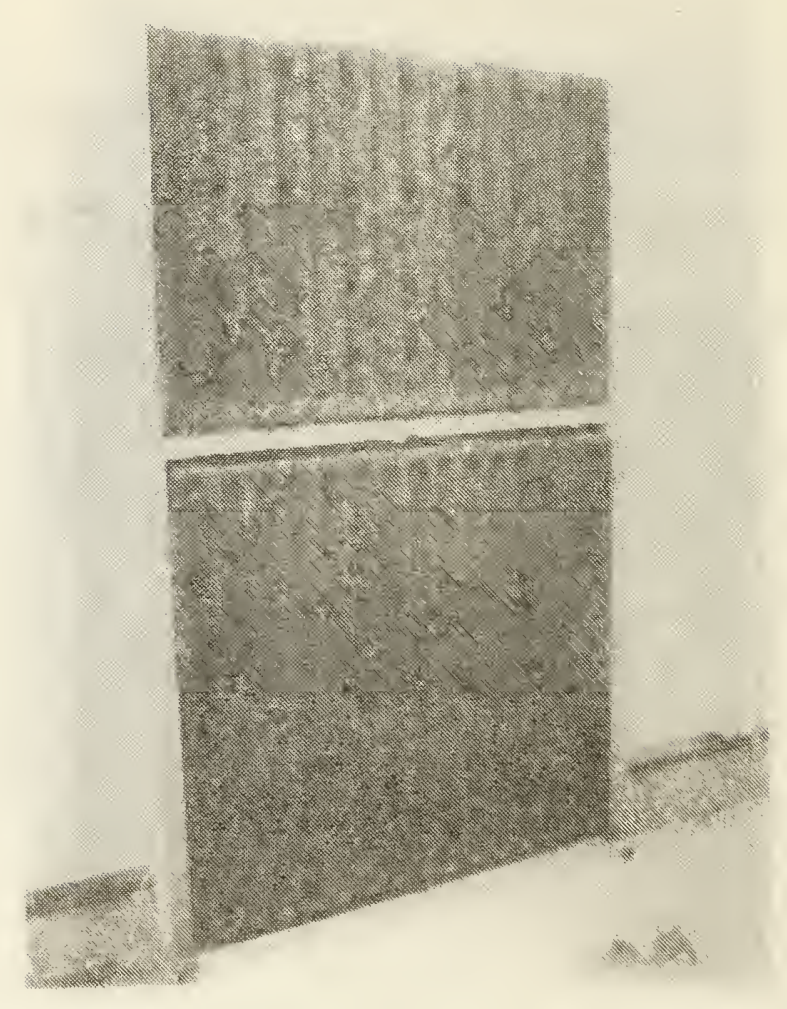

Figure 30. Photograph of collector-storage water wall installed in test frame

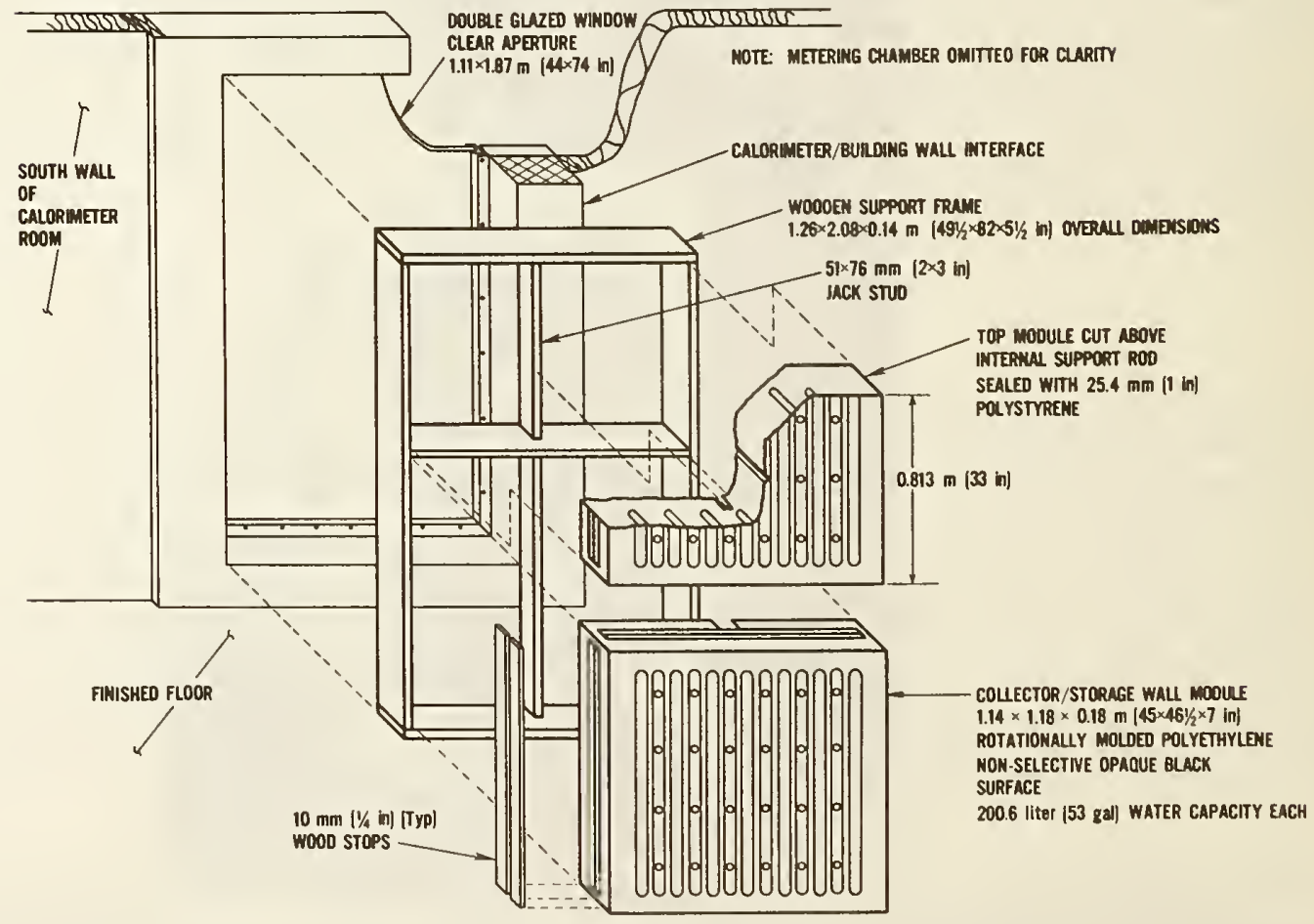

Figure 31. Drawing of collector-storage water wall installed in test building 
absorber panel circulating loop was not used in this test to improve the accuracy of the QNET measurement. QNET was measured exclusively by the air circulation loop. The direction of flow of conditioned air was from top to bottom at the surface of the test article, opposing the predominant direction of free convection. This situation has the potential for biasing test results, however no quantitative estimates are available as to the magnitude of this effect.

Testing of the water wall began on February 22 and continued through March 6. Data from five typical days for this period are presented in section 6.3 . Local wind speed and direction measurements were not available due to damage to the anemometers.

\subsection{COLLECTOR-STORAGE PCM WALL}

The collector-storage wall utilizing phase change materials (PCM) as the storage medium was installed in the aperture behind the standard double-glazed window. This component consists of five translucent pods, each containing 12 $\mathrm{kg}$ ( $291 \mathrm{bs}$ ) of calcium chloride hexahydrate. The pods are made from a sealed fiberglass reinforced polymer and are .41 (16 in.) high, 1.22 (48 in.) wide, and have a maximum thickness of 0.05 ( 2 in.). The PCM melts at $27.2^{\circ} \mathrm{C}\left(81^{\circ} \mathrm{F}\right)$ and has a latent heat of fusion of $190 \mathrm{~kJ} / \mathrm{kg}(82 \mathrm{Btu} / 1 \mathrm{~b})$ Figure 32 is a photograph of this component installed in the aperture.

Because the PCM pods were sealed units, special instrumentation was not installed within the storage medium. Thermocouples attached to the interior and exterior surfaces of the pods comprised the only direct measurements on this component. Although the test article has a solar transmittance varying between 0.15 and 0.25 depending on the melt-state of the PCM, this component of the energy balance was not measured either with a pyranometer behind the module or with the calorimeter absorber panel. The small amount of transmitted radiation was absorbed at the absorber panel and this heat was transferred to the circulating air. As was the case with the water wall, the forced flow of circulating air was in the opposite direction of the predominant free convection flow from the test article.

The testing began on March 8 and ended on March 22. Test results are presented in section 6.4. Data acquisition problems were encountered later in the test leaving only five days of useful data. 
(a) individual module showing solid phase (darker region) and liquid phase (lighter region)

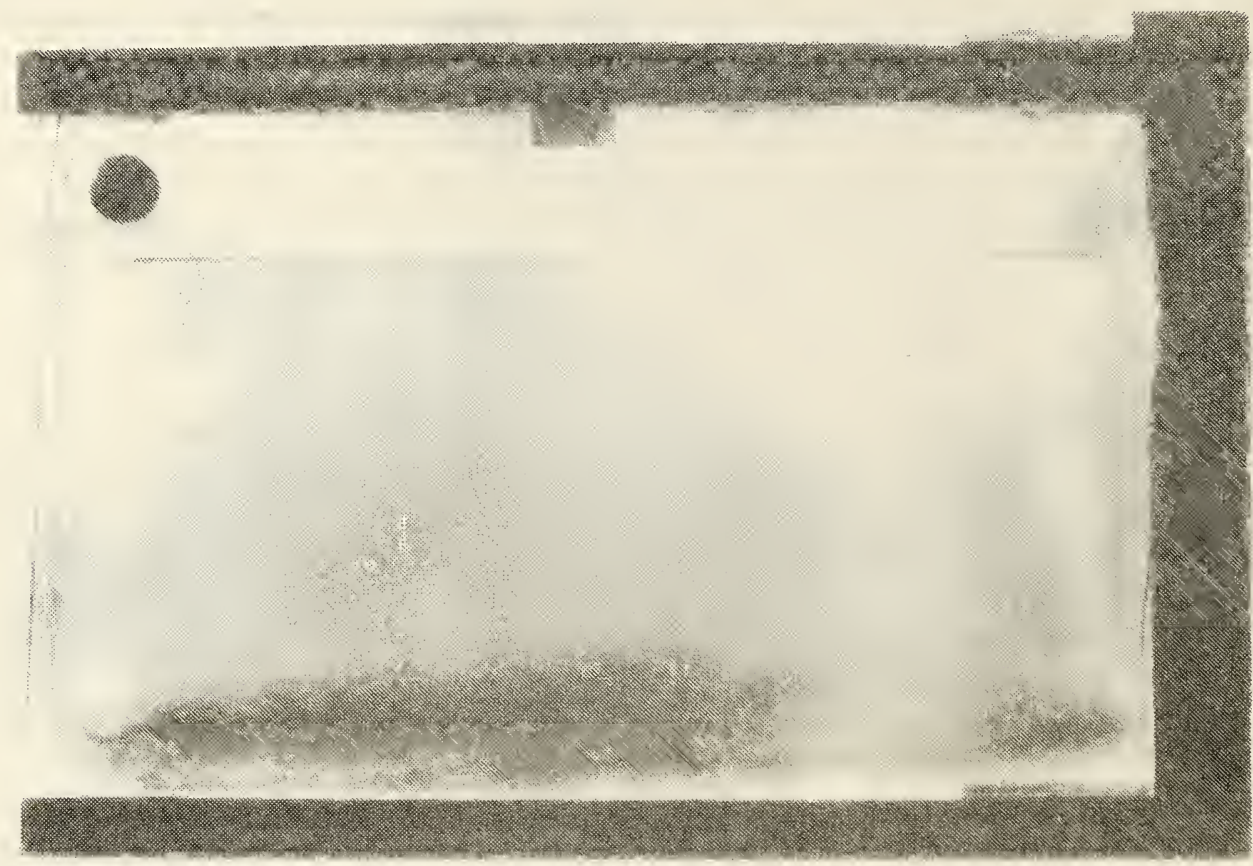

(b) installation in test building

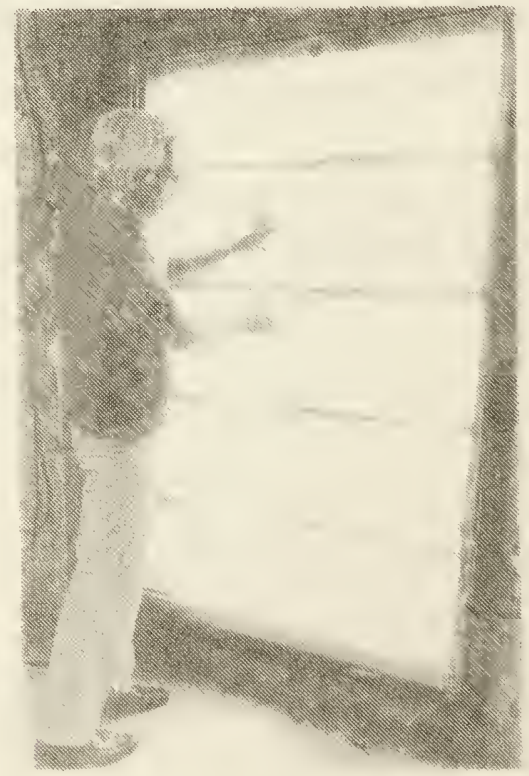

Figure 32. Photographs of collector-storage PCM wall 
A large range of detail and sophistication in the data is potentially available from the calorimeter test results. Different levels of detail would be useful to different users. Among the possible uses of the calorimeter test results would be the characterization of component thermal performance, evaluation of test procedures, computer model validation and basic heat transfer studies. Only the first utilization is addressed in this report.

At a primary level, a test article can be treated as a "black box" with no special instrumentation applied directly. The net rate of heat transfer, QNET and the environmental variables are measured with the standard facility instrumentation. Heat-transfer studies and model validation, however, demand more specific instrumentation that may be different for each type of component and for each research objective. The most important results may be the heattransfer parameters which can be used for rating components or performing design analyses. This implies that the data be reduced to one or two parameters that will be most useful. Alternatively, those who are developing models to compare analytical predictions with measured data may be more interested in detailed data covering a longer period of time. Collector-storage wall components are relatively insensitive to short-term changes in the outdoor environment so to obtain more meaningful results, the performance testing is carried out over a period of many days. On the other hand, the response of direct gain fenestrations such as windows is essentially instantaneous and, therefore a long continuous period of measurements is not required.

A general framework for presenting the calorimeter results is as follows:

- environmental data are presented in plots versus time,

- net heat flux data are presented in plots versus time,

- thermal performance parameters are estimated and summaries of data are made,

- correlations between parameters and environmental variables are made, where suitable correlations exist.

\subsection{TRIPLE-GLAZED WINDOW}

The environmental conditions during part of the triple-glazed window test are plotted as a function of time in figure 33 for a three day period in January 1983. Figure 33a shows total solar radiation incident on the vertical southfacing surface varied from mostly overcast conditions on January 17 to nearly cloudless on January 18. Figure $33 \mathrm{~b}$ shows the outside ambient temperatures ranged from $-10^{\circ} \mathrm{C}$ to $2^{\circ} \mathrm{C}\left(14^{\circ} \mathrm{F}\right.$ to $\left.36^{\circ} \mathrm{F}\right)$ representative of typical winter weather. Figure $33 \mathrm{c}$ shows wind speeds averaged over a 15 minute scan period ranged from near zero to $3.6 \mathrm{~m} / \mathrm{s}(8.1 \mathrm{mph})$.

Figure 34 shows the measured net heat transfer rate of the triple-glazed window closely follows the vertical solar irradiance during the daytime, with maximum daytime gain of $500 \mathrm{~W}(1700 \mathrm{Btu} / \mathrm{h})$ and maximum nighttime heat loss of $100 \mathrm{~W}$ (341 Btu/h). 


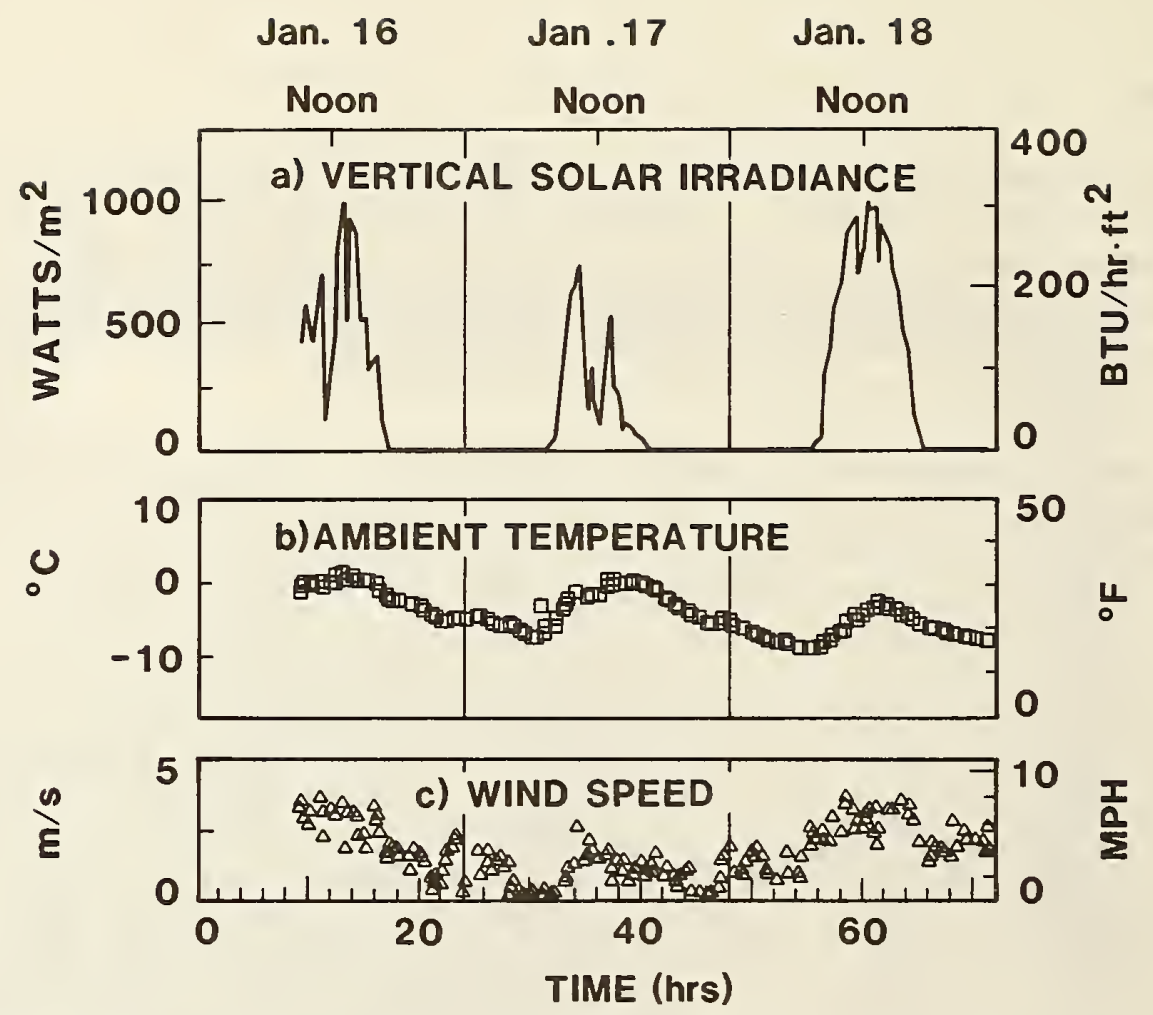

Figure 33. Environmental conditions for triple-glazed window

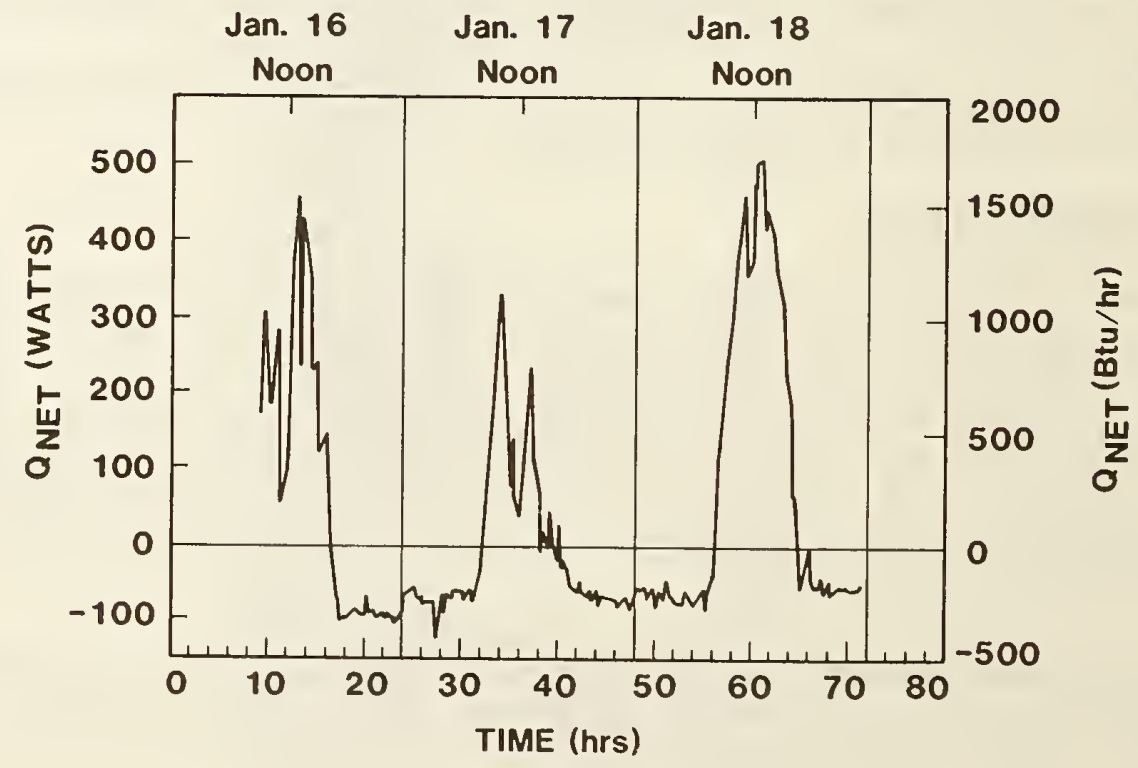

Figure 34. Net heat transfer rate for triple-glazed window 
Integrated dafly average of the test results are presented in table 1 for six sampling periods consisting of one complete day and five incomplete days. Rows 1 and 2 present the average ambient temperature and wind speed, respectively, for each sampling period. Rows 3 and 4 present the cummulative radiant solar energy incident on the window and the total heat gain, QNET, respectively. Rows 5 and 6 , respectively, resolve the value of QNET into a daytime and a nightime component.

The paraneters $U$ (overall heat transfer coefficient) and $F$ (dimensionless solar heat gain coefficient), which are presented in rows 7 to 9 of table 1 , are the most important results for a direct gain fenestration. These results are obtained by expressing equation (1) in terms of the total opaque heat transfer area $A$ of the window, including the frame and glazing, as:

$$
\mathrm{QNET}_{\mathrm{N}}=\left(\mathrm{FI}_{\mathrm{T}}+\mathrm{U} \Delta \mathrm{T}\right) \mathrm{A}
$$

At a given instant of time, $U$ and $F$ cannot be determined simultaneously because there are two unknowns and only one equation. However, by using regression analysis and a large sample of data, it is possible to determine $\mathrm{U}$ and $\mathrm{F}$ based on measured values of $Q_{N E T}, \mathrm{I}_{\mathrm{T}}$ and $\Delta \mathrm{T}$. At night when $\mathrm{I}_{\mathrm{T}}=$ 0.0 , $U$ can be independently determined, or during the day if $\Delta T=0$, $F$ can be directly determined.

The data are treated in three groups for the regression analyses. The "night only" data group provides a good estimate of $U$ but gives no information about F. The "night and day" group usually estimates U approximately equal to U from the "night only" group and provides an estimate of $F$ as well. This group, which uses all available data, is believed to provide the best estimate of average $U$ and $F$ values. For comparison, the "day only" group usually provides a significantly lower estimate of $U$ while $F$ is essentially the same as obtained from the day and night group. No explanation of why the "day only" U-Values are significantly lower then the "night only" U-Values is apparant. Theoretical analysis of heat transfer in a solar irradiated window suggests that the convective and radiative heat transfer coefficfents between each of the glazing layers should increase between night and day, due to absorption of radiant solar energy in each glazing layer and the resulting increased surface and air temperatures. The increased heat transfer coefficients should result in a slight increase in U-Value instead of the substantial decrease, as observed in the test results.

Figure 35(a) shows a plot of net heat transfer rate as a function of vertical solar irradiance. It is interesting to note the intersection of the regression line with the $Q_{N E T}=0$ line, which indicates a threshold radiation level for useful heat collection at the particular ambient temperature. The high degree of correlation of QNET with $I_{T}$ in figure $35(\mathrm{a})$ as indicated by the lack of scatter of data points suggests that during the daytime, the dominant heat transfer mechanism in the window is by direct radiant transmission and that heat loss to the outside ambient is of much lower significance.

Figure 35(b) shows a plot of nightime U-Values versus measured wind speed, ind1cating that U-Values tend to increase with increasing wind speed. Correlation 
Table 1. Test Results for Triple-Glazed Window

\begin{tabular}{|c|c|c|c|c|c|c|}
\hline DATE & $\begin{array}{l}\text { Jan } \\
16 / 17\end{array}$ & $\begin{array}{l}\mathrm{Jan} \\
17 / 18\end{array}$ & $\begin{array}{c}\text { Jan } \\
18 / 19\end{array}$ & $\begin{array}{r}\mathrm{J} \text { an } \\
19\end{array}$ & $\begin{array}{c}\text { Jan } \\
23 / 24\end{array}$ & $\begin{array}{c}\text { Jan } \\
24 / 25\end{array}$ \\
\hline $\begin{array}{l}\text { Time Period when } \\
\text { date were Available }\end{array}$ & $0915-0600$ & $0615-0600$ & $0616-0245$ & $1600-2300$ & $2015-0600$ & $0615-0130$ \\
\hline $\begin{array}{l}\text { Average Ambient } \\
\text { Temperature, }{ }^{\circ} \mathrm{C} \\
\end{array}$ & -3.1 & $-4 \cdot 0$ & -6.7 & -5.0 & 1.5 & 3.2 \\
\hline $\begin{array}{l}\text { Average Wind Speed, } \\
\mathrm{m} / \mathrm{s}\end{array}$ & 1.21 & 0.94 & 1.93 & 0.37 & 0.59 & 0.83 \\
\hline $\begin{array}{l}\text { Total Incident Solar } \\
\text { Radiation, kJ }\end{array}$ & 15172 & 8839 . & 22168 & 994. & -- & 5399. \\
\hline $\mathrm{Q}_{\mathrm{NET}}$ Total, $\mathrm{kJ}$ & 1779 . & -2706 & 3749 . & -1503 & -2027 & -1705 \\
\hline$Q_{\text {NET }}$ Day, $\mathrm{kJ}$ & 5824 . & 2077 . & 7503 . & 142 . & -- & 383 . \\
\hline$Q_{\mathrm{NET}}$ Night, $\mathrm{kJ}$ & -4045 & -4783 & -3754 & -1645 & -2027 & -2088 \\
\hline $\mathrm{U}$ Night only, $\mathrm{w} / \mathrm{m}^{2} \mathrm{C}$ & 2.60 & 2.73 & 2.68 & 2.41 & 2.21 & 2.24 \\
\hline $\begin{array}{l}\text { Night and day } \\
\mathrm{U}\left(\mathrm{w} / \mathrm{m}^{\circ} \mathrm{F}\right)\end{array}$ & 2.53 & 2.44 & 2.65 & 2.20 & 2.06 & 2.02 \\
\hline F & 0.52 & 0.49 & 0.49 & 0.50 & -- & 0.39 \\
\hline $\begin{array}{l}\text { Day only } \\
\mathrm{U}\left(\mathrm{w} / \mathrm{m}^{2}{ }^{\circ} \mathrm{C}\right)\end{array}$ & 1.69 & 1.63 & 2.69 & 1.49 & -- & 1.62 \\
\hline F & 0.49 & 0.44 & 0.49 & 0.50 & -- & 0.36 \\
\hline $\begin{array}{l}\text { Correlation Coeff., QNET } \\
\text { vs. } I_{T}\end{array}$ & 0.99 & 0.98 & 0.99 & 0.99 & -- & 0.89 \\
\hline $\begin{array}{l}\text { Correlation Coeff., U vs. } \\
\text { Wind Speed }\end{array}$ & 0.16 & 0.48 & -0.39 & 0.05 & -0.11 & 0.39 \\
\hline $\begin{array}{l}\text { Correlation Coeff., U vs. } \\
\text { Temperature }\end{array}$ & 0.23 & -0.26 & -0.19 & 0.00 & 0.40 & 0.00 \\
\hline
\end{tabular}




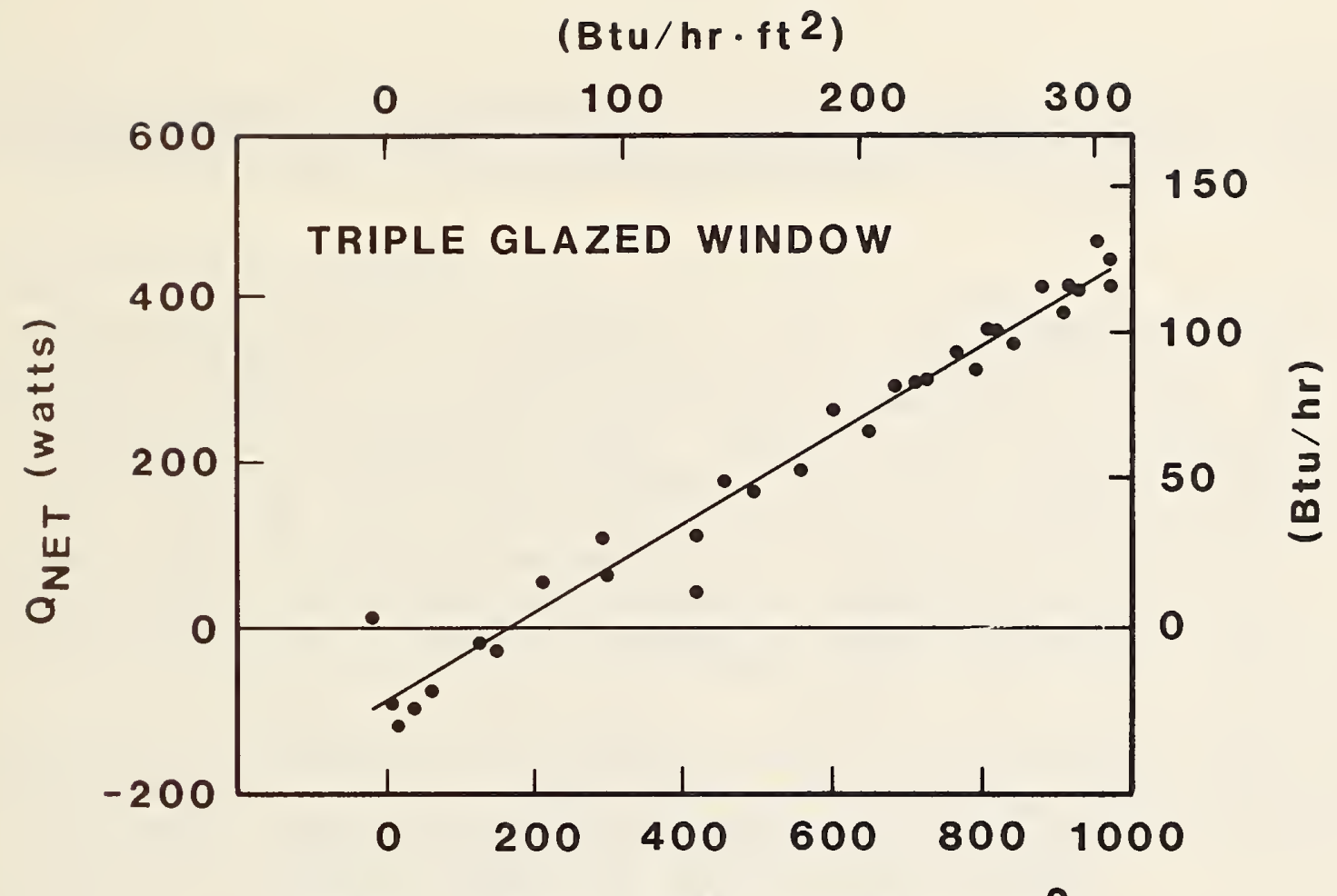

TOTAL SOLAR IRRADIANCE $\left(\mathrm{W} / \mathrm{m}^{2}\right)$

(a) Net heat flux vs total solar irradiance

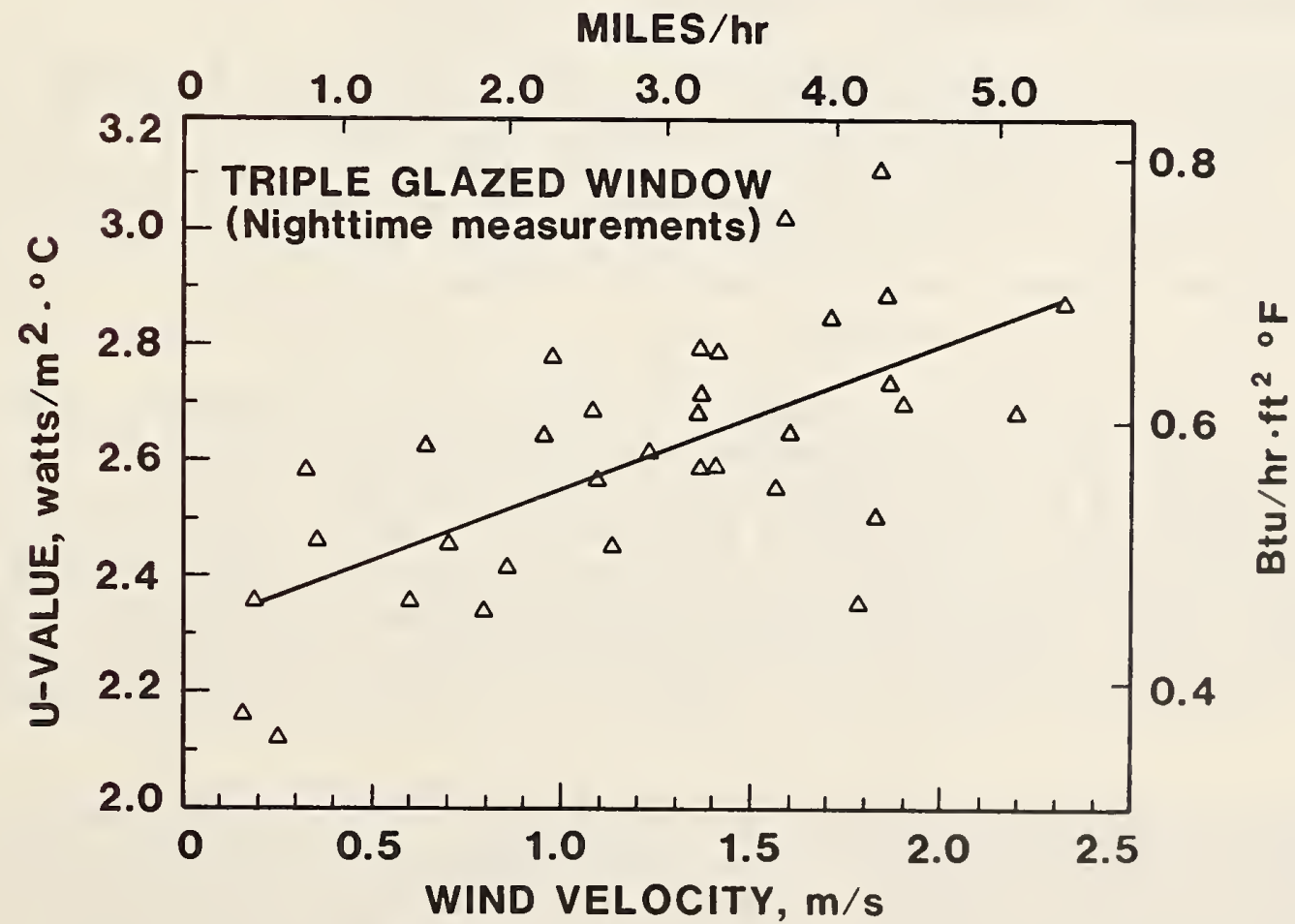

(b) U-Value vs wind velocity

Figure 35. Correlations for triple-glazed window 
coefficients between $Q_{N E T}$ and $U$ and the environmental conditions are presented in table 1. These coefficients show that QNET is highly correlated with $\mathrm{I}_{\mathrm{T}}$, as might be expected, and a weak dependence of U-Value on wind speed and ambient temperature is noted.

The calorimeter test results contrast with previous laboratory test results [15] for the same test article. In the laboratory tests, the lower sash at the window was covered by an insect screen, which was not present during the calorimeter tests. The laboratory test results showed a U-Value of approximately $1.68 \mathrm{w} / \mathrm{m}^{2}{ }^{\circ} \mathrm{C}\left(.30 \mathrm{Btu} / \mathrm{hr} / \mathrm{ft}{ }^{\circ} \mathrm{F}\right)$ at zero windspeed and $-8^{\circ} \mathrm{C}\left(18^{\circ} \mathrm{F}\right)$ ambient temperature as compared to a U-Value of $2.3 \mathrm{w} / \mathrm{m}^{2}{ }^{\circ} \mathrm{C}\left(.41 \mathrm{Btu} / \mathrm{hr} / \mathrm{ft}{ }^{\circ} \mathrm{F}\right)$ determined by extrapolation of the field test data to zero windspeed. Most likely the insect screen which covered approximately one-half the window area, contributed to the lower $U$-Value measured in the laboratory. Another possible cause of the difference between the field and laboratory test results is radiation loss to the cold night sky, which is absent in the laboratory test.

Another comparison can be made based on winter design U-Value in the ASHRAE Handbook [5]. ASHRAE U-Value data varies between 1.90 and $2.50 \mathrm{w} / \mathrm{m}^{2 \circ} \mathrm{C},(0.33$ and $0.44 \mathrm{Btu} / \mathrm{hrft}^{\circ} \mathrm{F}$ ), based on adjustment factors for a metal frame with a thermal break. Additional adjustment of these data to convert from design wind speeds of $6.7 \mathrm{~m} / \mathrm{s}(15 \mathrm{mph})$ to still air conditions provides an estimated range of $U$-Value between 1.7 and $2.1 \mathrm{w} / \mathrm{m}^{2}{ }^{\circ} \mathrm{C},\left(0.30\right.$ and $\left.0.37 \mathrm{Btu} / \mathrm{hrft}{ }^{\circ} \mathrm{F}\right)$ which is approximately 9 to 26 percent lower than the calorimeter measurements.

\subsection{SINGLE-GLAZED WINDOW WITH INSULATING SHUTTERS}

Table 2 summarizes daily performance for five days of data available for the single-glazed window with insulating shutters. Data for Jan.27, and Feb. 4 to 5 are with the shutters open and data for Feb. 1 and 2 are with the shutters closed. The first row of the table shows hours during which useable data are available. These data are arranged in the format previously described for the Triple-Glazed window. Note that complete 24 hour periods are not available for this test article so that daily total values are not directly comparable.

The most useful estimates of U-Value for these data are shown for the "Night Only" case. These estimates range from 3.92 to $5.42 \mathrm{w} / \mathrm{m}^{2 \circ} \mathrm{C}(0.69$ to $0.95 \mathrm{Btu} / \mathrm{hrft}{ }^{\circ} \mathrm{F}$ ) for single-glazing with shutters open and 0.80 to 0.99 $\mathrm{w} / \mathrm{m}^{2} \mathrm{C}\left(0.14\right.$ to $\left.0.17 \mathrm{Btu} / \mathrm{hrft}^{2 \circ} \mathrm{F}\right)$ with shutters closed. These can be compared with ASHRAE U-Values for single glass ranging from $6.2 \mathrm{w} / \mathrm{m}^{2}{ }^{\circ} \mathrm{C}\left(1.09 \mathrm{Btu} / \mathrm{hrft}{ }^{\circ} \mathrm{F}\right)$ for winter design conditions with $6.7 \mathrm{~m} / \mathrm{s}(15 \mathrm{mph})$ wind to $4.9 \mathrm{w} / \mathrm{m}^{2}{ }^{\circ} \mathrm{C}(0.86$ $\mathrm{Btu} / \mathrm{hrft} 2^{\circ} \mathrm{F}$ ) for still air. Previous laboratory measurements of this component with closed shutters indicated a U-Value of $0.90 \mathrm{w} / \mathrm{m}^{2}{ }^{\circ} \mathrm{C}\left(0.16 \mathrm{Btu} / \mathrm{hrft}{ }^{\circ} \mathrm{F}\right)$ [15].

The highest measured solar heat gain coefficient F for single glass was 0.59 which is significantly lower than the ASHRAE value of 0.87 . The size of this sample of data, however, is relatively small and no definitive conclusions are drawn. The correlation coefficients presented in the last three rows of the table show similar trends to those for the triple-glazed window. 
QNET is highly correlated with irradiance and again there is no general relationship between $U$-Value and wind speed. There is some negative correlation between ambient temperature and U-Value when no insulation is used.

\subsection{COLLECTOR-STORAGE WATER WALL}

Figures 36 and 37 , respectively, show plots of climatic conditions and water wall thermal performance for a four day sequence in early March of 1983. As shown in figure 36(a), the first day was completely overcast, followed by two very bright days and then by a partially overcast day. Figure $37(a)$ shows the net rate of heat transfer between the water wall and the metering chamber. Delivery of stored solar energy during the night is noted and there is an approximate five hour time lag between peak solar irradiance and peak heat transfer rate. Figure $37(\mathrm{~b})$ shows the temperature distribution on the outer and inner surfaces and in the water at mid-height of the upper module. The lower module displayed similar temperature distributions. Vertical temperature (not shown) was also measured in both modules. The maximum vertical temperature difference in the lower module was approximately $6^{\circ} \mathrm{C}\left(11^{\circ} \mathrm{F}\right)$ in contrast to a maximum difference of $3^{\circ} \mathrm{C}\left(5.4^{\circ} \mathrm{F}\right)$ measured in the upper module. The difference in vertical temperature distribution between lower and upper modules was apparantly due to the foreshortened upper module used in the test.

\subsection{COLLECTOR-STORAGE PCM WALL}

Test data for the collector-storage PCM wall are summarized in figures 38 and 39. Solar irradiance at the vertical aperture, and ambient temperature are plotted in figures $38(\mathrm{a})$ and $38(\mathrm{~b})$, respectively, for a three day period in mid-March 1983. Ambient air temperature varied between 1 and $13^{\circ} \mathrm{C}$ ( 34 and $55^{\circ} \mathrm{F}$ ) and sky conditions varied from mostly clear on day one to overcast on day three. It was observed that the interior surface temperature of the test-article never reached the PCM melting point of $27.2^{\circ} \mathrm{C},\left(81^{\circ} \mathrm{F}\right)$ indicating that the PCM did not completely melt.

Figure 39(a) shows a plot of QNET and figure 39(b) shows plot of the temperature difference, $T_{\text {WALL }}-\mathrm{T}_{\mathrm{AIR}}$, during the measurement period. Delivery of stored energy at night is observed, however, almost no time-lag existed between the time of peak solar irradiance and peak heat transfer rate. That suggests that direct transmission of solar energy is the dominant heat transfer mechanism for the translucent PCM module, and this test article has less effective thermal storage than the water wall. It was also observed that there are some periods of time when QNET is negative and temperature difference is positive. This suggests the possibility of significant thermal losses through the aluminum support frame provided by the manufacturer.

Unseasonably warm ambient temperatures and difficulties with the data acquisition system resulted in the termination of data gathering for the fleld test. However, the test article remained in place in the calorimeter and was visually observed for three additional months. One observation of significance was that leakage of 1iquid (probably a solution of $\mathrm{CaCl}_{2}$ in water) occurred at the fill ports of several of the PCM modules. During the entire three month 
Table 2. Test Results for Single-Glazed Window with Insulating Shutters

\begin{tabular}{|c|c|c|c|c|c|}
\hline Date & Jan 27 & Feb $1 / 2$ & Feb $2 / 3$ & Feb $4 / 5$ & Feb 5 \\
\hline $\begin{array}{l}\text { Time Period Data were } \\
\text { Available }\end{array}$ & $1245-2345$ & $|1845-0545|$ & $0615-0545$ & $1545-0600$ & $0615-2245$ \\
\hline Average Ambient Temperature, $\left({ }^{\circ} \mathrm{C}\right)$ & 2.7 & 2.9 & 11.1 & $-4 \cdot 0$ & -1.5 \\
\hline Average Wind Speed, (m/s) & 0.66 & 0.75 & 2.66 & 2.66 & 0.51 \\
\hline Total Incident Solar Radiation, (kJ) & 7333. & -- & -- & 394 . & 21334 . \\
\hline QNET Total, (kJ) & 11. & -919. & -714 & -6424 & 4124 \\
\hline QNET Day, (kJ) & 2711 & & & 955. & 6897 . \\
\hline QNET Night, $(k J)$ & -2700 & -919. & -714 & -7379 & -2773 \\
\hline U Night only $\left(w / \mathrm{m}^{2 \circ} \mathrm{C}\right)$ & 4.55 & 0.80 & 0.99 & 5.42 & 3.92 \\
\hline $\begin{array}{l}\text { Day and Night } \\
\mathrm{U} \quad\left(\mathrm{w} / \mathrm{m}^{2 \circ} \mathrm{C}\right) \\
\mathrm{F}\end{array}$ & $\begin{array}{l}4.28 \\
0.59\end{array}$ & 0.80 & 1.00 & $\begin{array}{l}5.50 \\
0.26\end{array}$ & $\begin{array}{l}3.76 \\
0.56\end{array}$ \\
\hline $\begin{array}{ll}\text { Day On1y } \\
\mathrm{U} \quad\left(\mathrm{w} / \mathrm{m}^{2 \circ} \mathrm{C}\right)\end{array}$ & $\begin{array}{l}2.00 \\
0.50\end{array}$ & -- & 1.16 & $\begin{array}{l}5.14 \\
0.26\end{array}$ & $\begin{array}{l}3.03 \\
0.52\end{array}$ \\
\hline Correlation Coefficient, QNET vs. $I_{t}$ & 0.92 & & & 0.38 & 0.88 \\
\hline $\begin{array}{l}\text { Correlation Coefficient, U vs. } \\
\text { Wind Speed }\end{array}$ & -0.59 & 0.42 & 0.07 & -0.09 & 0.94 \\
\hline $\begin{array}{l}\text { Correlation Coefficient, U vs. } \\
\text { Ambient Temperature }\end{array}$ & -0.71 & -0.09 & -0.10 & -0.46 & -0.63 \\
\hline
\end{tabular}




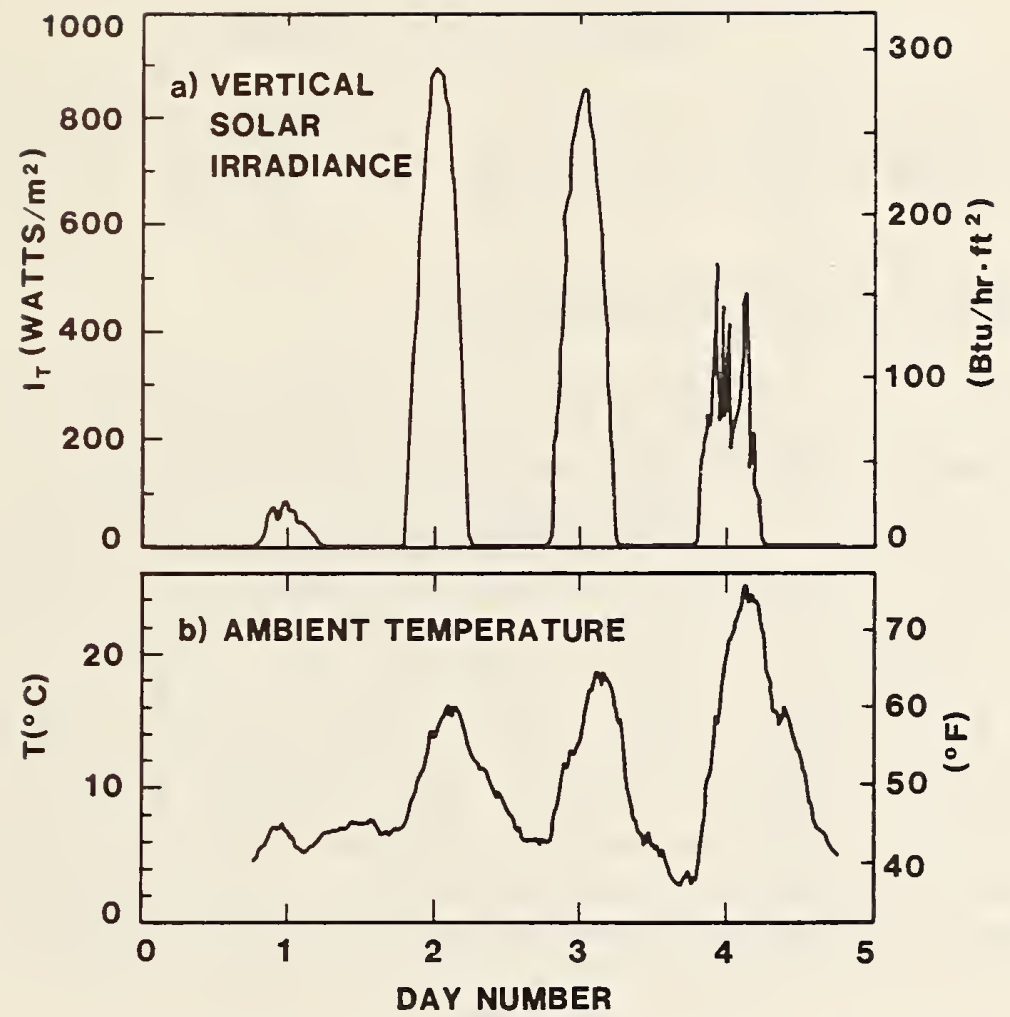

Figure 36. Environmental conditions - collector-storage water wall
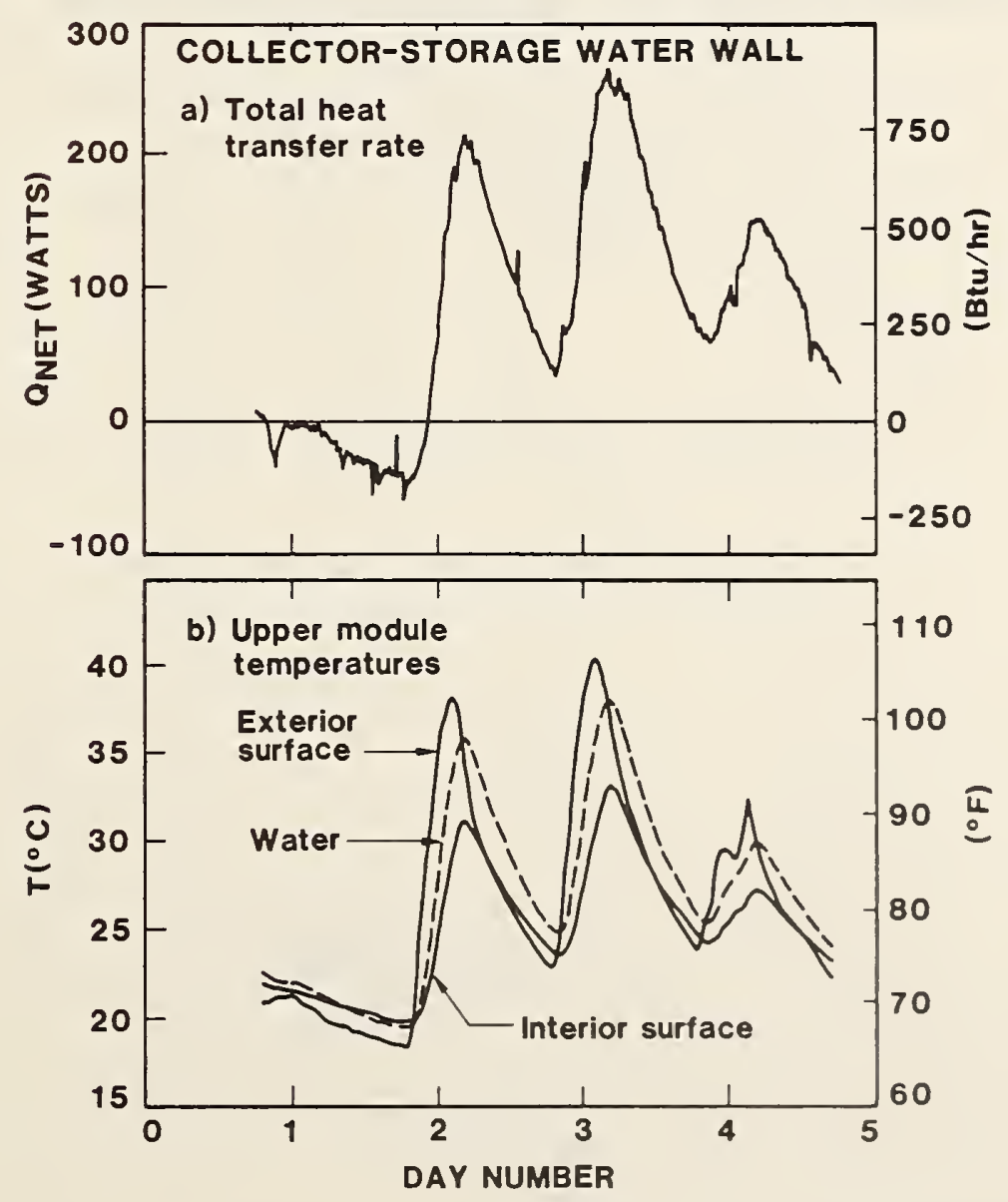

Figure 37. Net heat transfer rate and temperatures - collector-storage water wall 
observation period, neither complete melting nor complete solidification were ever observed. The PCM material separated into solid and liquid phases which never recombined.

\subsection{CORRELATION NEEDS FOR COLLECTOR-STORAGE WALLS}

In contrast to the non-energy storing test articles such as the Triple-Glazed Window, standard methods of correlation for collector-storage walls do not yet exist, therefore, generalization of the test results presented here for the water wall and for the PCM wall are not possible. One of the potential uses for thermal performance data for energy storage devices such as those tested in the NBS calorimeter is to provide a correlation data base. Techniques using thermal response coefficients to normalize collector-storage wall test data have been described [13]. Frequency response techniques [14], have also been suggested as a means of generalizing dynamic test data for passive solar buildings, and have been proposed for validation at the component level. Based on carefully controlled test conditions and accurate heat transfer data, it is believed that the validity or limitations for both the thermal response coefficient and the frequency-response concepts can be established. Future testing of collectorstorage walls is planned for the NBS calorimeter in order to provide such a data base. 


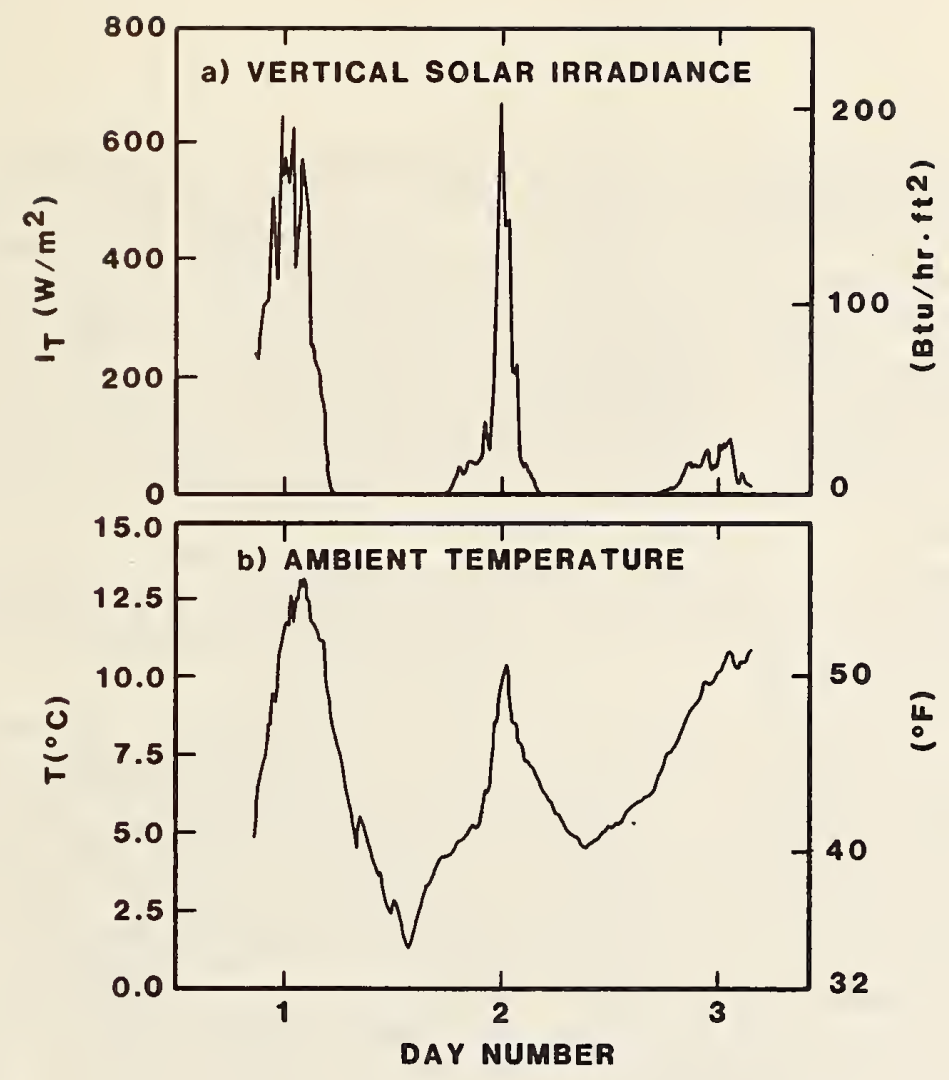

Figure 38. Environmental conditions - collector storage PCM wall

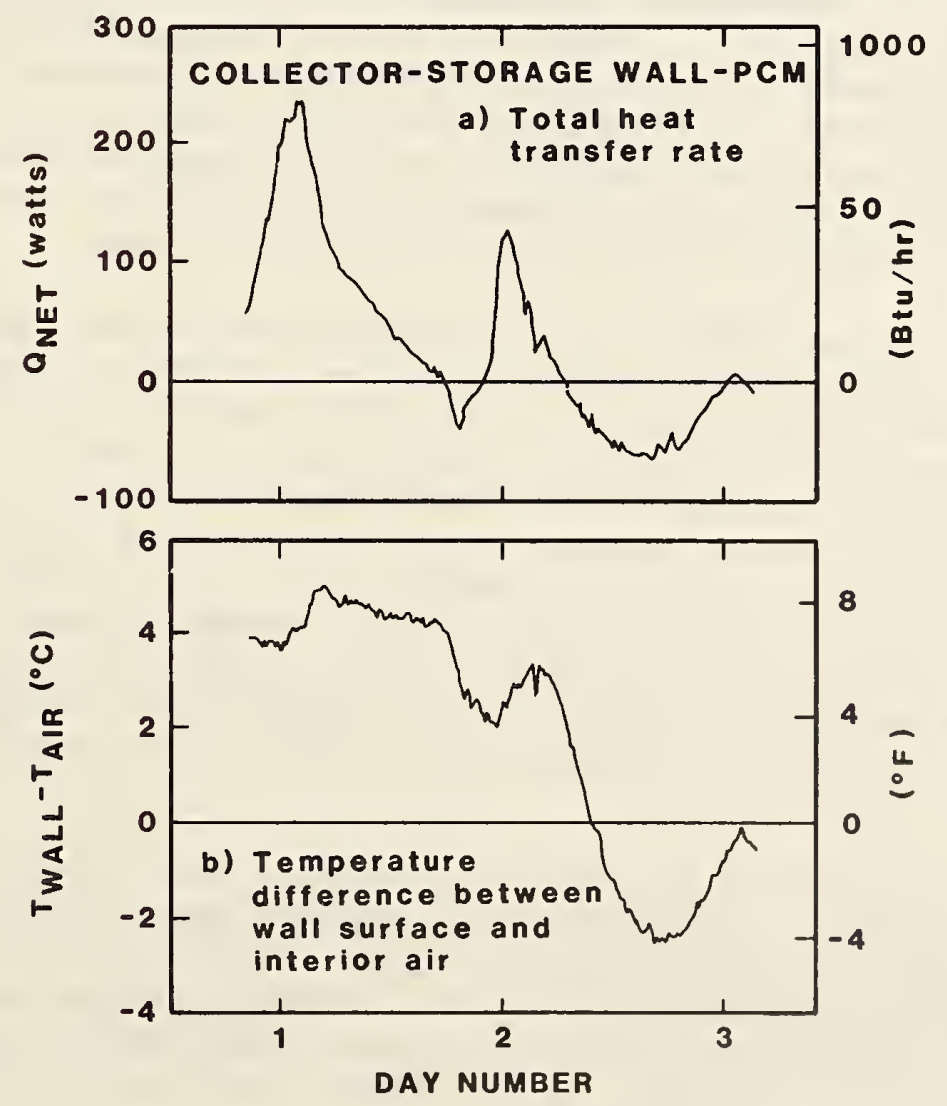

Figure 39. Net heat transfer rate and $\Delta T$ - collector-storage PCM wall 


\section{EVALUATION OF INITIAL OPERATION OF NBS PASSIVE SOLAR CALORIMETER}

Operation of the calorimeter during the first three months of 1983 demonstrated the ability of this test facility to perform calorimetric measurements on various types of passive solar components. The facility was generally able to maintain controlled interior conditions while test articles were exposed to the actual exterior environment. Measurements made with the calorimeter can provide insight into basic heat transfer mechanisms as well as detailed information on the performance of specific components. However, several operational and measurement problems were noted during these tests, which could significantly affect the accuracy of the results. The nature of some of these problems is discussed and possible solutions are recommended in the following paragraphs.

One of the design features of the facility is the capability to measure net heat flux and to resolve this into radiant and convective components. To accomplish this, average absorber temperature and average air temperature inside the metering chamber must be equal within very small tolerances. The present control system relies upon having the air and absorber temperature control signals operate on two separate controllers, which does not tend to enforce the equality of air and absorber temperatures. Steady-state temperature difference bewtween values for $\mathrm{T}_{A I R}$ and $\mathrm{T}_{\mathrm{ABS}}$ were observed to vary between 0.0 and $1.0^{\circ} \mathrm{C}$ as environmental conditions slowly changed, due to the different response characteristics of the air and absorber panel fluid conditioning loops. This temperature control problem limits the capability to resolve radiative and convective components of heat flux, however, it does not appear to have any significant impact on overall measurement accuracy. The recommended improvement is to measure temperature difference between the air and absorber panel with a differential thermopile and to control the air and absorber conditioning loops to minimize this temperature difference. It is anticipated that this can be accomplished by using a micro-computer and by making some component changes in the fluid conditioning loops.

Another problem in distinguishing between radiative and convective fluxes arises if any terms of the energy balance equation can not be associated exclusively with either the air stream or absorber panel. In the present system, the fan is powered by belt-driven motor that is located in the space behind the absorber panel, which is not in the conditioned air flow stream. Because the motor is not cooled directly by air from the circulating loop, an unknown fraction of the fan energy is probably radiatively transferred to the absorber panel. This does not affect the overall energy balance of the calorimeter, but it constitutes an uncertainty for the resolution of radiation and convection. The recommended solution to this problem is to change the fan to a direct-driven fan, thereby eliminating any possible heat transfer to the absorber panel.

It has not yet been determined by experiment whether the forced circulation of air causes any disturbance in the natural convection heat transfer from test articles. In testing fenestration systems having high overall thermal resistance, the temperature difference between the interior surface and adjacent air is small. This suggests that convective heat flows might easily be disturbed by fan forced air. However, in that case, the film resistance is a 
small part of the total resistance and thus the measurement error incurred is small. The more important situation arises in testing thermal storage walls which rely upon free convection to transfer heat to the interior. In that case, the calorimeter's forced flow of air may cause significant change, especially if the natural convective flow reverses direction over a day and the forced flow does not. It is recommended that air flow velocities be set as low as possible while still retaining adequate control and that provision be made for automatically reversing forced flow direction when the free convection flow changes.

It was apparent from the error analysis of section 4.1 that the measurement of $Q_{A B S}$ was the greatest single source of error. QABS varies over an extremely wide range from more than $600 \mathrm{~W}(2050 \mathrm{Btu} / \mathrm{h})$ of heat rejection on a typical winter day to less than $30 \mathrm{~W}(100 \mathrm{Btu} / \mathrm{h})$ of heat addition on a typical winter night for the same test article. The specific problem is that the mass flow rate of water through the absorber is constant, producing $\Delta T^{\prime} s$ of 1 to $2^{\circ} \mathrm{C}$ (2 to $4^{\circ} \mathrm{F}$ ) during daytime radiation but less than $0.1^{\circ} \mathrm{C}\left(0.2^{\circ} \mathrm{F}\right.$ ) at night. One obvious solution for this problem is to control the flow rate to a range which provides a reasonably measurable $\Delta \mathrm{T}$. This might be accomplished by using a multiple-speed pump or a throttling valve. It is anticipated that flow rate changes would be infrequent, perhaps changing only twice dally. Another possible solution would be to install electrical heaters on the absorber panel rear surface. The test facility would be operated so that the conditioning loop controls the absorber panel during the day with the heaters shut off and the heaters control the panel temperature during the night, with the conditioning loop shut off. 
One of the original objectives proposed for the NBS Passive Solar Calorimeter was in the development of outdoor test procedures for measuring thermal performance of passive solar components. A description of existing laboratory test procedures for thermal performance measurements of windows was presented in a previous report [1], and recommendations were made for comparison between laboratory and field measurements. The NBS calorimeter was proposed as the test facility to perform the field measurements and this use was a primary factor motivating construction. Laboratory measurements of U-value had previously been made for the two fenestration systems (Triple-Glazed Window and Single-Glazed Window with Insulating Shutters) described in this report. The laboratory test results for the Triple-Glazed Window, which displayed considerable sensitivity to wind velocity and wind direction, and the SingleGlazed Window with Insulating Shutters, are presented in reference 15 . The original plan was to compare the laboratory data with the field test data from the calorimeter, and to recommend one of two alternative laboratory testing methods as being preferred. The choice would be based on the laboratory test results that best correlated with the test results from the NBS Calorimeter.

After completion of the analysis of the field test results for the TripleGlazed Window, it was concluded that there are insufficient data to make such a determination. First, it was determined that the test article had a slightly different configuration between the laboratory tests and the field test. During both of the laboratory tests, the lower window sash was fitted with an insect screen, which inadvertantly, was not installed during the field test. The presence of an insect screen on the exterior of a window has an unknown, but possibly significant, effect on both the air flow rate and convective heat transfer coefficient at the glass surface, as well as on the radiative heat transfer between the outer glazing surface and the environment. (Personal observations of frost patterns on double-glazed windows with partial insect screen covers often show significant frost buildup on the unscreened portion with litle or no frost on the adjacent screened section.) A second problem was that wind velocity measured during the field test never approached the $6.7 \mathrm{~m} / \mathrm{s}$ ( $15 \mathrm{mph}$ ) conditions imposed during the laboratory tests. Most often the measured wind velocities were below $3 \mathrm{~m} / \mathrm{s}(5 \mathrm{mph})$. At those low wind conditions, difference between the two laboratory test results was not significant, therefore the field test results are inconclusive for making a selection between alternative laboratory tests.

A third problem in using the calorimeter test results for windows as a basis for comparison with laboratory test results is the inability to control climatic conditions, such as wind, cloud cover, ambient temperature and solar radiation. This is very evident in the observed scatter of the data. Balcomb [16], reported a large degree of scatter in measuring nighttime U-Value for a double-glazed window installed in an outdoor test cell having a collector-storage wall. In addition to wind, he concluded that there are other effects which lead to variations in the glazing U-Value, such as changes in the heat transfer mechanisms between the storage wall and glazing. It is evident that data must be taken over much longer time periods then originally planned, possibly 
an entire month, to have sufficient variation in the climatic conditions to enable meaningful attempts at correlating U-Value with climate variables.

In subsequent work, it became apparent that at least three other test methods are reported as useful for measuring U-Values for windows. Since those test methods and/or test facilities were not considered in the original evaluation of laboratory methods and there is no statistical significance to the limited number of samples tested, it appears inappropriate to draw conclusions and to make any recommendations at the current time.

Based on discussions with researchers from several universities and government laboratories, fenestration manufacturers, testing laboratory operators, and information obtained by participation in standards committees, the proper method of simulating wind in laboratory testing of windows appears to be unresolved. Furthermore, since most fenestration systems display a significant variation in U-Value with exterior surface coefficient, the appropriateness of testing windows at a single specified wind velocity of $6.7 \mathrm{~m} / \mathrm{s}$ ( $15 \mathrm{mph}$ ) is open to question. In addition, the variation in fenestration U-Value due to variations in ambient temperature that occur between summer and winter might also be significant, especially with regard to predicted energy performance for passive solar buildings with large glazing areas.

It appears that a testing procedure which produces U-Value data appropriate both for seasonal energy calculations and for performance ratings would be of greater value than that avallable from the current practice, which provides data for a single, winter-design condition. It is obvious that substantial research will have to be undertaken to resolve such issues as the effects of wind velocity and direction, sky and ground temperature, and solar irradiance on the field behavior of fenestration systems. It is proposed, however that a procedure for performance testing of fenestration systems be prepared which address at least some of the needs of the potential users of these data. With these limited objectives in mind, an outline of a standard procedure for measuring and reporting U-Values of fenestration systems has been prepared and presented in appendix A. 
9. NOMENCLATURE

$\mathrm{Cp} \quad$ specific heat, $\mathrm{kJ} / \mathrm{kg}{ }^{\circ} \mathrm{C}\left(\mathrm{Btu} / 1 \mathrm{~b}^{\circ} \mathrm{F}\right)$

e

electromotive potential, volts

F

solar heat gain coefficient, dimensionless

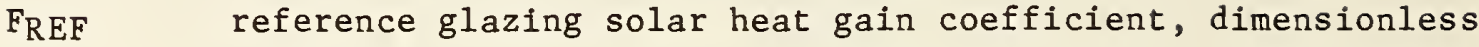

$\mathrm{I}_{\mathrm{T}}$

total solar irradiance normal to fenestration, W/m ${ }^{2}$ (Btu/hrft ${ }^{2}$ )

$\dot{\mathrm{M}}$

mass flow rate, $\mathrm{kg} / \mathrm{sec}(1 \mathrm{~b} / \mathrm{hr})$

$P$

pressure, pascals (in. $\mathrm{H}_{2} \mathrm{O}$ )

QABS rate of heat removal in absorber panel (Eq. 3), W(Btu/hr)

QCC rate of heat removal by air heat exchanger (Eq. 4), W(Btu/hr)

QFAN fan power, $W(B t u / h r)$

$\mathrm{Q}_{\mathrm{HC}} \quad$ rate of heat added by electrical heaters (Eq. 5), W(Btu/hr)

Q LS rate of heat transfer between metering chamber and room air, W(Btu/hr)

QNET net rate of heat transfer through window or test article, W(Btu/hr)

$\mathrm{q}_{\mathrm{NET}} \quad$ heat transfer rate per unit area (Eq. 1), W/m $\mathrm{m}^{2}\left(\mathrm{Btu} / \mathrm{hrft} \mathrm{t}^{2}\right)$

$\mathrm{R} \quad$ electrical resistance, ohms

T temperature, ${ }^{\circ} \mathrm{C}\left({ }^{\circ} \mathrm{F}\right)$

$t \quad$ time, sec

$\mathrm{U}$ overall heat transfer coefficient, $\mathrm{W} / \mathrm{m}^{2 \circ} \mathrm{C}\left(\mathrm{Btu} / \mathrm{hrft}^{2}{ }^{\circ} \mathrm{F}\right)$

(UA) MC overall conductance of metering chamber, $\mathrm{W} /{ }^{\circ} \mathrm{C}\left(\mathrm{Btu} / \mathrm{hr}{ }^{\circ} \mathrm{F}\right)$

$\mathrm{V} \quad$ velocity, $\mathrm{m} / \mathrm{s}(\mathrm{mph})$

$\Delta \quad$ difference

\section{SUBSCRIPTS}

ABS absorber panel

AIR metering chamber air 


$\begin{array}{ll}\text { CC } & \text { cooling coil } \\ \text { HC } & \text { heating coil } \\ \text { RM } & \text { room air } \\ 1 & \text { inside air } \\ 0 & \text { outside air }\end{array}$


1. M. McCabe, W. Ducas, M. J. Orloski, and K. N. Decorte. "Passive/Hybrid Solar Components - An Approach to Standard Thermal Test Methods," NBSIR 81-2300, July 1981.

2. D. J. Vild, "Solar Heat Gain Factors and Shading Coefficient" ASHRAE Journal, 1964.

3. E. A. Farber et al., "Theoretical Analysis of Solar Heat Gain Through Insulating Glass with Inside Shading," ASHRAE Journal, 1964.

4. C. W. Pennington et al., "Experimental Analysis of Solar Heat Gain Through Insulating Glass with Indoor Shading," ASHRAE Journal, 1964.

5. ASHRAE Handbook -- 1981 Fundamentals, (Atlanta: ASHRAE, 1981).

6. Private communication with John Yellott, President, John Yellott Engineering Associates, Inc.

7. S. Selkowitz, C. Lampert, and M. Rubin, "Advanced Optical and Thermal Technologies for Aperture Control," Proceedings of the Passive and Hybrid Solar Energy Update, Washington, D.C., September 1983.

8. F. Moore, "Passive Solar Test Modules," Passive Solar Journal, Vol. 1, No. 2, spring 1982 .

9. M. McCabe, S. T. Bushby, and W. Ducas, "Conceptual Design and Performance Specification for the Passive Solar Component Calorimeter," letter report from NBS to DoE, March 1982.

10. M. McCabe, S. Robinson, and J. LeCourt, "Calorimeter Test Facility for Measuring Thermal Performance of Passive/Hybrid Solar Components," Proceedings of ASHRAE/DoE Conference of Thermal Performance of the Exterior Envelope of Buildings II, Las Vegas, Nevada, December 1982, pp. 678-686.

11. K. W. Lindler, "National Bureau of Standards Passive Solar Test Building Handbook," NBS-GCR 82-398, August 1982.

12. "SINDA - Systems Inproved Numercial Differencing Analyzer," available from COSMIC, Uiversity of Georgia, Athens, 30602.

13. W. Kennish, M. Ahmed, M. McCabe, annd M. McKinstry, "Determination of Thermal Performance Characteristics of Modular Passive Solar Storage Walls," Proceedings of the 5th National Passive Solar Conference, Vol. 5.2, October 1980 .

14. Subbarao, K., "Determining Passive Building Dynamics from Performance Data" AIChE 38th Annual Heat Transfer Conference, Seattle, Washington, July 1983. 
15. Ducas, W., McCabe M., Cholvibul, R., and Wormser, P., "U-Value Measurements for Windows and Movable Insulations from Hot Box Tests in Two Commercial Laboratories," draft paper submitted to ASHRAE.

16. Balcomb, J. D., "Dynamic Measurement of Nighttime Heat Loss Coefficients Through Trombe Wall Glazing Systems," Proceedings of The Sixth National Passive Solar Conference, Vol. 6, September $19 \overline{81 .}$ 


\section{ACKNOWLEDGMENT}

The authors wish to thank all persons who contributed to the design, construction, and operation of the test facility. In particular, continued financial and management support from the Passive and Hybrid Solar Energy Division, Office of Solar Heat Technologies, U.S. Department of Energy, is acknowledged. The original conceptual design of the facility was the result of discussions with John Jenkins. Steve Bushby provided the refined engineering calculations using a thermal model. The final design and construction drawings drew heavily upon the engineering and architectural services provided by the Plant Division of NBS, in particular, Jim Hyatt and Ken DeCorte. The test facility was constructed by engineering technicians in the Center for Building Technology, in particular, Donn Eberts, Frank Rankin, and Walt Ellis, with substantial assistance from the undergraduate students, Allan Swim, Jenifer Cooley, Michael O'Boyle, and Susan Reiley. William Ducas assisted in the design of the instrumentation and selection of sensors. Graduate students Susan Robinson and John LeCourt assisted in development of operational procedures and in the initial operation of the facility.

John Yellott, Professor Emeritus at Arizona State University and designer, owner, and operator of a similar calorimetric test facility, provided a very useful review of the conceptual design and proposed instrumention, calibration, and operating procedures. In addition, John Yellott, William Brown of the National Research Council Canada, and Joseph Klems of Lawrence Berkeley Laboratory, each provided outside peer review and substantial commentary on the draft manuscript of this report, for which we are indebted. Finally, substantial technical review and management support from within NBS came from Kent Reed, Robert Jones, and Robert Dikkers. 
Appendix A

Outline of Draft Standard Procedure for Measuring and Reporting

U-Value for Fenestration Systems

Background:

Calculation of the rate of heat transfer through fenestration systems, such as windows, patio doors, and skylights commonly performed in building energy analysis, is often based on data given in the ASHRAE Handbook of Fundamentals for U-Value and Shading Coefficient. Those data are based on two sets of extreme conditions which never occur simultaneously. Therefore, their application for the design of residential and commercial buildings with large areas of fenestration, presents the possibility of substantial error in energy performance prediction, and poor selection between alternative fenestration systems.

A fenestration system usually consists of a glazing unit installed in an opaque frame. In the absence of solar radiation, the transfer of heat through a fenestration system consists of components of energy convected and radiated through the glazing unit, conducted through the frame, and transferred by infiltration at joints and seals. Since convective and radiative heat transfer across enclosed air spaces are temperature-dependent processes, variation in the heat transfer rate through the glazing component can occur due to variations in ambient temperature. In addition, significant variation in the heat transfer rate can occur due to wind-induced convection at the exterior surface. Analysis of conductive heat flow through framing members is often difficult because of complex framing geometry, the presence of dissimilar materials with unknown values of contact resistance, and the possibility of thermal bridges at the interface with the glazing unit. Predictive methods for analyzing thermal behavior of fenestration systems would be limited to a few relatively simple frame configurations which would probably be inadequate for the majority of available systems.

The preferred alternative to establishing thermal performance ratings of fenestration systems is measurement of U-Value in laboratory test facilities in which outdoor conditions are simulated. Although a number of different laboratory procedures for testing of building thermal envelope components are avallable, no consensus currently exists as to which procedure is most suitable for measuring the U-Value of fenestration systems. Comparison between two existing test procedures conducted in two commercial testing laboratories, revealed substantial differences between measured U-Value for a triple-glazed window. These differences were attributed to the different techniques used by each laboratory to simulate wind.

It is evident that a standard procedure is required for measuring and reporting the U-Value of fenestration systems, which includes the sensitivity to variations in the ambient air temperature and the convective heat transfer coefficlent at the exterior surface. The following outline describes a proposed standard procedure that will provide useful thermal performance data for many types of 
fenestration systems. It is anticipated, however, that a number of research tasks will be required to validate or modify the proposed standard, prior to its acceptance by consensus standards writing organizations.

Objective: To define a standard procedure for measurement of U-Value for fenestration systems

Scope :

The procedure is limited to fenestration systems including windows, patio doors, and skylights in which the glazing component consists of either; (1) a singleglazing layer, or (2) a multiple-layer, factory-sealed glazing unit (SGU), either of which must have one surface exposed to outdoor ambient conditions and the other surface exposed to indoor conditions.

Approach :

U-Value measurements shall be performed on individual SGU's and on fenestration systems containing a SGU installed in a frame.

Apparatus :

Test data shall be obtained on test articles at steady-state conditions in calibrated hot boxes such as described in ASTM C976 or in guarded hot boxes such as described in ASTM C236. A heat flow meter (HFM) shall be used to measure both the exterior and interior surface heat transfer coefficients at the specified test conditions.

Test Conditions:

A range of outdoor conditions shall be simulated in the outdoor chamber of the hot box, varying between summer and winter temperatures and between forced and free convection on the exterior surface. Solar radiation, air infiltration, or moisture transfer will not be included. Indoor test conditions in the metering chamber shall be maintained constant at $21.1 \pm 1.1^{\circ} \mathrm{C}\left(70^{\circ} \mathrm{F} \pm 2^{\circ} \mathrm{F}\right)$, with natural convection conditions maintained at the interior surface of the test article. Relative humidity shall be measured and controlled to a value such that no moisture condensation occurs on any surface in the metering chamber.

The SGU and the HFM are installed in the normal orientation, with vertical orientation for windows and doors, sloped or horizontal orientation for skylights. The proposed exterior test conditions for the SGU, the HFM and the fenestration assembly are shown in Table A-1. Hypothetical test results for the SGU at the proposed test conditions are plotted in Figure A-1. It is assumed that statistical analysis of the measured data for each SGU can be used to produce a repeatable functional relationship between the overall conductance-area product (UA), ambient temperature, and exterior surface heat transfer coefficient. 
The overall UA of a fenestration system shall be measured utilizing a representative SGU installed in a standard size frame assembly at the test condition specified in Table A-1. All joints and moving surfaces shall be sealed with tape at the interior to exclude possible air infiltration. Removable insect screens or sunshading devices that are not an integral part of the SGU shall be removed prior to testing. The contribution of the frame conductance to the overall UA of the system shall be determined by subtracting that of the SGU from that of the system. Heat transfer through the frame is assumed to be essentially conductive and therefore not sensitive to variation in exterior convection and ambient temperature.

Heat Flow Meter ( HFM):

The HFM consists of a sealed and laminated, three-layer assembly having its outer and inner layers identical in material, thickness, and surface treatment to those of the SGU. The middle layer consists of a $6.3 \mathrm{~mm}(1 / 4 \mathrm{inch})$ layer of aged polystyrene or polyurethane insulation. The size and shape of the HFM shall be similar to that of the exterior surface of the SGU. The thermal conductance of the HFM or a representative sample thereof shall be measured in a guarded hot plate apparatus similar to that of ASTM C177, at the same surface temperatures as those used in the measurement of exterior surface coefficient.

Arrays of 25 calibrated thermocouples are installed on opposite sides of each surface of the HFM at locations corresponding to approximately equal areas, and the average surface-to-surface temperature difference is measured during each calibration test. Similar arrays of 25 calibrated thermocouples are installed in the free stream on both the exterior and interior side of the HFM and the average surface-to-air temperature differences are measured. These data are used to determine the conductive heat flow rate and the average exterior surface and interior surface heat transfer coefficient at each test condition specified in Table A-l.

\section{Performance Rating:}

The thermal performance of a fenestration system is the sum of the glazing heat flow component and frame heat flow component as follows:

$$
\mathrm{UA}_{S Y S}\left(\mathrm{~T}_{\mathrm{O}}, \text { ho }\right)=\mathrm{UAFR}_{F}+\mathrm{UA}_{S G U}\left(\mathrm{~T}_{\mathrm{O}}, \text { ho }\right)
$$

It is anticipated that thermal performance measured in tests on a standard size fenestration system can be scaled for systems having smaller or larger dimensions than those tested. Therefore, these results will be assumed applicable to other fenestration systems containing an identical SGU and for similar framing and sash components, provided the overall projected area of the system 18 not less than 50 percent or greater than 150 percent of that of the actual configuration tested. 
Table A-1. Proposed Test Conditions for Sealed Glazing Unit and Fenestration System

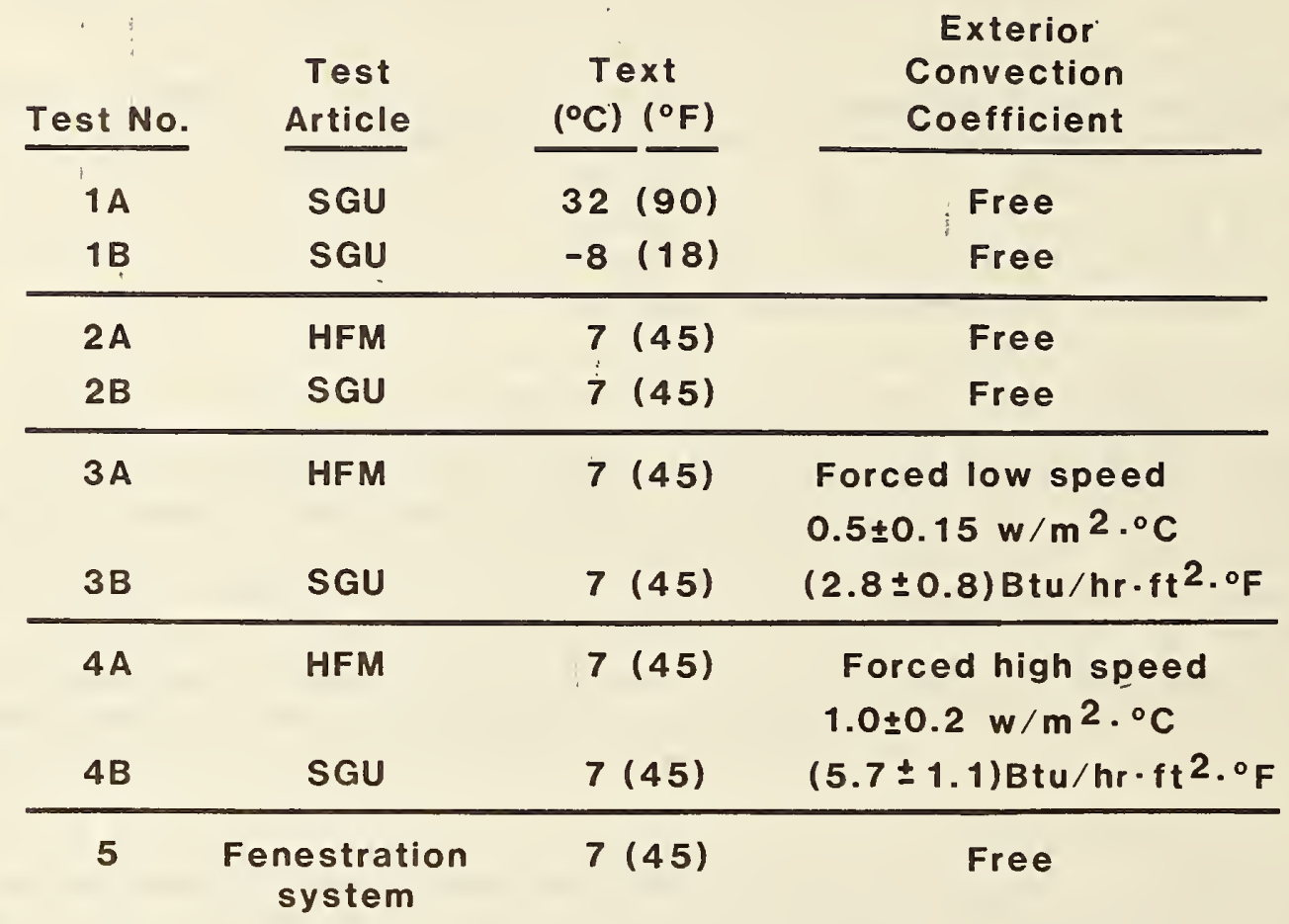

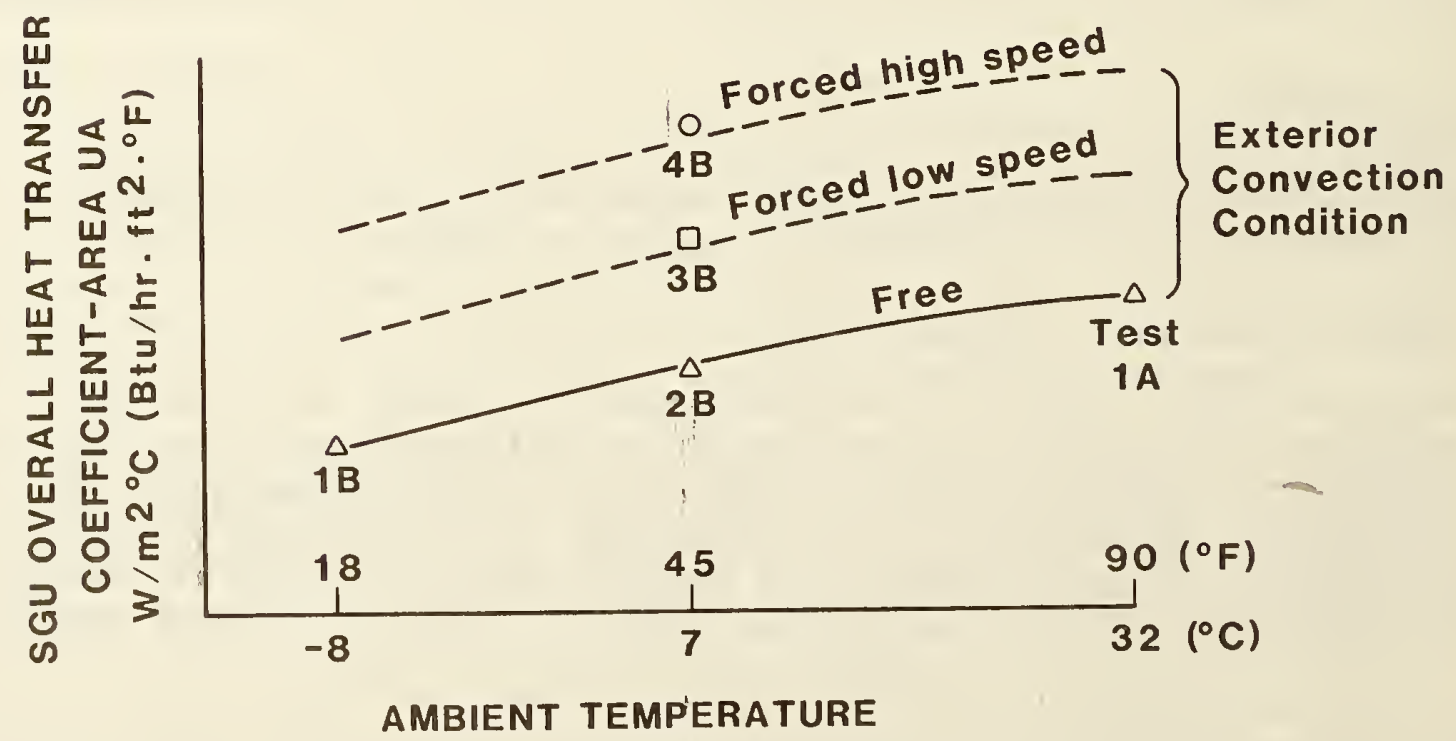

Figure A-1. Hypothetical performance of sealed glazing unit 
4. TITLE AND SUBTITLE

\section{THERMAL PERFORMANCE TESTING OF PASSIVE SOLAR COMPONENTS IN THE NBS CALORIMETER}

5. $\operatorname{AUTHOR}(S)$

Michael E. McCabe, Charles E. Hancock, Marc Van Migom

6. PERFORMING ORGANIZATION (If joint or other thon NBS, see instructions)

MATIONAL BUREAU OF STANDARDS

DEPARTMENT OF COMMERCE

WASHINGTON, D.C. 20234

9. SPONSORING ORGANIZATION NAME AND COMPLETE ADDRESS (Street. City. StOTE, ZIP)

7. Contract/Grant No.

U.S. Dept. of Energy

Division of Passive and Hlybrid Solar Energy

Forrestal Building

Washington, D.C. 20585

10. SUPPLEMENTARY NOTES

Document describes a computer program; SF-185, FIPS Software Summary, is attached.

11. ABSTRACT (A 200-word or less factual summary of most significant information. If document includes a significant bibliogrophy or literoture survey. mention it here)

Studies of the thermal performance of passive solar buildings have indicated a need for precise measurement of solar heat gain and thermal heat loss or gain for modular passive/hybrid solar components in the outdoor environment. A description of the design, calibration, and initial operational results for a new calorimetric test facility designed to perform these measurements is presented in this report. The test facility is located at the National Bureau of Standards in Gaithersburg, $\mathbb{D D}$, and it is anticipated that it will provide a substantial improvement in the measuring techniques for passive and hybrid solar components over the field test cells currentl in use. Thermal performance data were taken for four passive solar test articles during the winter of 1982-1983, including two windows and two collectol itorage walls Test results are correlated as U-values and Shading Coefficients for the two windows. Operational problems with the test facility are described and improvements suggested. The application of the test results for evaluation of standard laboratory test procedures for windows are discussed. A draft procedure for measuring and reporting U-Values for windows based on laboratory testing is presented.

12. KEY WORDS (Six to twelve entries; alphobetical order; copitalize only proper nomes; ond seporote key words by semicolons) Calorimeter; fenestration test methods; insulating shutters; passive solar; phase change storage wa11; shading coefficient; solar energy; U-value; water storage wall

13. AVAILABILITY

X] Unlimited

$\square$ For Official Discribution. Do Not Release to NTIS

[ Order From Superintendent of Documents, U.S. Government Printing Office, Washington, D.C. 20402.

[X] Order From National Technical Information Service (NTIS), Springfield, VA. 22161

14. NO. OF PRINTED PAGES 70

15. Price $\$ 10.00$ 


